Andrea Heistinger, Elisabeth Kosnik, Gabriele Sorgo

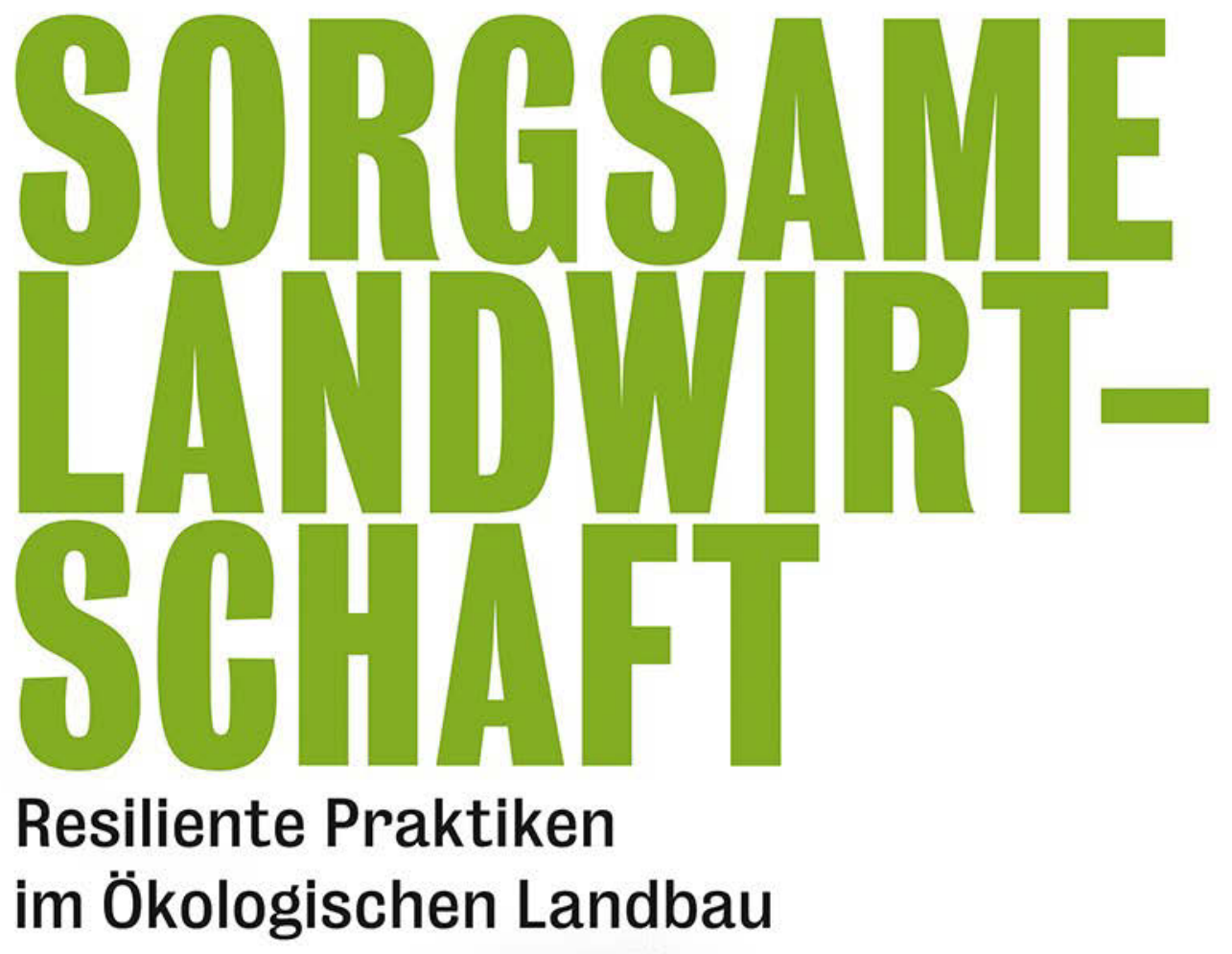


Andrea Heistinger, Elisabeth Kosnik, Gabriele Sorgo

Sorgsame Landwirtschaft

Neue Ökologie | Band 4 
Sorgsame Landwirtschaft. Sorgsame Forschung. Sorgsamer Druck.

Wie alle Forschung sind auch Bücher vergänglich und sollen wieder in einen StoffKreislauf eingehen können. Was Sie gerade in Händen halten, ist ein Cradle to Cradle@ und PurePrint $\odot$ Silver zertifiziertes Buch. Es enthält nur gesunde Substanzen - anders als herkömmliche gedruckte Bücher. Möglich machen dies die von der Druckerei gugler* in Melk entwickelten Druckverfahren. Die Papiersorten, Farben und Lacke sind ökologisch so optimiert, dass sie zu 100\% wiederverwendet werden. So könnten Sie dieses Buch kompostieren und als Dünger für Ihr Gemüse verwenden. Vorher bitte lesen und gerne weitergeben.

Dankeschön!

Andrea Heistinger (Dipl.-Ing.), geb. 1974, hat Landwirtschaft mit den Schwerpunkten Ökolandbau und Agrarsoziologie studiert. Ihre Forschungsschwerpunkte sind Innovationen im Ökologischen Landbau und Familiensoziologie, Systemische Beratung für Familienbetriebe und Organisationen. www.andreaheistinger.at

Elisabeth Kosnik (Mag. Dr. phil.), geb. 1983, Kulturanthropologin, war als Postdoc am Forschungsprojekt Bio Hoch Drei beteiligt. Die Schwerpunkte ihrer Forschung und Lehre an der Universität Graz sind ökonomische Anthropologie, Umweltanthropologie und Food Studies.

Gabriele Sorgo (PD Dr. phil.), geb. 1961, Kulturhistorikerin, lehrt Pädagogische und Historische Anthropologie an der Universität Innsbruck. Ihre Forschungsschwerpunkte sind Konsumtheorie, Gabenökonomien und Geschlechterforschung. 
Andrea Heistinger, Elisabeth Kosnik, Gabriele Sorgo

\section{Sorgsame Landwirtschaft}

Resiliente Praktiken im Ökologischen Landbau

[transcript] 
Diese Publikation wurde vom Land Steiermark, Referat Wissenschaft und Forschung, finanziert.

Das land

Steiermark

$\Rightarrow$ Wissenschaft und Forschung

\section{Bibliografische Information der Deutschen Nationalbibliothek}

Die Deutsche Nationalbibliothek verzeichnet diese Publikation in der Deutschen Nationalbibliografie; detaillierte bibliografische Daten sind im Internet über http://dnb.d-nb.de abrufbar.

\section{(1) (1) $\Theta \Theta$}

Dieses Werk ist lizenziert unter der Creative Commons Attribution-NonCommercial-NoDerivs 4.0 Lizenz (BY-NC-ND). Diese Lizenz erlaubt die private Nutzung, gestattet aber keine Bearbeitung und keine kommerzielle Nutzung. Weitere Informationen finden Sie unter https://creativecommons.org/licenses/by-nc-nd/4.o/deed.de

Um Genehmigungen für Adaptionen, Übersetzungen, Derivate oder Wiederverwendung zu kommerziellen Zwecken einzuholen, wenden Sie sich bitte an rights@transcript-publishing.com

Die Bedingungen der Creative-Commons-Lizenz gelten nur für Originalmaterial. Die Wiederverwendung von Material aus anderen Quellen (gekennzeichnet mit Quellenangabe) wie z.B. Schaubilder, Abbildungen, Fotos und Textauszüge erfordert ggf. weitere Nutzungsgenehmigungen durch den jeweiligen Rechteinhaber.

\section{(C) 2022 transcript Verlag, Bielefeld}

Umschlaggestaltung: Maria Arndt, Bielefeld

Umschlagabbildung: Andrea Heistinger

Druck: Gugler GmbH, Melk/Donau

Print-ISBN 978-3-8376-4898-0

PDF-ISBN 978-3-8394-4898-4

https://doi.org/10.14361/9783839448984

Buchreihen-ISSN: 2569-7900

Buchreihen-eISSN: 2703-1039

Cradle to cradle Certified ${ }^{\mathrm{TM}}$ Pureprint.

Innovated by gugler*

Gesund. Rückstandsfrei. Klimapositiv.

Besuchen Sie uns im Internet: https://www.transcript-verlag.de

Unsere aktuelle Vorschau finden Sie unter www.transcript-verlag.de/vorschaudownload 


\section{Inhalt}

Danksagung ...........................................

Prolog: Szenen aus dem Leben als Organisationsberaterin, Autorin und Forscherin

Andrea Heistinger ..........................................

\section{Einleitung}

Andrea Heistinger, Elisabeth Kosnik, Gabriele Sorgo ..................... 13

Sozialen Sinn verstehen

durch rekonstruktive Genogrammarbeit

Andrea Heistinger ............................................ 29

Care Diskurse und Praktiken ökologischer Foodways

Elisabeth Kosnik ............................................ 43

Wie aus Familiengeschichten

sorgsame Landwirtschaft entsteht

Andrea Heistinger .............................................. 63

Wirtschaften im Zusammenhang:

Sorge, Sympathie, Sinn

Gabriele Sorgo ........................................... 89 
"Es muss net alles immer nur auf Gewinn auf'baut sein." Zusammenfassung und Ausblick

Elisabeth Kosnik, Andrea Heistinger, Gabriele Sorgo

Literatur .125 


\section{Danksagung}

Wir möchten uns insbesondere bei allen Forschungsteilnehmer*innen bedanken, die uns ihre Zeit großzügig zur Verfügung gestellt haben. Wir bedanken uns bei Ao.Univ.-Prof. i.R. Dr. Helmut Eberhart, der als zweiter Projektleiter an allen Treffen der Projektmitglieder beteiligt war und durch sein umfangreiches Wissen $z \mathfrak{u}$ den Themen der Forschung das Projekt maßgeblich beeinflusst hat. Unser Dank gilt weiters Prof. i.R. Dr. Bruno Hildenbrand, der uns zweimal in Graz besuchte und sich intensiv an der Analyse unserer Forschungsdaten beteiligte. Weiters bedanken wir uns bei Christian Hiß M.A. und Dr. Frieder Thomas, die für eine ausführliche Diskussion unserer Forschungsergebnisse zur Verfügung standen, sowie bei den Studierenden der Karl-Franzens Universität Graz, die an der Gruppenanalyse teilnahmen. Schließlich wollen wir uns noch beim Institut für Kulturanthropologie und Europäische Ethnologie der Universität Graz bedanken, wo das Projekt Bio Hoch Drei institutionell verankert war. Das Projekt sowie die vorliegende Publikation wurden vom Land Steiermark, Referat Wissenschaft und Forschung, finanziert.

Sorgsame Landwirtschaft. Sorgsame Forschung. Sorgsamer Druck. Wie alle Forschung sind auch Bücher vergänglich und sollen wieder in einen Stoff-Kreislauf eingehen können. Was Sie gerade in Händen halten, ist ein Cradle to Cradle $\odot$ und PurePrint $\odot$ Silver zertifiziertes Buch. Es enthält nur gesunde Substanzen - anders als herkömmliche gedruckte Bücher. Möglich machen dies die von der Druckerei gugler* in Melk entwickelten Druckverfahren. Die Papiersorten, Farben und Lacke sind ökologisch so optimiert, dass sie zu $100 \%$ wiederverwen- 
$8 \quad$ Danksagung

det werden. So könnten Sie dieses Buch kompostieren und als Dünger für Ihr Gemüse verwenden. Vorher bitte lesen und gerne weitergeben. Dankeschön! 


\section{Prolog: Szenen aus dem Leben als Organisationsberaterin, Autorin und Forscherin}

Andrea Heistinger

Es ist Mitte Jänner des Jahres 2020. Bevor ich mich in meine Schreibklausur aufmache, um die Ergebnisse meiner Forschung zu Papier zu bringen - denn zu Hause neben meinen Kindern hat mein Schreiben keinen Platz - gehe ich noch einkaufen am Bauernmarkt in St. Pölten und auf einen Cappuccino in das Café, in dem ich auch immer wieder schreibe. Am Markt treffe ich auf Heidemarie ${ }^{1}$, die Blumenfrau. Sie sagt, sie hätte etwas für mich und holt eine kleine Flasche hervor, in die sie eine einzelne Tulpe gemeinsam mit Weidenzweigen arrangiert hat. Ein kleiner Brief hängt daran. Sie wünsche mir alles Gute beim Schreiben und die Blume möge mich bestärken. Offenbar hat sie schon damit gerechnet, dass ich heute vorbeikomme. Ich bin gerührt. Heidemarie kennt und schätzt meine Bücher. Letzte Woche hatte ich ihr erzählt, dass ich einen Buchbeitrag schreiben müsse und dass mir das viel leichter fallen würde, wenn auch nur eine Blume am Schreibtisch stünde. Gerade ist Rosemarie die einzige Blumenfrau in der Innenstadt von St. Pölten. Seit Anfang des Jahres steht sie nun einen Tag mehr pro Woche mit ihrem Stand am Herrenplatz. Sie fragt mich, ob ich Fotos von ihr in einigen Gruppen der Sozialen Netzwerke der Stadt posten

1 Alle Namen von Gesprächspartner*innen in diesem Forschungsprojektes wurden anonymisiert. 
könne, um die Menschen in der Stadt darüber zu informieren, dass sie nun auch freitags hier sei.

Im Café überfliege ich die Tageszeitungen. An dem Artikel in der Süddeutschen bleibt mein Blick hängen. Mit »Die Entfremdung« ist ein Artikel über die gegenwärtige Lage der Landwirtschaft in Europa tituliert. Dabei geht es um die Entfremdung zwischen jenen Menschen, die Lebensmittel erzeugen und jenen Menschen, die diese essen. "Ein neuer Gesellschaftsvertrag ist nötig, um Bauern und Verbraucher zu versöhnen«, schreibt der Autor. ${ }^{2}$ Dem kann ich mich nur anschließen. Hoch an der Zeit, die Ergebnisse unseres Forschungsprojektes auf Papier zu bringen. Wir haben uns viele Gedanken zum Thema gemacht, wie soziale Beziehungen zwischen Menschen gestärkt werden oder neu entstehen können und sorgfältig Fallbeispiele recherchiert, wo Menschen mit und durch die Lebensmittel, die sie erzeugen, neue Beziehungen hergestellt haben und pflegen: Zueinander, zum Boden, zu den Kulturpflanzen, die sie kultivieren, zu den Wildpflanzen, die ihre Äcker umgeben, zu den Tieren, die sie halten, zu den Wildtieren, die sich auf ihren Flächen tummeln.

Eine zweite Szene vom Markt. Sie ereignete sich im Oktober letzten Jahres: Bei einem Biogemüse-Stand kaufe ich Kohlrabi. Es ist eine bunte Vielfalt, die ein Mann mittleren Alters anbietet. Rote Rüben, Tomaten und Kohlrabi liegen sorgfältig zu kleinen Grüppchen zusammengestapelt auf einem mit Jute bespannten Tisch. Sie erinnern mich an die Arrangements von Früchten auf den Gemüse- und Obstmärkten, die ich vor vielen Jahren auf einer Reise durch Burkina Faso gesehen hatte. Daneben frische Asia-Salate und frischer Spinat, bereits portionsweise in Papiertüten abgepackt. Auf einer Tafel steht mit Kreide von Hand geschrieben der Name des Betriebs. Ich greife zu einem Kohlrabi und sehe, dass er am Blattansatz voller Läuse ist. Der GemüseMann will ihn mir wieder aus der Hand nehmen und gegen einen lauslosen Kohlrabi umtauschen. Ich meine, das passe schon, die mehlige Kohlblattlaus käme ohnehin in den Bio-Abfall. Er lacht und meint, ob ich Schädlings-Expertin sei. Ich lache und sage, nein, aber Expertin

2 Vgl. Bauchmüller 2020. 
für Bio-Gemüsebau. Ich hätte schon einige Bücher darüber geschrieben. Er meint: »Sie sind aber nicht die Andrea Heistinger?«»Doch« sage ich. Fast ehrfürchtig sagt der Mann, dass alles Gemüse, das er hier verkaufe nach den Anleitungen meiner Bücher angebaut sei. Ich bin gerührt. Das ist das schönste Kompliment, das ich als Autorin bekommen kann. Er erzählt weiter, dass er und seine Frau einen Acker gepachtet hätten. Glücklicherweise werde dieser schon lange biologisch bewirtschaftet. Nun würden sie aber einen Hof suchen, den sie übernehmen könnten.

Beide Markt-Geschichten haben einen gemeinsamen Nenner. Sie erzählen von derselben Ingredienz, die auch alle unsere Fallbeispiele gemeinsam haben: Beziehung. Dialog. Ins Gespräch kommen. Neue Kooperationen finden. In den Beziehungen erwächst für jeden und jede neues Wissen. Ich als Forscherin erfahre, was Menschen, die in der Landwirtschaft tätig sind, gerade beschäftigt, wie sie ihre Betriebe aufbauen, welche Schritte sie in der Vermarktung gehen. Die Betriebsleiter*innen kommen am Markt mit ihren Kund*innen ins Gespräch, bekommen Rückmeldungen, welche Gemüsesorten besonders gut schmecken, und von den Kund"innen Hinweise, wo sie sich bei ihrer Suche nach einem Hof hinwenden könnten oder Unterstützung beim Marketing.

Ich fahre von der Stadt aufs Land, ziehe mich hier für drei Tage zum Schreiben zurück. Im Dorf ist es ruhig. Nebel liegt über der Landschaft. Ein gutes Wetter zum Schreiben. Heidemaries Tulpe steht neben mir. Argument um Argument, Satz und Satz aneinanderreihen, wie Schritt um Schritt, um auch, wenn sich der Weitblick für Momente entzieht, den Weg unter den Füßen nicht zu verlieren. Ich hatte vergessen, mein Telefon auszuschalten. Es läutet. Eine Journalistin einer österreichischen Tageszeitung ruft an und bittet um ein Interview zum Thema Hofübergabe außerhalb der Familie. Ich verweise sie auf die Vermittlungsplattform Perspektive Landwirtschaft und eine Kollegin, die dort arbeitet. Dann eine Nachricht auf meinem Handy: Ein befreundeter Bauer - er ist auch Obmann eines Bauernverbands und kennt die Szene daher gut - schickt mir eine Sterbeanzeige eines Kollegen, ein 61-jähriger Bauer, der »sein Leben in Gottes Hand gegeben hat «. So steht es auf der Sterbeanzeige. Ich erinnere mich an ein Gespräch mit ihm, das wir vor 
ein paar Monaten geführt hatten. Damals erzählte er von elf Bauern, die er persönlich gekannt hat, die sich das Leben genommen hätten aus Verzweiflung über die - ökonomisch wie sozial aussichtslos empfundene - Situation auf ihren Höfen. Kurz darauf läutet das Telefon wieder. Ein Journalist, der eine Fernsehserie dreht über Menschen, die sich auf den Weg machen, ihre Lebensmittel selbst anzubauen, bittet mich, ob ich beim Dreh für die nächsten Folgen dabei sein könnte, um einen Mann bei seinen nächsten Schritten auf diesem Weg zur Selbstversorgung zu beraten. Ich erfahre, dass der Mann seinen Job an den Nagel gehängt hätte. Ich frage nach, welchen. Er hätte ein europäisches Pharmaunternehmen, das in der Organtransplantation tätig ist, in Asien vertreten. Nun hätte sich der Mann einen kleinen Hof gekauft. Dieser liegt in der Nähe der Region, in der wir unser Forschungsprojekt durchgeführt hatten. Ich kenne die Gegend daher gut. Ich sage einem Termin in einem Monat zu. Ich drehe mein Telefon ab und wende mich dem Schreiben zu. 


\section{Einleitung}

Andrea Heistinger, Elisabeth Kosnik, Gabriele Sorgo

In der europäischen Landwirtschaft sind die Zeiten großen Mangels lange vorbei, jetzt geht auch die Zeit der großen Agrarmodelle zu Ende: global umfassende Agrarmodelle, die sich nach dem zweiten Weltkrieg in rasender Geschwindigkeit verbreiteten, Ozeane wie Landesgrenzen überwindend, und als propagierter technischer und ökonomischer Fortschritt bis hinein in kleinste Winkel von Talschaften und hoch hinaus bis auf entlegenste Bergkuppen Verbreitung fanden. Mittlerweile liegen auch die negativen - nicht intendierten - ökologischen und sozialen Auswirkungen dieser Entwicklung vor. Das Fachgremium des Weltagrarberichtes von 2008 ist sich einig, dass die Steigerung der Produktivität durch die Industrialisierung der Landwirtschaft an ihre ökologischen und gesellschaftlichen Grenzen gelangt ist. Stattdessen sei, um die Zukunft der Lebensmittelversorgung zu sichern, sowohl eine Stärkung der kleinbäuerlichen ökologischen Landwirtschaft wie auch standortspezifischer Anbaumethoden notwendig. ${ }^{1}$ Selbst der Präsident der Deutschen Landwirtschaftsgesellschaft (DLG) Carl-Albrecht Bartmer stellte in einem Interview im Jahr 2017 fest, dass eine industriell geprägte Landwirtschaft für die Zukunft nicht mehr tragfähig sei. ${ }^{2}$ Das ist insofern bemerkenswert, als gerade die DLG - ähnlich wie die österreichischen Landwirtschaftskammern - über Jahrzehnte die Industrialisierung der Landwirtschaft eingefordert und vorangetrieben

1 Vgl. IAASTD 2008.

2 Vgl. Grossarth 2017. 
hatte. Nun wird ein Paradigmenwechsel angedacht. Aufgrund der negativen Effekte des hohen Spezialisierungsgrades landwirtschaftlicher Betriebe sieht Bartmer die Versorgungssicherheit gefährdet. Durch zu enge Fruchtfolgen und zu hohen Chemikalieneinsatz seien immer mehr Schädlinge und Krankheitserreger gegenüber den verfügbaren chemisch-synthetischen Pflanzenschutzmitteln resistent geworden. »Wie geht es anders? «, fragen sich viele Expert*innen ebenso wie Praktiker*innen in Europa und anderswo. Die Covid-19 Pandemie hat die Suche nach regionalen und resilienten Alternativen noch weiter beschleunigt. ${ }^{3}$ Dabei gibt es allerorts mögliche Vorbilder.

Bei genauerer Betrachtung zeigt sich, dass zahlreiche Bäuerinnen und Bauern weltweit weiterhin oder erneut andere Formen des Lebens und Arbeitens in der Landwirtschaft praktizieren. Der Agrarsoziologe Jan Douwe van der Ploeg spricht gar von einem Prozess der »Wiederverbäuerlichung « (re-peasantization), den er aktuell vor allem unter dem Leitstern der Agrarökologie beobachtet - einer Bewegung, die die landwirtschaftliche Produktion wieder mit Ökologie sowie den natürlichen Ressourcen vor Ort in Verbindung bringen will. ${ }^{4}$ Von vier solchen Betrieben, deren Bewirtschafter*innen sich auf den Weg zu einer ökologisch, sozial und wirtschaftlich nachhaltigen Landwirtschaft gemacht haben, handelt dieses Buch. Ihnen gemeinsam ist, dass sie ihre eigenen theoretischen Überlegungen und Überzeugungen sowie Inspirationen aus ihrem sozialen Umfeld und all jene Kompetenzen, die sie in ihrem bisherigen (Berufs-)leben erworben haben in ihrer landwirtschaftlichen Praxis neu zusammenführen. Sie schöpfen aus ihrer eigenen Geschichte und knüpfen Beziehungen zu Boden, Pflanzen und Tieren, sowie zu jenen Menschen, die sie mit den Zutaten für ihr tägliches Essen versorgen. Diesen Ansatz bezeichnen die Autorinnen als sorgsame Landwirtschaft (caring agriculture). Ihre Abwendung von einer industriell organisierten, global verschränkten, konventionellen Landwirtschaft geht mit der Hinwendung zu anderen Denkweisen und Handlungspraktiken 
einer ökologischen Produktion einher. Damit setzen sie genau jenen Paradigmenwechsel um, der bereits seit fünf Jahrzehnten eingefordert wird. $^{5}$

Der Begriff der sorgsamen Landwirtschaft ist nicht gleichzusetzen mit dem principle of care der International Federation of Organic Agriculture Movements (IFOAM), das zu den 2005 verabschiedeten vier Grundprinzipien des Öko-Landbaus - Gesundheit, Ökologie, Gerechtigkeit und Sorgfalt - zählt. ${ }^{6}$ Der mit "Sorgfalt« übersetzte care-Begriff steht im Kontext von Nachhaltigkeitsdiskursen, mit Bezug auf Vorsicht, Vorsorge und Verantwortung für kommende Generationen. Es handelt sich daher um einen wesentlich eingeschränkteren care-Ansatz als der einer sorgsamen Landwirtschaft. Des Weiteren steht der Begriff der sorgsamen Landwirtschaft in Abgrenzung zu care farming, auch bekannt als green care. Diese in den alternativen Bewegungen der 1970er Jahre wurzelnde Idee meint die Betreuung von Menschen mit besonderen Bedürfnissen, Kindern oder Senior*innen auf Bauernhöfen. ${ }^{7}$ Dabei bleibt care auf den Kontext der Versorgung von Menschen und der Erfüllung ihrer Bedürfnisse beschränkt. ${ }^{8}$

Diskurse zur Agrarökologie betonen bereits die Notwendigkeit, Nahrungserzeugung interdisziplinär zu untersuchen und die auf Effizienz ausgerichteten Wörter mit Agrar- als Vorsilbe durch Begriffe wie Nahrungssysteme zu ersetzen, um die regionalen und globalen Interdependenzen als lebendiges System begreifbar zu machen. ${ }^{9}$ Insbesondere die Überlegungen zu soil care der Science and Technology Studies-Forscherin María Puig de la Bellacasa erscheinen uns für die vorliegende Studie anschlussfähig. Puig de la Bellacasa verbindet den

5 Vgl. Meadows u.a. und Club of Rome 1972.

6 VgI. IFOAM: The Principle of Care. Siehe ebenso Willer und Schmid 2016.

7 Vgl. Ploeg 2018b, Milone und Ventura 2014.

8 Für eine ausführliche Übersicht über die Entwicklungen feministischer careDiskurse und über aktuelle Forschungsstränge zu Sorge-Verhältnissen von Menschen, Naturen und Kulturen aus kulturwissenschaftlicher Perspektive sei hier auf den Sammelband »Care: Praktiken und Politiken der Fürsorge« von Beate Binder u.a. 2019 verwiesen. Vgl. Francis u.a. 2003. 
care-Begriff feministischer Diskurse mit dem Forschungsfeld der »NaturenKulturen« und plädiert für eine Überwindung der Natur/Kultur Dichotomie. Damit erweitert sie die Perspektive auf Mensch-BodenBeziehungen im Rahmen von soil communities und foodwebs, welche neue Fragen der Konvivialität menschlicher und nicht-menschlicher Akteur*innen eröffnen, denen in den folgenden Kapiteln weiter nachgegangen wird. ${ }^{10}$

\section{Das Forschungsprojekt}

Das vorliegende Buch entstand im Rahmen eines durch das österreichische Bundesland Steiermark finanzierten Forschungsprojektes zwischen 2017 und 2019. Ausgehend davon formierte sich am Institut für Kulturanthropologie und Europäische Ethnologie der Universität Graz ein transdisziplinäres Forscher*innen-Team mit einem gemeinsamen Interesse an Fragen $\mathrm{zu}$ einer nachhaltigen Produktion von Lebensmitteln und ihren Erzeuger*innen in Europa. Derlei Fragen ergeben sich aus dem spezifischen Kontext und historischen Entwicklung europäischer Landwirtschaftssysteme. So beziffert die EU-Kommission für Umwelt die Schäden an der Fruchtbarkeit von Ackerböden in der EU mit 390 Milliarden Euro jährlich - das sind umgerechnet 250 Euro pro Hektar und Jahr. ${ }^{11}$ Gleichzeitig lag zu Beginn des 21. Jahrhunderts jeder dritte Hektar Ackerland für den EU-Konsum außerhalb der Grenzen der Europäischen Union. ${ }^{12}$ EU-Bürger*innen sind massiv von Lebensmittelimporten abhängig, regionale Distribution lokal erzeugter Grundnahrungsmittel existiert dagegen kaum mehr. Eine Studie der Stadt Freiburg i.Br. aus dem Jahr 2016 offenbarte, dass nur rund acht Prozent des Obstes und 13 Prozent des Gemüses, das in Freiburg gegessen wird, aus der Region stammen. Über alle Produktgruppen

\footnotetext{
10 Vgl. Puig de la Bellacasa 2015, 2017.

11 Vgl. Hintz u.a. 2017.

12 Vgl. Institut für Soziale Ökologie der Universität Klagenfurt 2015.
} 
hinweg wurde ein Anteil von etwa 20 Prozent errechnet. ${ }^{13} \mathrm{Zu}$ einem ähnlichen Ergebnis kommt die österreichische Studie »Graz ernährt sich « von 2017. ${ }^{14}$ Eine erstaunlich geringe Quote für Regionen, in denen eigentlich alles gedeihen würde, was die Menschen, die hier wohnen, an Lebensmitteln benötigen.

Gleichzeitig ist das fortschreitende Wachstum des Öko-Sektors innerhalb der EU bemerkenswert. In den letzten zehn Jahren stieg der Anteil ökologisch bewirtschafteter Flächen innerhalb der EU um $70 \%$, während EU-Bürger*innen die zweitgrößte Konsument"innengruppe für ökologische Lebensmittel weltweit sind..$^{15}$ Österreich liegt sowohl beim Konsum als auch bei der Produktion von ökologischen Lebensmitteln im EU-Spitzenfeld. Hier betrug der Anteil an ökologisch bewirtschafteter Fläche $201926 \%$, womit Österreich an der Spitze aller EU-Staaten liegt. ${ }^{16}$

Ausgehend von diesen Entwicklungen fragt die vorliegende Studie nach resilienten Praktiken und Handlungsmustern einer ökologischen Landwirtschaft, die Grundnahrungsmittel für Menschen produziert, während sie gleichzeitig den Lebensmittelproduzent"innen materiell, sozial und umweltethisch zufriedenstellende Lebensbedingungen ermöglicht. Resilienzforschung gab und gibt es in verschiedenen wissenschaftlichen Disziplinen. Psychologie, Ethnologie, Ökonomie, Geographie, Politikwissenschaft und verschiedene Teilbereiche der Soziologie haben sich mit Resilienz befasst. Seit ca. fünf Jahrzehnten werden Konzepte von Resilienz, die in der Ökologie wurzeln, zur Beschreibung und Analyse wirtschaftlicher Systeme und menschlicher Gemeinschaften herangezogen. Übertragungen von ökologischen Systemen der Tier- und Pflanzenwelt auf soziokulturelle Zusammenhänge

13 Vgl. Moschitz u.a. 2015.

14 Vgl. Hintz u.a. 2017.

15 Hinter den USA, siehe European Commission 2019. Die Mitteilung der EUKommission »Vom Hof auf den Tisch«nennt als Ziel, bis zum Jahr $203025 \%$ der landwirtschaftlichen Flächen in der EU ökologisch zu bewirtschaften (European Commission 2020). 
sind jedoch aus sozial- und kulturwissenschaftlicher Sicht bedenklich. Denn soziale Systeme sind zwar in natürliche Öko-Systeme eingebettet, verfügen jedoch zusätzlich über eine symbolische Dimension, die mit naturwissenschaftlichen Methoden nicht erfasst werden kann.

Dessen ungeachtet übernahmen ökonomische Diskurse über Resilienz Forschungsergebnisse aus dem Tier- und Pflanzenreich und rückten damit Märkte und ihre Dynamiken in die Nähe von natürlichen Phänomenen. Die Entscheidungen menschlicher Individuen auf der Basis ihrer je kulturspezifischen Erfahrungen verschieben sich in solchen evolutionstheoretisch untermauerten Theorien von ökologischen und sozialen Systemen in den Hintergrund. Managementlehren und Organisationsberatungs-Diskurse haben sich reichlich an jenem Konzept von Resilienz bedient, welches der Entomologe Crawford S. Holling vor fast 50 Jahren für ökologische Systeme ohne Menschen ersann und später auf ökonomische und soziale Systeme übertrug. ${ }^{17}$ Seine Theorien über die Stabilität von Systemen bereicherte zwar die Nachhaltigkeitsforschung, ließ sich aber auch dazu verwenden, neoliberale Wirtschaftsstrategien zu naturalisieren, wobei sich Resilienz in eine fast inhaltsleere Chiffre für Überlebensfähigkeit und Durchhaltevermögen in ökonomischen Problemlagen verwandelte. ${ }^{18}$ In der postfordistisch inspirierten Psychologie wurde Resilienz etwa als ein Bündel an Verhaltensweisen und Einstellungen definiert, die jede Person lernen und entwickeln könne. ${ }^{19}$ Diese Beschreibung von Resilienz als selbstverständlich $\mathrm{zu}$ erwerbende Risikobereitschaft und Widerstandsfähigkeit interpretiert lebensweltliche Unsicherheiten stets als individuelle Chancen und naturalisiert zugleich eine wirtschaftlich instabile und ungerechte Welt, wo Menschen als zweckrational agierende Manager ihres Lebens vorgestellt werden. Besonders nach der Finanzkrise von 2008 entstand eine Rhetorik der Resilienz, ${ }^{20}$ die nur allzu oft Bürger*innen auf der lokalen Ebene abverlangt, mit

\footnotetext{
17 Vgl. Holling 1973, 2001.

18 MacKinnon und Driscoll Derickson 2012, S. 256.

19 O'Malley 2010, S. 498.

20 Hroch 2013, S. 30.
} 
ihren persönlichen Ressourcen Probleme zu lösen, welche in erster Linie auf globaler Ebene von den global players verursacht werden. ${ }^{21}$ Resilienz wird heute in Betriebswirtschaftslehren immer noch als etwas gedacht, das in Organisationen und individuellen Lebenszusammenhängen die richtigen Maßnahmen ergreifen hilft, mit denen nach ökonomischen Krisen alles wieder ins Lot kommen soll. ${ }^{22}$ Aus dieser der darwinistisch argumentierenden Ökologie entstammenden systemtheoretischen Sicht wäre Resilienz aber nicht wirklich innovativ, sondern nur ein stabilisierendes Werkzeug. ${ }^{23}$

In der vorliegenden Studie wird Resilienz nicht derart instrumentalisierbar gedacht. Vielmehr orientieren wir uns an der Sicht der klinischen Soziologie, die davon ausgeht, dass menschliche Lebensführung und Familiensysteme keine absolute Stabilität erreichen können. Für die Entfaltung des eigenen Potentials ist die Konfrontation mit Krisenmomenten notwendig. Daher besteht der Soziologe Bruno Hildenbrand darauf, dass Krisen sogar konstitutiv für die Autonomie einer resilienten Lebenspraxis sind. ${ }^{24}$ Im Unterschied zu ökologischen Resilienztheorien vertritt er eine völlig andere Sichtweise, die den Fokus nicht auf die Wiederherstellung eines alten Gleichgewichts legt, sondern darauf, dass metastabile Familiensysteme - in die letztlich jedes Individuum zeit seines Lebens mehr oder minder eingebunden bleibt - die Entwicklung von Menschen beeinflussen. Mit metastabil ist hier gemeint, dass sich alle Beteiligten und das System selbst je in Wechselwirkung mit den sozialen, kulturellen und natürlichen Umwelten verändern. Resilienz dient also nicht als Mittel zur Wiederherstellung eines verlorenen Gleichgewichts, sondern repräsentiert die Dynamik des Lebens gegenüber dem Unverfügbaren. Resilienz wird sowohl an den individuellen wie an den zugleich mit ihnen verschränkten kollektiven Individuationsprozessen ablesbar, wobei die natürlichen, sozio-kulturellen und technologischen Umwelten in diesen Prozessen 
mitwirken. Während der Resilienzbegriff der Naturwissenschaften die symbolische Dimension der Menschen den Naturgesetzen unterzuordnen versucht und Menschen dadurch zu Erfüllungsgehilfen eines unbestimmbaren evolutionären Prozesses degradiert, kann dieser soziologische Resilienzbegriff die NaturKultur-Grenze überschreiten und die lebenden Mitwesen den Menschen gleichberechtigt als Mitwirkende an einem gemeinsamen Wachstumsprozess zur Seite stellen. Wolfgang Bonß hat diesen soziologischen Zugang, der Beziehungen $\mathrm{zu}$ nicht-menschlichen Umwelten einschließt, als »reflexive Resilienz« bezeichnet. "Einfache« Resilienzkonzepte beziehen sich nur auf die unmittelbaren Reaktionen auf widrige Umstände, reflexive Resilienz wäre hingegen als eine Haltung zu begreifen, den Unsicherheiten des Lebens gut vorbereitet und proaktiv begegnen zu wollen. ${ }^{25}$

Die vorliegende Studie betrachtet Öko-Landwirtschaften aus einer breiten und transdisziplinären Perspektive - in ihren ökonomischen, sozialen, lokalen und ökologischen Dimensionen - die auch nichtmenschliche Akteur*innen in die Betrachtung miteinbezieht. Dadurch sollen vorschnelle Kategorisierungen wie "zum Sterben verurteilte Kleinstbetriebe« oder "Aussteiger- und Hobby-Landwirtschaften « vermieden werden. Dichotome Denkmuster, die zeitgenössische Landwirtschaft in "Agrar-Industrie « und »Landromantik« teilen, verhindern die Betrachtung tatsächlicher, lebensweltlicher Erfahrungen von Landwirt*innen. Gleichzeitig zeigt diese Perspektive auf, dass es keinen homogenen Öko-Sektor gibt - die Akteur*innen, ihre Handlungsstrategien und Motivationen, sind vielfältig. Bisher mangelt es an differenzierten Betrachtungsweisen denen es einerseits gelingt, die Mikro-Perspektive der Akteur*innen im ökologischen Landbau, ihre Praktiken und Denkweisen, darzustellen und gleichzeitig gesamtgesellschaftliche Bezüge im Auge zu behalten. Ausgehend von Studien, welche die wichtige Rolle kleinbäuerlicher Betriebe für die Welternährung betonen, ${ }^{26}$ liegt der Fokus unserer Forschung daher

\footnotetext{
25 Bonß 2015, S. 28.

26 Vgl. IAASTD 2008; Ploeg 2018b.
} 
auf Betriebsleiter*innen, die sich aktuellen Tendenzen der Rationalisierung im ökologischen Landbau entziehen. Diese Landwirt*innen verkleinern z.B. ihre Betriebe oder bleiben bewusst klein. Sie praktizieren Landbaumethoden, die weit über die Öko-Standards der EU hinausgehen. Ihre Produkte vertreiben sie - vollständig oder teilweise - abseits von Großabnehmern über CSAs (Community Supported Agriculture), Foodcoops, Bauernmärkte und regionale Öko-Läden. Aber auch Vielfalt und Multifunktionalität sowie Biodiversität spielen eine wichtige Rolle auf ihren Höfen.

Für die vorliegende Studie haben wir vier ökologische Betriebe im Osten Österreichs untersucht: drei in der historisch als Oststeiermark bezeichneten Region, einen in Niederösterreich. ${ }^{27}$ Es handelt sich um strukturschwache Landwirtschaftsgebiete, historisch geprägt durch ihre Lage an der östlichen Grenze Österreichs zu den heutigen Ländern Tschechien und Ungarn. Die Bundesländer Niederösterreich und Steiermark weisen die meisten Land- und Forstwirtschaftlichen Betriebe Österreichs, sowie die meisten Land- und Forstwirtschaftlichen Arbeitskräfte auf, wobei der Großteil der Betriebe im Nebenerwerb geführt wird. ${ }^{28}$ Der Anteil an Bio-Betrieben liegt in der Steiermark mit 18,4 \% etwas unter dem Österreich-Durchschnitt (22,2\%), während Niederösterreich mit 22,7\% leicht darüber liegt. Der größte politische Bezirk der Oststeiermark, Hartberg-Fürstenfeld, liegt mit knapp 14\% ökologisch bewirtschafteter Betriebe weit darunter. Im Jahr 2018 wurden 2.857 landwirtschaftliche Betriebe in diesem Bezirk bewirtschaftet, 386 davon biologisch. ${ }^{29}$ Die erforschten Betriebe liegen, gemäß den Kategorien der Europäischen Union, in sogenannten benachteiligten landwirtschaftlichen Gebieten, wo Landwirt*innen unter erschwerten Produktionsbedingungen wie steile Flächen, Höhenlagen und damit

27 Um die Anonymität der Cewährspersonen zu wahren, werden die einzelnen politischen Bezirke hier nicht genauer erwähnt.

28 Wobei vor allem in der Steiermark der Anteil an Nebenerwerbsbetrieben sehr hoch ist, siehe Statistik Österreich 2016a, 2016b, 2016c.

Vgl. Bio Austria Presseaussendung (veröffentlicht am 14.2.2020); Statista 2020. 
verbundenem ungünstigem Klima oder abgeschnittener Lage wirtschaften. ${ }^{30}$ Wobei die geringe Größe der von uns erforschten Betriebe (zwei Kleinstbetriebe unter 2 ha und zwei mittlere Betriebe mit knapp 10 bzw. 30ha) bedeutet, dass die damit verbundenen flächenbezogenen staatlichen Förderungszahlungen für sie sehr gering ausfallen. ${ }^{31}$

Gegen Ende des 20. Jahrhunderts weckte die Oststeiermark wissenschaftliches Interesse hinsichtlich ihrer Agrar- und Wirtschaftsgeschichte (Kapitel Kosnik), weil dort die Industrialisierung verglichen mit anderen Gebieten Europas erst spät einsetzte, dann aber ab der Mitte des 20. Jahrhunderts umso energischer vorangetrieben wurde. War die Region vormals durch Selbstversorgung gekennzeichnet, setzte nun auf den landwirtschaftlichen Betrieben eine Entwicklung ein, die der Wirtschaftshistoriker Karl Polanyi als Entbettung der wirtschaftlichen Verhältnisse bezeichnet. ${ }^{32}$ Produktion und Distribution von Lebensmitteln wurden rationalisiert, kleinstrukturierte Betriebe verschwanden zusehends und die Bevölkerungszahl in den ländlichen Gebieten sank. Im größten politischen Bezirk der Oststeiermark halbierte sich die Anzahl der landwirtschaftlichen Betriebe alleine in den 40 Jahren zwischen 1970 und 2010 (in absoluten Zahlen: 9.563 im Jahr 1970 stehen 5.210 im Jahr 2010 gegenüber). ${ }^{33}$ Im Jahr 2012 zählte die Region 3.715 landwirtschaftliche Betriebe, im Jahr 2018 noch 2.857. Dabei fällt auch auf, dass die Anzahl der Bio-Betriebe in der Region zunahm: von 322 im Jahr 2012 auf 386 im Jahr 2018, während

30 Die von uns untersuchten Regionen fallen insbesondere unter die Kategorien »Sonstige Benachteiligte Gebiete« (aus erheblichen naturbedingten Cründen benachteiligt, z.B. Klima, Boden und Hangneigung) und »Kleine Cebiete« (aus anderen spezifischen Gründen benachteiligt). Rund $80 \%$ der Landesfläche Österreichs gelten als benachteiligte Cebiete; siehe Bundesministerium Landwirtschaft, Regionen und Tourismus (2020).

31 So beträgt die Förderung für das Fallbeispiel Adam nach eigener Angabe $€ 1.800$-/Jahr.

32 Vgl. Polanyi 1977.

33 Vgl. Landwirtschaftskammer Steiermark 2016. 
die absolute Zahl an Betrieben sank. ${ }^{34}$ Seit dem Jahr 2001 ist in der gesamten Region ein Rückgang der Bevölkerung zu verzeichnen. ${ }^{35}$

\section{Der ökologische Landbau}

Die Bezeichnung ökologisch dient uns als Überbegriff für nicht-konventionelle Landbaumethoden, worunter eine Vielzahl unterschiedlicher Produktionsmethoden fällt. In Österreich, wie in der Schweiz, sind die Begriffe »bio« bzw. »biologisch« üblicher und sind in diesem Band als Synonym zu verstehen. In der EU ist der Begriff Bio/Öko gesetzlich definiert. Öko-Bauern und Bäuerinnen müssen eine Reihe gesetzlicher Vorgaben und Richtlinien berücksichtigen, ihre Einhaltung wird jährlich von einer unabhängigen Kontrollstelle geprüft. Nur Produkte, die diese gesetzlichen Mindestkriterien erfüllen, dürfen als ökologisch bezeichnet und mit einem entsprechenden Siegel versehen werden. Darüber hinaus können Öko-Verbände oder auch der Lebensmittelhandel den Produzent*innen noch detailliertere und strengere Richtlinien auferlegen.

Im Öko-Landbau sind chemisch-synthetische Pflanzenschutzmitteln verboten. Weitere Eckpfeiler sind: Kreislaufwirtschaft, der Verzicht auf schnell-lösliche mineralische Dünger und das Verbot von Gentechnik (auch bei Futtermitteln), sowie eine artgerechte Haltung und Fütterung von Nutztieren. Zudem wachsen Öko-Produkte im Boden und nicht etwa in einer Nährlösung. ${ }^{36}$ Der Agrarwissenschaftler Gunter

Zahlen zur Verfügung gestellt vom Verband Bio Austria Steiermark.

Der Ökolandbau verbraucht im Durchschnitt $45 \%$ weniger Energie und ist damit energie-effizienter als konventionelle Anbausysteme. Das Ertragsniveau der biologischen Kulturen ist im Ackerbau im Durchschnitt um $20 \%$ geringer, der Einsatz von Düngemitteln und Energie um $34 \%$ bis $53 \%$ und der Einsatz von Pestiziden um $97 \%$. Wahrscheinlich führen die erhöhte Bodenfruchtbarkeit und die größere biologische Vielfalt dazu, dass diese Systeme weniger auf Zufuhr von außen angewiesen sind. Siehe Mäder u.a. 2002. 
Vogt grenzt ökologische Landbausysteme von anderen Landbausystemen erstens über ein biologisches Verständnis von Bodenfruchtbarkeit, zweitens einen begrenzten Einsatz außerbetrieblicher Hilfsmittel und drittens durch die Erzeugung (ernährungsbezogener) hochwertiger Nahrungsmittel ab. Während chemisch-technisch intensivierte Landbausysteme auf chemisch-synthetische Mittel (Mineraldünger und Pestizide) bei der Landbewirtschaftung zurückgreifen, sind ökologische Landbaumaßnahmen durch die Aktivitäten von Bodenlebewesen geprägt und die Bewirtschaftung (Düngung, Bodenbearbeitung, Pflanzenschutz) erfolgt mithilfe ökologischer Mittel.

Um die Jahrtausendwende setzte eine Entwicklung ein, die in der agrarsoziologischen und agrarökonomischen Literatur als Konventionalisierung des ökologischen Landbaus beschrieben wird. Konventionalisierung bezeichnet einen Biolandbau, der wesentlich von Zielen und Denkmustern der konventionellen Landwirtschaft geprägt ist. Durch die Dominanz dieser Ziele sind die ökologischen und sozialen Prinzipien des Biolandbaus zunehmend unter Druck geraten. ${ }^{37}$ Die großen österreichischen Handelsketten haben den Öko-Trend Mitte der 1990er aufgegriffen und bieten eine wachsende Palette an ÖkoProdukten kostengünstig an. Dafür wurden eigene Marken konstruiert und mit der industriellen Produktion ökologischer Waren begonnen (Kapitel Sorgo). Im Sinne Rosa Luxemburgs Theorie der Landnahme will ein kapitalistischer Markt auch Alternativen der Verwertung zuführen. ${ }^{38}$ Viele ökologisch wirtschaftenden Bäuerinnen und Bauern stehen diesen Wachstumsbestrebungen der Öko-Branche kritisch gegenüber und versuchen indessen einige Elemente der Pionierzeit des Ökolandbaus wieder neu zu beleben. Ein Beispiel dafür sind etwa CSA Betriebe, die in ihren Grundzügen an die Erzeuger-Verbraucher-Initiativen der 1980er erinnern (Kapitel Heistinger).

37 Vgl. Guthman 2014; Ploeg 2018b; Groier 2013.

38 Vgl. Soiland 2017. 


\section{Transdisziplinarität im Forschungsprozess}

Unser Forschungsteam bringt Wissenschaftler*innen aus Kulturgeschichte, Europäischer Ethnologie und Kulturanthropologie zusammen mit einer aus der Praxis kommenden Agrarberaterin und Fachbuchautorin für den Ökologischen Landbau. Andrea Heistinger stand als Agrarberaterin über ihre Klient"innen in einem fließenden Dialog mit Akteur"innen des Ökolandbaus und mit regionalen Initiativen in Österreich. Die zur Datenanalyse eingeladenen Expert"innen aus Soziologie, Agrarwissenschaft und Gartenbau, sowie Social Banking and Social Finance brachten zusätzliche Perspektiven in den Forschungsprozess ein. Darüber hinaus wurden Studierende aller Disziplinen der Universität Graz eingeladen, sich in zwei Sitzungen an der Gruppenanalyse für die rekonstruktive Genogrammarbeit (siehe Methodenkapitel) zu beteiligen. Gespräche wurden außerdem mit einer Expertin für alternative landwirtschaftliche Vermarktungsformen sowie mit einem gerichtlich beeideten Sachverständigen für den Marktwert landwirtschaftlicher Flächen und Betriebe durchgeführt. Nicht zuletzt ist die Bedeutung der Zusammenarbeit mit den Gewährspersonen als epistemische Partnerschaft hervorzuheben, die wesentlich zur Analyse beiträgt. ${ }^{39}$

Damit die Forschung über reine Multidisziplinarität hinausreicht, wurde innerhalb unseres Forschungsteams viel Zeit in die Zusammenarbeit investiert. Epistemologische und methodologische Differenzen mussten erkannt und Lösungen gefunden werden, um eine gemeinsame Basis des wissenschaftlichen Arbeitens zu schaffen. Wir lernten voneinander unterschiedliche theoretische und methodische Ansätze, den jeweiligen Fachjargon und unsere Erfahrungshintergründe kennen und konnten so das Projekt inhaltlich immer wieder neu fassen und schließlich eine gemeinsame Form der Publikation unserer Ergebnisse erarbeiten. ${ }^{40}$ Als common ground nutzen wir einen kulturwissenschaftlichen Zugang und geben damit der qualitativen Forschung den Vorzug. 
Die familienbiografischen Daten wurden nach der Methode der rekonstruktiven Genogrammarbeit nach Hildenbrand erhoben, sowie durch mehrfache Hofbesuche und narrative Interviews mit den betriebsleitenden Personen (zum Teil auch jenen, die heute nicht mehr am Betrieb leben) ergänzt.

Die Studie basiert als common case study auf der gemeinsamen Analyse von vier Fallbeispielen. Die Auswahl der Fälle beruht auf vier Grundkriterien: erstens musste es sich um nach dem österreichischen System zertifizierte Öko-Betriebe handeln; zweitens mussten diese Betriebe Grundnahrungsmittel für Menschen produzieren, wodurch spezialisierte Betriebe (Wein, Honig etc.), aber auch die reine Futtermitteloder Biomasseproduktion, bzw. reine Forstwirtschaft ausgeschlossen wurden. Die Produkte sollten drittens auch (aber nicht unbedingt ausschließlich) regional vertrieben werden. Schließlich suchten wir nach Vollerwerbsbetrieben, die nach dem eigenen Empfinden der Betriebsleiter*innen wirtschaftlich rentabel sind, ihnen somit ein gutes Leben ermöglichen und gleichzeitig nicht nur durch Fördergelder oder externe Einkünfte »am Leben erhalten« werden. Im Forschungsteam konnten wir grundlegende Übereinstimmungen analytischer Positionen finden, doch auch Unterschiede blieben bestehen. Unsere unterschiedlichen Herangehensweisen sollen und dürfen in den einzelnen Kapiteln beschreibend, analytisch oder problemlösungsorientiert ausgerichtet, auf die Mikro- oder Makroebene bezogen - hervortreten.

Andrea Heistinger beschreibt im Methodenkapitel die rekonstruktive Genogrammarbeit in Theorie und Praxis. Sie legt anhand ihrer Analyse dar, dass es familiäre Muster sowie Ressourcen in den Biografien der Menschen sind, aus denen sich letztlich auch die neuen Formen des Lebens, Arbeitens und Wirtschaftens auf ihren Höfen entwickeln. Elisabeth Kosnik befasst sich in ihrem Kapitel mit den historischen und gesellschaftlichen Kontexten, in welche die Fallbeispiele der vorliegenden Studie eingebettet sind, insbesondere mit der Verbreitung des ökologischen Landbaus. Ploegs Begriffe des peasant farming und entrepreneurial farming ${ }^{41}$ werden als Denkfiguren herangezogen, um

41 Vgl. Ploeg 2010, 2014, 2018a, 2018b. 
diese Entwicklungen zu analysieren. Puig de la Bellacasas Überlegungen zu soil care dienen als theoretischer Rahmen, um Diskurse von care mit den Mikroperspektiven der Akteur*innen - ihren Handlungen und Vorstellungen in Bezug auf Produktion, Verarbeitung, Distribution und Konsum (kurz foodways) - zusammenzudenken. Im folgenden Kapitel beschreibt Andrea Heistinger die vier untersuchten Familienbetriebe und geht auf die Biografien der Betriebsleiter*innen ein. Dabei legt sie den Fokus auf jene sozialen und ökonomischen Ressourcen, die Menschen aus ihrer Familiengeschichte mitbringen, die einen Einfluss auf die erfolgreiche Bewirtschaftung der Betriebe haben. Dabei kann sie zugleich Resilienz-Praktiken anhand konkreter Biographien sichtbar werden lassen. Im letzten Kapitel leitet Gabriele Sorgo den Begriff der "Sorgsamen Landwirtschaft" von der Verknüpfung der Ernährung, die hier als Begriff alle Prozesse der Herstellung, Verteilung und des Verzehrs umfasst, mit dem Begriff der Sorge her. Sorge oder care soll hier umschreiben, dass ökologisch engagierte Akteure*innen zusätzlich zur Handarbeit und zur Wissensarbeit auch emotional-affektive Arbeit leisten, die unverkäufliche aber unentbehrliche Beziehungen herstellt. Ziel dieser Perspektive ist es, die realen Beziehungsgeflechte, in denen Nahrungsmittel zwischen Menschen, Pflanzen, Tieren und Boden entstehen, konkret und sichtbar werden zu lassen. 



\section{Sozialen Sinn verstehen durch rekonstruktive Genogrammarbeit}

Andrea Heistinger

Im sinnverstehenden Ansatz der Genogrammarbeit geht es um Interaktion, um Verbindung, um das Sichtbarmachen von WechselWirkungen zwischen Makrosoziologie - großen gesellschaftlichen Entwicklungen - und der individuellen Biografie eines Menschen oder einer Familie - der Mikrosoziologie. In anderen Worten: Es geht um Beziehung. Konkret fokussiert die rekonstruktive Genogrammarbeit auf historischen und familiensoziologischen Daten der letzten drei Generationen eines individuellen Menschen. In unserem Fall waren dies je die vier Großeltern und zwei Eltern der beiden Betriebsleiter*innen. Dabei geht die rekonstruktive, ressourcenorientierte Genogrammarbeit davon aus, dass aus der Vergangenheit keine kausalen oder linearen Linien in eine Zukunft hineingezogen werden können. Vielmehr bildet die Vergangenheit einen Rahmen, der mögliche Entwicklungen offen hält und der auch überschritten werden kann. ${ }^{1}$

\section{Eine kurze Theorie der Genogrammarbeit}

\section{Genogrammarbeit versteht Sinn als sozialer Sinn}

Der Genogrammarbeit nach Bruno Hildenbrand liegt die objektive Hermeneutik als Sichtweise des Verstehens menschlichen Verhaltens zu- 
grunde. Sie hat sich als spezifische Variante der objektiven hermeneutischen Fallrekonstruktion entwickelt. ${ }^{2}$ Sie geht davon aus, dass Werke objektivierte Gegenstände sind, die auf menschliches Handeln zurückgehen. ${ }^{3}$ Mit anderen Worten: Im »Werk « manifestiert sich ein Objekt, das von einem Subjekt geschaffen wurde. Menschen schaffen Werke und realisieren sich darin als Menschen - und zwar in Auseinandersetzung und in Beziehung mit anderen Menschen. Die Genogrammarbeit knüpft hier an und versteht das Genogramm eines Menschen als Werk. ${ }^{4}$

Die Frage ist nun, wie regionale Muster der Daseinsbewältigung ${ }^{5}-$ die ja kollektive Muster sind - mit den individuellen Momenten im Leben eines Menschen (den objektiven Daten in seinem Genogramm) verbunden sind. Hier knüpft Hildenbrand an das Menschenbild des französischen Soziologen Pierre Bourdieu an und zwar konkret an dessen Begriffe Habitus und Praktiken.

In unserem Ansatz der sorgsamen Landwirtschaft gehen wir darüber hinaus und auch davon aus, dass Menschen sich in den von ihnen geschaffenen Werken auch durch ihre Auseinandersetzung mit der $\mathrm{Na}$ tur, mit den Tieren, die sie halten, mit den Pflanzen, die sie anbauen, mit den Äckern, die sie kultivieren, realisieren. In der Landwirtschaft

2 Unter Objektiver Hermeneutik werden Interpretationsverfahren der empirischen Sozialforschung verstanden, die im Wesentlichen auf den Soziologen und Sozialpsychologen Ulrich Oevermann zurückgehen. Dabei gibt es nicht die objektive Hermeneutik, sondern ein gemeinsames Grundverständnis für die Herangehensweise an die Deutung von Daten. (Vgl. Kruse 2015: 417).

3 Hildenbrand 2013:93.

4 Hildenbrand 2013, ebenda.

5 Für die Forschungsregion Südoststeiermark beschreiben die Kulturanthropologen Karl Kaser und Karl Stocker dies so: »In den einzelnen Dörfern hatten sich im Laufe der Jahrhunderte >ungeschriebene Gesetze< entwickelt, die das Leben der BewohnerInnen regelten. Mochten sie auch für so manchen Außenstehenden unverständlich sein, für die südoststeirische bäuerliche Bevölkerung waren sie durchaus leicht erfassbar. Ob es sich um Richtlinien für die Arbeit (so galt es etwa >fleißig`zu sein), um Regeln für die lokalen sozialen Beziehungen (...) oder um die Haltung zur Kirche handelte, niemand zweifelte diese sungeschriebenen< Gesetze an.« Kaser u.a. 2003:307f. 
kann das Objekt ein Hof sein, aber auch die angebauten Pflanzenarten, die gehaltenen Tierrassen, der auf eine bestimmte Art hergestellte Käse, ein verwendetes Gerät, die über die Praktiken und Vorstellungen der Menschen, die einen Betrieb bewirtschaften, verbunden sind. ${ }^{6}$

\section{Handeln und Familienmuster}

Familienmuster prägen latent die Entscheidungen, die in der Familie getroffen werden. ${ }^{7}$ Muster, die aus der vollzogenen Lebenspraxis der Vergangenheit stammen, geben einerseits Dynamiken - im Sinne von Handlungsorientierungen - vor, andererseits können sie sich laufend wandeln. Und genau das ist entscheidend: Familienmuster sind immer veränderbar. Dieser Fokus ist sowohl für die Forschung, wie auch für die Beratung essentiell. ${ }^{8}$ Familienmuster sind wie kognitive - also gedachte - Landkarten mit deren Hilfe sich ein System, in unserem Fall ein Familiensystem, in seiner Wirklichkeit orientiert. Diese Orientierungsstrukturen betreffen "nicht nur die kognitive Ebene, sondern gleichermaßen emotionale sowie vor-kognitive Muster alltagsweltlicher Orientierung. «9 Familienmuster haben kollektive Anteile, die für die Zeit und die Region typisch sind und Anteile, die für die Familie typisch sind. Das Individuelle einer Geschichte ist stets in kollektive Handlungsmuster eingewoben. Bruno Hildenbrand beschreibt dies so: "Akteure arbeiten sich interpretierend am Vorgegebenen (»objektive Daten «) ab und transformieren das Vorgegebene in ein Aufgegebenes, das heißt zu Gestaltendes, indem sie unter objektiv gegebenen Möglichkeiten auswählen. ${ }^{10}$

6

Siehe ausführlich das Kapitel von Gabriele Sorgo sowie das Kapitel Wie aus Familiengeschichte sorgsame Landwirtschaft entsteht.

7 Hildenbrand 2018:20.

8 Auch die Agrarsoziologin Ika Darnhofer legt in ihren Forschungen zur Resilienz von Familienbetrieben den Fokus auf die Frage, welche Beziehungsmuster (i.O. »patterns of relations«) es sind, die einen transformativen Wandel ermöglichen. Darnhofer u.a. 2016.

9 Welter-Enderlin und Hildenbrand 2004:21.

10 Hildenbrand 2005:23. 


\section{Die Praxis der Genogrammarbeit - Die einzelnen Arbeitsschritte der Genogrammarbeit im Forschungskontext}

\section{Zur Fallauswahl - Theoretisches Sampling von Fall zu Fall}

Für die Fallauswahl wurde keine Stichprobe gewählt, sondern das theoretische Sampling erfolgte von Fall zu Fall. Diese Methode folgt dem von Hildenbrand vorgeschlagenen Weg, nicht alle Familienstudien (= Fallbeispiele) zu Beginn des Forschungsprozesses auszuwählen, sondern zunächst den ersten Fall, diesen durch die sequentielle Interpretation $\mathrm{zu}$ erschließen und nach Formulierung einer Fallstrukturhypothese zu den Familienmustern des ersten Falls den zweiten Fall in einer maximalen Fallkontrastierung zum ersten Fall auszuwählen. ${ }^{11}$ Im Forschungsprojekt haben wir die Methode dahingehend abgewandelt, dass wir nicht nach Familienmustern kontrastiert haben, sondern nach betrieblichen Daten - die wiederum als objektive Werke in der Biografie einer Familie verstanden werden. Nachdem der erste Betrieb ein neu gegründeter Betrieb war, haben wir als zweiten Fall einen Betrieb ausgewählt, der in der Familie nach patrilinearer Vererbungspraxis übergeben wurde und in dem das Betriebsleiterpaar eine neue Wirtschaftsweise eingeführt hat. Als dritten Betrieb einen Tierhaltungsbetrieb mit Direktvermarktung, der von einem Ehepaar neu gegründet worden war und als vierten Fall wiederum einen spezialisierten Betrieb, der von der dritten Generation (unseren Interviewpartner*innen) vom Hobbybetrieb in einen Haupterwerbsbetrieb umgewandelt wurde.

\section{Daten erheben}

Die Genogrammdaten wurden im Gespräch mit den Betriebsleiter*innen direkt bei den Besuchen auf den Betrieben während der Feldforschung erhoben. Diese Daten wurden von den Gesprächspartner*innen

11 Hildenbrand 1999. Siehe dazu ausführlich das Kapitel »Wie aus Familiengeschichten sorgsame Landwirtschaft entsteht«. 
entweder spontan erinnert, fehlende Daten haben die Gesprächspartner*innen auf unsere Bitte hin nachrecherchiert und uns nachträglich per E-Mail übermittelt. In der Regel werden die Genogrammdaten der letzten drei Generationen einer Person erhoben (also des/der Betriebsleiter*innen - auch der ehemaligen Partner*innen, falls diese auch für den Betrieb relevant waren, Geschwister, Eltern und Tanten/Onkeln sowie Großeltern/wenn möglich auch Großtanten und Großonkeln); in unserem Fall von allen Betriebsleiter"innen, inklusive ehemaliger Partner*innen. Insbesondere interessieren jene Entscheidungsbereiche, die für die Identitätsbildung und eine autonome Lebenspraxis entscheidend sind: Die Entscheidung für einen Beruf (die materielle Selbsterhaltung), die Partner*innenwahl und die Entscheidung für oder gegen Kinder und die Herstellung eines Bezugs zum Gemeinwesen (Wahl des Wohnorts, Beziehungen zu Institutionen). ${ }^{12}$ Erhoben werden ausschließlich objektive Daten. ${ }^{13}$ Der Vergleich der spontan erinnerten mit den nachträglich von den Interviewpartner*innen recherchierten Daten trägt zum Fallverstehen und zur Rekonstruktion des Familienmusters bei. Folgende Daten werden - im optimalen Fall der Vollständigkeit von Daten - erhoben:

- Vorname(n) und Nachname

- Geburtsjahr und allenfalls Sterbejahr

- Partnerschaften/Eheschließungen

- Allenfalls Trennung oder Scheidung (Jahr)

- Schulbildung und allenfalls weitere Ausbildungen

- Ausgeübte(r) Beruf(e)

12 Siehe dazu ausführlich Hildenbrand 2005:19.

13 Wir haben bis auf eine Ausnahme, wo wir Genogrammdaten auch im Gespräch mit der Mutter eines Betriebsleiters erhoben haben, nicht mit den Eltern, Onkeln, Tanten, Großeltern oder Geschwistern, persönlich gesprochen. Die Interviewpartner*innen sind unsere Informant*innen zu allen anderen Personen, lebend oder verstorben - es sind also ihre erinnerten oder preisgegebenen Daten sowie Daten, die unsere Interviewpartner*innen selbst noch innerhalb der Familie nachrecherchiert haben und die manchmal auch die im Gespräch spontan erinnerten Daten revidiert haben. 
- Wohnort(e) und Wohnortwechsel

- In günstigen Fällen auch Daten zu Zeiten der Beschäftigung/Arbeitslosigkeit/Militär- oder Zivildienst und Pensionierung

- Karenzzeiten

Die Vollständigkeit der neun im Forschungsprojekt erhobenen Genogramme ist unterschiedlich. Zum Teil mussten wir auch mit unvollständigen Genogrammen arbeiten, weil Genogramme nicht genau erinnert wurden oder unsere Gesprächspartner*innen nicht alle Daten nachrecherchieren konnten, weil beispielsweise der Kontakt zu einem Familienmitglied abgebrochen war.

\section{Im Team das Genogramm sequentiell rekonstruieren und Familienmuster beschreiben}

Im Verständnis von Hildenbrand werden Familienmuster nicht in die Genogrammdaten hineingedeutet, sondern aus ihnen herausgelesen. Ein wesentliches Element der Methode der Genogrammarbeit ist es, die Entscheidungen, die einzelne und ihr Familien getroffen haben, sowie die Spuren, die sie in der sozialen Wirklichkeit hinterlassen haben, zu rekonstruieren. ${ }^{14}$ Die rekonstruktive Genogrammarbeit ist daher - wie in der objektiven Hermeneutik üblich - eine Sequenz-Analyse. ${ }^{15}$ Man fängt bei einem Großvater oder einer Großmutter der »Indexperson « in unserem Falle der Betriebsleiter oder die Betriebsleiterin - an und notiert seinen/ihren Namen, Geburtsort, Geburtsjahr und Beruf auf ein Flipchart. Nun geht es darum, an jeder biografischen Entscheidungssequenz die begründbaren Handlungsmöglichkeiten zu rekonstruieren und erst in einem zweiten Schritt die im Einzelfall tatsächlich gewählte Option offenzulegen. Am einfachsten ist dies, wenn die Person, die das

\footnotetext{
14 Hildenbrand 2013.

15 Die theoretische Grundlage der Sequenzanalyse ist: Die Lebenspraxis als Prozess der Krisenbewältigung zu sehen. Welter Enderlin und Hildenbrand 2004:32.
} 
Genogramm erhoben hat, zunächst nur zuhört und die anderen Personen der Arbeitsgruppe - oder des Arbeitstreffens - Hypothesen formulieren. Dazu ist ein sozioökonomisches und historisches Hintergrundwissen zur Region, in der der Betrieb liegt, und zu den agrarpolitischen Rahmenbedingungen der jeweiligen Zeit notwendig und es ist hilfreich, wenn ein Team von mehreren Forscher*innen am Deutungsprozess beteiligt ist. Was waren zu diesem Zeitpunkt mögliche Optionen für die Großmutter, den Großvater, den Vater und die Mutter des/der Betriebsleiter"in? Man beginnt also jeweils mit der Großelterngeneration. Jedes Datum, jede Angabe wird im Forschungsteam zunächst so besprochen, indem nach allgemeinen, (damals) denkbaren Handlungsoptionen gefragt wird. Dieser Schritt ist ein kontextfreies Analysieren - der unmittelbare, spezielle Kontext der Fallgeschichte wird also zunächst bewusst ausgeblendet. ${ }^{16}$ Erst nachdem wir die objektiv möglichen Handlungsmuster benannt haben, wird aufgedeckt, wie die konkrete Person tatsächlich gehandelt hat. Von hier aus befassen wir uns mit den tatsächlich eingetretenen Möglichkeiten, bis wir in der Gegenwart angekommen sind und verdichten so die Arbeitsthesen zu Familienmustern.

Damit das gelingt, werden Genogrammdaten konsequent von den subjektiven Erzählungen in der Familie getrennt. Auch und gerade dann, wenn es sich um in der Familie tradierte Erzählungen handelt. Das Genogramm wird nicht vollständig im Team präsentiert, sondern im Team gemeinsam Schritt-für-Schritt rekonstruiert. Konkret haben wir zur Rekonstruktion eines Genogramms zwischen zwei bis vier Stunden verwendet. Auf diese Weise ist nicht nur das Interpretationsverfahren sehr entschleunigt, was die Perspektive der Forscher*innen öffnet und ein Grundprinzip im Deutungsprozess rekonstruktiv-hermeneutischer Verfahren entspricht, ${ }^{17}$ sondern die

16 Auch dieses bewusste Ausblenden erfordert Übung. Und da wir ja die Cenogramme der beiden, den Betrieb bewirtschaftenden Partner*innen erhoben haben, war bei der Interpretation des jeweils zweiten Genogramms einiges bereits bekannt. Für die Benennung von möglichen Handlungsoptionen war dies allerdings nicht hinderlich. 
Person, die gerade im Fokus der Genogrammarbeit steht, wird in ihren jeweiligen Rahmenbedingungen und Handlungsmöglichkeiten - ähnlich wie eine Rolle in einem Theaterstück - sicht- und wahrnehmbar. In der rekonstruktiven Genogrammarbeit werden so Schritt für Schritt die Lebens- und Familienthemen der letzten drei Generationen zu einer Fallstrukturhypothese verdichtet. Diese Form der Rekonstruktion von Genogrammen hat auch eine durchwegs heitere und spannende Komponente. Je nachdem, wie umfangreich das Wissen über die Lebensverhältnisse $\mathrm{zu}$ dieser Zeit und an diesem Ort sind, können detailreichere Thesen formuliert werden.

Entscheidungen, die aufs erste als individuelle unternehmerische Entscheidungen erscheinen, stehen häufig auch in einer Interaktion mit Dynamiken und Handlungsmustern innerhalb der Familie. Dazu ein Fallbeispiel aus unserer Forschung: Die Entscheidung des Ehepaars Bergmanns, die Intensiv-Hühnermast aufzugeben und den Betrieb auf einen CSA-Gemüsebetrieb umzustellen scheint aufs erste ein radikaler Bruch mit der Geschichte des Betriebs zu sein. Bei einer sequentiellen Analyse des Genogramms der Eltern und Großeltern von Herrn Bergmann wird sichtbar, dass auch sie sich jeweils als erste in der Region auf radikal Neues einlassen konnten - den Anbau damals neuer Kulturen, neuer Anbaumethoden sowie neuer Vermarktungsmethoden. Ebenso spiegelt sich die Offenheit der Betriebsleiter*innen, ihre Erfahrungen zum Gemüseanbau auch an andere Interessierte weiterzugeben, in der Tätigkeit des Großvaters wider, der in den 1950er Jahren andere Betriebe als Obstbau-Berater bei der Anlage von Intensiv-Obstbaukulturen unterstützt hat. Nur der Rahmen hat sich geändert: Während der Großvater in der Region als Obstbauberater tätig war, steht der Betrieb Bergmann heute im Austausch mit Betrieben aus ganz Österreich und arbeitet eng mit einem Betrieb aus Bayern bei der Entwicklung eines speziellen Anbau-Verfahrens zum ökologischen Gemüsebau zusammen. Dieses Familienmuster haben wir so beschrieben: Durch die familiäre Offenheit und Risikobereitschaft für neue Wirtschaftsweisen - die im Widerspruch zur herrschenden Praxis in der Region stehen - entstehen neue Perspektiven für die Bewirtschaftung des Betriebes, die neue Einkommensmöglichkeiten für den Betrieb schaffen und die eigene Ar- 
beitsfähigkeit und Motivation stärkt. Die Familie ist auch offen dafür, sich auch auf neue Arbeitsabläufe und neue Beziehungsgeflechte - zum Beispiel in Form von Lieferbeziehungen - einzulassen.

\section{In Bezug setzen zur erlebten Lebensgeschichte}

Erst nachdem die zentralen Themen und die Muster in der Familie aus den »objektiven « Daten des Genogramms rekonstruiert und in Form einer Fallstrukturhypothese beschrieben wurden, beschäftigen wir uns mit den subjektiven Erzählungen innerhalb der Familie zu diesen einzelnen Daten. Die Grundlage dafür sind qualitative Interviews, die wir mit den Betriebsleiter*innen geführt haben, sowie ihre Erläuterungen zu den Genogrammen. Dazu Hildenbrand: »Wir unterscheiden also zwischen einer gelebten Lebensgeschichte, welche die Genogrammdaten und die daraufbezogene Sequenz-Analyse enthält und der erlebten Lebensgeschichte, welche die biografischen Erzählungen der Klienten « enthält. ${ }^{18}$

\section{Meine berufliche Biografie und meine Rolle im Forschungsprojekt}

In der qualitativen Sozialforschung ist es Standard, sich selbst als Forscher*in $\mathrm{zu}$ verorten und den eigenen Bezug zum Forschungsfeld offenzulegen. Das Prinzip der Betroffenheit bedeutet, dass die (Selbst-)Reflexivität im Forschungsprozess für eine kritische Forschung notwendig ist. Dies bedeutet gleichzeitig, dass die eigene subjektive Perspektive der Forscherin den Forschungsprozess und die Qualität der Ergebnisse grundlegend prägt und andere Forscher aus ihrer Perspektive zu abweichenden Ergebnissen kommen können. Im Forschungsprojekt "Bio Hoch Drei«, in dessen Rahmen wir die vorliegende Publikation erarbeitet haben, führte ich die Interviews und empirischen Arbeiten »im Feld « - wie es in der Kultur- und Sozialanthropologie heißt - durch. Mit Feld ist hier nicht der Acker gemeint - 
den man auch mit mir in Verbindung bringen könnte, schließlich bin ich seit 20 Jahren als Agrarwissenschafterin tätig. Hingegen nimmt die Kultur- und Sozialanthropologie das soziale Feld in den Blick und fragt danach, wie Menschen - alleine und in Gemeinschaft - ihr Leben gestalten und ihr Zusammenleben ausrichten. Seit zwei Jahren bin ich auch als Organisationsberaterin und Beraterin für Familienbetriebe tätig und diese Tätigkeit liegt auch wie ein weites Feld vor mir, wenn ich in meine berufliche Zukunft blicke. Wenn ich den Blick in meine Vergangenheit richte, blicke ich auf fast 20 Schreibjahre zurück: Ich habe zahlreiche Fachbücher zum ökologischen Anbau von Gemüse, Obst und Kräutern verfasst. Diese Bücher sind in der »Bio-Szene« in Österreich und Deutschland sehr bekannt. Ein weiteres Tätigkeitsfeld war die Betreuung von Regionalentwicklungsprojekten für und mit Bergdörfern in Südtirol und das Konzipieren und Durchführen von Weiterbildungen für Bäuerinnen und Bauern an einer Südtiroler Fachschule für Landwirtschaft. Ich arbeite seit Abschluss meines Studiums der Agrarwissenschaften im Jahr 2000 für und mit Bauern und Bäuerinnen und durfte viele ein Stück ihres Weges begleiten, wenn es für sie gerade darum ging, neue Perspektiven für ihre Betriebe zu finden - sei es neue Kulturpflanzen anzubauen, sich Wissen zur Saatgutvermehrung anzueignen, neue Verarbeitungsmethoden oder neue Vermarktungsmethoden zu entwickeln. Auch habe ich in den letzten Jahren zahlreiche Vorträge gehalten - zum Beispiel im Jahr 2016 den Eröffnungsvortrag bei den Gemüsebau-Fachtagen des größten Österreichischen Bio-Verbandes Bio Austria. ${ }^{19}$ Ich erwähne konkret diesen Vortrag, weil ein Interview-Partner aus unserem Forschungsprojekt mich von diesem Vortrag kannte. Als ich ihn drei Jahre später in meiner Rolle als Wissenschaftlerin kontaktierte, stimmte er einem Interview sofort $\mathrm{zu}$ und rief seiner Frau zu, während ich mit ihm telefonierte: »Die Heistinger kommt zu uns. Hast du kommenden Dienstag Zeit?« Zwei andere Interviewpartner*innen kannten mich persönlich durch meine

19 Eröffnungsvortrag der Bio Austria Gemüsetage am 30.11.2015 in St. Pölten zum Thema »Bäuerliche Landwirtschaft neu denken. Abschied von Mythen und Cestalten neuer Möglichkeiten «. 
ehrenamtliche Tätigkeit im Vorstand des Vereins Arche Noah ${ }^{20}$ und durch Gespräche, die ich mit ihnen im Rahmen der Recherche für das im Jahr 2018 erschienenen Buch »Basiswissen Selbstversorgung. Individuelle und gemeinschaftliche Wege und Möglichkeiten« geführt habe. Mit meinen Gesprächspartner*innen im Niederösterreich tausche ich mich, seit sie ihren Betrieb gegründet haben, immer wieder zu Fachfragen zum Gemüsebau und zur Vermarktung aus. Einigen meiner Gesprächspartner*innen des Forschungsprojektes war ich aus diesen Zusammenhängen persönlich bekannt. Das hat einen Einfluss auf die Beziehung zwischen mir als Forscherin und den beforschten Familien und Betrieben. Die unmittelbarste Wirkung war vermutlich, dass sie recht umgehend zustimmten als Fallbeispiel für unser Forschungsprojekt Bio hoch drei zur Verfügung zu stehen. Wobei ich hier auch ergänzen möchte, dass vor allem die beiden Interviewpartner*innen, die CSA-Betriebe bewirtschaften, es gewohnt sind, dass Studierende und Forscher*innen ihre Betriebe besuchen und mit ihnen Interviews führen - über ihre Anbaumethoden und über die von ihnen gewählte Form der Vermarktung ihrer Produkte. ${ }^{21}$ Andere Reaktionen auf die Anfrage zu einem Interview waren: Freudig und rasch zu einem Gesprächstermin bereit und das Gespräch auch als Gelegenheit zur Reflexion über das eigene Tun oder als Möglichkeit zum fachlichen Austausch oder zur Inspiration wahrzunehmen. Erwähnen möchte ich an dieser Stelle auch, dass ein Betriebsleiter, den ich im Rahmen des

20 Der Verein Arche Noah mit Sitz im Niederösterreichischem Schiltern erhält in seinem Netzwerk aus Gärtner*innen und Landwirt*innen einige tausend historische Kulturpflanzensorten, die im Zuge der Industrialisierung der Landwirtschaft an Bedeutung verloren haben (www.arche-noah.at) und ist im engen Austausch mit vielen bäuerlichen Betrieben, die aus diesen Sorten wieder neue Produkte entwickeln.

21 In den letzten Jahren wurden in Österreich und Deutschland zahlreiche Forschungsprojekte und wissenschaftliche Abschlussarbeiten durchgeführt, die sich mit der Community-Supported Agriculture - auf Deutsch auch als Solidarische Landwirtschaft bezeichnet - auseinandergesetzt haben. Zum Beispiel als Case-Study im EU Horizon2020-Forschungsprojekt Simra (www.simrah2020.eu) zu sozialen Innovationen in marginalisierten ländlichen Gebieten. 
Forschungsprojektes kontaktiert hatte, es ablehnte für ein Forschungsprojekt des Landes Steiermark zur Verfügung zu stehen. Ich hatte ihn über meine offizielle E-Mail Adresse der Universität Graz kontaktiert und um ein Gespräch gebeten. Die Antwort fiel harsch aus: »Ich bin immer wieder einmal verwundert, warum es selbstverständlich ist, dass Landesoder Bundesstellen auf kostenlose Mitarbeit jener »Pioniere« zurückgreifen, denen sie davor das Leben extrem schwer gemacht haben«. In seiner Antwort wird deutlich, dass die Person mich als Forscherin als Teil des öffentlichen Bürokratiesystems sowie, dass sie sich als innovativ und Behörden nicht als Partner, sondern als Hürden der betrieblichen Innovationen wahrnimmt. Über ähnliche Erfahrungen haben Bäuerinnen und Bauern immer wieder berichtet. ${ }^{22}$ Und: Gerade unter Pionier*innen ist es weit verbreitet, dass sie mit ihrer Zeit sehr gezielt und überlegt umgehen (müssen), da die Entwicklung eines neuen Betriebszweiges, einer neuen Vermarktungs- oder Finanzierungsform sehr zeitintensiv ist. $^{23}$

\section{Schlussbemerkung}

Dieses Kapitel stellt die Methode der rekonstruktiven Genogrammarbeit vor, die eine ressourcenorientierte Methode der sinnverstehenden Sozialforschung ist. Dabei ist die rekonstruktive Genogrammarbeit eine Methode, die stark »Zwischen dem Feld« und der Theorie vermitteln

22 So berichtet eine Gesprächspartnerin: »Es war so ein Grundgedanke, dass wir da einen Stall bauen. (...). Das wurde zuerst auch genehmigt. (...) Es war die Baugenehmigung da und es ist dann an einer einzigen Person bei einer Behörde gescheitert. (...) Es waren tausende Sachen zum Umplanen, was jedes Mal etwas gekostet hat. Bis dann jeder gesagt hat, das kann man bleiben lassen. (...) Also da ist halt die Bürokratie auch blöd." (Interview am 5.7.2018) Siehe dazu auch Kapitel von Elisabeth Kosnik.

23 Von manchen Betrieben kenne ich auch die Vereinbarung, dass jemand, der über den Betrieb forschen will, auch am Betrieb mitarbeiten muss, um eine adäquate Gegenleistung für die Informationen, die für die empirische Forschung zur Verfügung gestellt wurden, im Betrieb einzubringen. 
kann, genauso wie zwischen Zukunft, Gegenwart und Vergangenheit und zwischen einem Kollektiv und Individuen, zwischen Makro- und Mikrosoziologie. Ihre Stärke ist es insbesondere, dass sie sich grundsätzlich an einem konkreten Fall orientiert: Die Grundlage der Methode ist, tatsächlich »ins Feld « zu gehen und mit den Menschen in Beziehung zu kommen. Das Kapitel »Wie aus Familiengeschichte sorgsame Landwirtschaft entsteht« führt die Analyse der vier Fallbeispiele weiter. 



\section{Care Diskurse und Praktiken ökologischer Foodways}

Elisabeth Kosnik

In der Forschungsregion Oststeiermark erfolgte die weitgehende Umstellung der Landwirtschaft, weg von Selbstversorgung und hin zur Marktproduktion, teilweise erst in den 1970er Jahren und damit, im Vergleich $\mathrm{zu}$ anderen Regionen Westeuropas, verhältnismäßig spät. ${ }^{1}$ Historiker*innen betrachten diesen tiefgreifenden und rasanten Wandlungsprozess in der Region unterschiedlich, von positiv bis kritisch. ${ }^{2}$ Etwa zur selben Zeit begann sich die ökologische Produktionsweise in Österreich zu verbreiten. ${ }^{3}$ Dass diese Form der Landwirtschaft aus einer Kritik an der industriellen, chemisch-technischen Landwirtschaft hervorging, ist eine vielfach wiederholte Aussage und gleichzeitig eine vereinfachende Perspektive, die zumal vorrangig die Sichtweise der Konsument*innen wiedergibt. Die Motive für eine Umstellung auf ökologische Produktion waren und sind vielfältig, wie im Folgenden aufgezeigt wird.

Dieses Kapitel befasst sich mit den historischen und gesellschaftlichen Kontexten, in welche die Fallbeispiele unserer Studie eingebettet sind. Dabei soll insbesondere auf Diskurse und Entwicklungen im

\footnotetext{
1 Vgl. Eberhart 1991.
}

2 Siehe hierzu die eher positive Darstellung bei Posch 1978a, 1978b, bzw. die kritische Einschätzung von Kaser u.a. 2003, Kaser und Stocker 1986, 1987.

Die Bezeichnung »ökologischer Landbau« dient hier als Überbegriff für sämtliche ökologische Landbausysteme und in Abgrenzung zum sogenannten »konventionellen « Landbau, beziehungsweise zu tradierten Formen von Landwirtschaft. Der in Österreich üblichere Begriff »bio« ist als Synonym zu verstehen. 
ökologischen Landbau im deutschsprachigen Raum eingegangen werden, beziehungsweise auf die Geschichte der Landwirtschaft der Forschungsregion Oststeiermark. Die spärliche Datenlage zu den Anfängen des ökologischen Landbaus in der Steiermark lässt dabei kaum Generalisierungen über Akteur*innen und ihre Motive $\mathrm{zu} .^{4}$ Gleichzeitig würde eine ausführliche Darlegung der historischen Entwicklungen der Landwirtschaft den Rahmen dieses Kapitels überschreiten. Der Fokus wird daher auf Aspekte gelegt, die im Kontext unserer Forschung besonders relevant erscheinen, wobei aus kulturwissenschaftlicher Perspektive die unterschiedlichen Diskursstränge mit den Mikroperspektiven der Akteur*innen, ihren Handlungen und Deutungshorizonten, zusammengedacht werden sollen.

Die Analyse baut auf den vier Fallbeispielen der vorliegenden Studie auf, erweitert durch meine seit 2009 laufenden ethnografischen Forschungen zu Leben und Arbeiten auf ökologischen Betrieben und Selbstversorgerhöfen. Im Zuge dieser Forschungen fanden mehrtägige Feldforschungsaufenthalte auf zwölf ökologischen Landwirtschaften im deutschsprachigen Raum statt, acht davon in der Steiermark. ${ }^{5}$ Es sind daher vorrangig die Produzent*innen, deren Praxen und Vorstellungen - in Bezug auf Produktion und Verarbeitung, Distribution und Konsum (kurz foodways) - die im Fokus dieses Kapitels stehen. Konkret geht es um Lebensmittelproduzent*innen, die Grundnahrungsmittel (Obst, Gemüse, Fleisch, Eier, Milch und Milchprodukte) für Menschen sich selbst und andere - produzieren.

Wie in der Einleitung zu diesem Band bereits angemerkt wurde, gibt es keinen politisch oder ideologisch homogenen ökologischen

4 Wichtige Hinweise zur Geschichte des ökologischen Landbaus in Österreich liefern die Recherchen von Aurelia Jurtschitsch 2010, 2009, 1998, sowie die Forschungsberichte der Bundesanstalt für Bergbauernfragen: Groier und Gleirscher 2005; Groier und Schermer 2005; Groier 2013. Zur Entwicklung des ökologischen Landbaus im deutschsprachigen Raum siehe: Vogt 2000, 2001a, 2001b; Willer und Schmid 2016; Staudenmaier 2013. Zur Reformbewegung in Österreich siehe z.B. Farkas 1998.

5 Vgl. Kosnik 2015, 2017, 2019. Weitere drei Höfe in Tirol (Österreich), einer in Thüringen (Deutschland). 
Landbau. Ökologischer Landbau war und ist mit unterschiedlichsten Weltanschauungen vereinbar, von Umweltschutz $\mathrm{zu}$ neoliberalem Marktrationalismus $\mathrm{zu}$ nationalistisch-völkischem Gedankengut. Trotz dieser Heterogenität von Akteur"innen, Motivationen und Praktiken lassen sich in der Geschichte des ökologischen Landbaus einige wesentliche Elemente erkennen, auf die im Folgenden genauer eingegangen wird. Dabei geht es nicht darum, vermeintliche Kontinuitäten aufzuzeigen. Vielmehr soll die Prozesshaftigkeit von Diskursen und Praktiken, insbesondere in Bezug auf das Konzept einer sorgsamen Landwirtschaft, betrachtet werden. María Puig de la Bellacasas Überlegungen $\mathrm{zu}$ soil care, human-soil relations und soil communities sollen hier insbesondere als theoretischer Rahmen fungieren. ${ }^{6}$ Als Forschungsfeld der "NaturenKulturen« (im Sinne einer Überwindung der Natur/Kultur-Dichotomie) werden dabei Beziehungen zwischen Menschen und anderen Lebewesen, beziehungsweise Ökosystemen (morethan-human) thematisiert und damit das bisherige Care-Verständnis feministischer Diskurse erweitert. ${ }^{7}$

Des Weiteren werden Jan Douwe van der Ploegs Begriffe des peasant farming und entrepreneurial farming ${ }^{8}$ als Denkfiguren herangezogen, um die differenzierten Entwicklungen im ökologischen Landbau zu analysieren (während die Kategorie capitalist/corporate farming - mobile AgroUnternehmen, die dort produzieren, wo Land und Arbeitskräfte am billigsten sind - hier weniger relevant erscheint). In Ploegs gewollt objektivierenden Kategorien steht peasant farming - unter anderem, aber insbesondere und im Gegensatz zu entrepreneurial farming - für Autonomiebestrebungen, etwa durch das Vermeiden von Schulden (Fremdkapital) und die Vermeidung von Verflechtungen mit vor- und nachgelagerten Industrien und damit den globalen Lebensmittelsystemen. »Thus, enlarging self-reliance and resilience are essential and this involves an enduring struggle for autonomy. «" Ploeg hebt dabei die Prozesshaftigkeit

\footnotetext{
6 Vgl. Puig de la Bellacasa 2014, 2015, 2019.

7 Vgl. Binder und Hess 2019.

8 Vgl. Ploeg 2010, 2014, 2018a, 2018b.

9 Ploeg 2018b, S. 30, Hervorhebung original.
} 
von peasantry hervor, als sich kontinuierlich (re-)konstituierend, transformierend, wachsend oder schwindend und sich dabei einer linearen Entwicklung hin zu entrepreneurial und capitalist farming verweigernd. ${ }^{10}$ Die Begriffe sind nicht streng voneinander trennbar, ihre Grenzen nach innen und außen verschwommen und auch in sich nicht als homogen $\mathrm{zu}$ verstehen. "Peasant farming contains a wide range of shades and nuances, which can range from pluriactivity to the situation of the landless and the many urban workers who cultivate plots for self-consumption ${ }^{11}{ }^{11}$ In diesem Kapitel sollen Ploegs Denkfiguren auf konkrete Fallbeispiele angewandt und erweitert werden.

Das Kapitel ist weitgehend chronologisch aufgebaut, beginnend mit den Anfängen institutionalisierter ökologischer Landwirtschaft in Österreich in der Nachkriegszeit - eine Zeitspanne, die sich mit den erinnerten Familienbiografien der Interviewten deckt. Im ersten Abschnitt wird die Rolle der Ernährungs- und Lebensreformbewegung für den ökologischen Landbau beleuchtet, die - insbesondere aus Eigensorge - zu einer ablehnenden Haltung ernährungsbewusster Konsument*innen und Produzent*innen gegenüber stickstoffhaltigem Mineraldünger und schwermetallhaltigen Pestiziden führte. ${ }^{12}$ CareDiskurse tauchen hier auch als »Versorgung des Bodens« auf, sowohl in der industrialisierten Landwirtschaft als auch im ökologischen Landbau. Diskurse der Ernährungsreform, so wird im zweiten Abschnitt deutlich, sind eng mit dem Vertrauensverlust in Produzent"innen verbunden. Konsument"innen forderten von der Landwirtschaft in ihrer Rolle als »Versorgerin der Gesellschaft« qualitätsvolle Nahrungsmittel und steigerten damit die Nachfrage nach anders produzierten Lebensmitteln. Der dritte Abschnitt beleuchtet die Entstehung einer "eco-entrepreneurial agriculture" (in Anlehnung an Ploegs Begriff) in den letzten drei Jahrzehnten, daher die Produktion ökologischer Waren für den Weltmarkt. Demgegenüber stehen aktuelle Konzepte von human-soil relations als sich gegenseitig versorgende Gemeinschaften

\footnotetext{
10 Vgl. Ploeg 2018b, S. 25, Ploeg 2018a.

11 Ploeg 2018b, S. 4.

12 Vgl. Vogt 2001b.
} 
von Mensch und Boden(-lebewesen), die abseits von Agrarromantik produktivistische Ideologien in Frage stellen.

\section{Die Rolle der Lebens- und Ernährungsreformbewegung für den ökologischen Landbau}

Nach dem zweiten Weltkrieg legte der sogenannte Marshall Plan ${ }^{13}$ die Richtung für die österreichische Wirtschaft fest. Die Landwirtschaft sollte modernisiert und für den westlichen Markt geöffnet werden. Staat und geldgebende Institutionen forcierten Wachstum und damit verbunden die chemisch-technische Intensivierung der landwirtschaftlichen Produktionsmethoden. Die "Produktionsgesinnung « ${ }^{14}$ wurde mithilfe staatlicher Berater*innen für landwirtschaftliche Betriebe, sowie von Landwirtschaftsschulen und -zeitschriften verbreitet - mit tatkräftiger Unterstützung der Kunstdüngerindustrie. ${ }^{15}$ Die Bodenwissenschaften der Zeit standen ebenfalls im Dienst dieser Entwicklung: Boden-Sorge wurde verstanden als Versorgung des Bodens mit $\mathrm{Zu}$ satzstoffen, um Pflanzenwachstum $\mathrm{zu}$ fördern und Schädlinge $\mathrm{zu}$ vernichten, wie Puig de la Bellacasa in ihrer Arbeit zu Bodenbeziehungen (human-soil relations) deutlich macht: "Soil care in a productionist frame is aimed at increasing soil's efficiency to produce for humans at the expense of all other relations «. ${ }^{16}$

Die Milchwirtschaft wurde in der zweiten Hälfte des 20. Jahrhunderts $\mathrm{zu}$ einem land- beziehungsweise marktwirtschaftlichen Schwerpunkt der Oststeiermark, sowie Massentierhaltung (insbesondere Schweine und Hühner) und Intensivobstbau. Ziegen, wie sie Familie Conrad heute hält, und Schafe gab es hingegen in der Region

13 US-amerikanisches Wiederaufbauprogramm für Europa (European Recovery Program, ERP).

$14 \quad$ Kaser und Stocker 1986, S. 197.

15 Vgl. Eberhart 1987; Jurtschitsch 2010; Kaser und Stocker 1987; Plakolm 2017.

16 Puig de la Bellacasa 2015, S. 700. 
nie in großer Zahl. ${ }^{17}$ Die Entwicklung der Landwirt*innen hin $\mathrm{zu}$ Rohstoffproduzent"innen, verflochten mit vor- und nachgelagerten Industrien (Ploegs entrepreneurial farming), lässt sich exemplarisch am Beispiel von Familie Bergmann nachzeichnen: Großvater Emil, selbst als staatlicher Landwirtschaftsberater tätig, stellte seinen Betrieb in der Nachkriegszeit früh auf Intensivobstbau um. In den 1970er Jahren folgte sein Sohn Richard neuen Empfehlungen zur stärkeren Spezialisierung und begann mit Geflügelwirtschaft. Küken und Futtermittel wurden aus dem Ausland bezogen, das Endprodukt (Bruteier) an fixe Abnehmer geliefert. Sein Sohn Martin bestätigt: »Es hat keinen fachlichen oder betrieblichen Grund gegeben, das zu ändern, nein, wir haben sicher nicht schlecht verdient in dieser Branche. Das war eine Nische und wenn du da gut warst, hast du gut damit verdient, keine Frage (Interview am 2.3.2018). Seit 2013 führt Martin Bergmann den Betrieb nun als ökologische Gemüse-CSA. Dabei wird die Familientradition, sich aktuellen Trends anzupassen, durchaus aufrechterhalten, wenn man die Entwicklungen und die fortschreitende gesellschaftliche Akzeptanz des ökologischen Landbaus in Österreich in Betracht zieht (siehe Kapitel Heistinger).

Allgemein führten die hohen Kosten für Investitionen seit der Nachkriegszeit zu einer breiten Verschuldungswelle unter den Landwirt*innen der Oststeiermark. Gleichzeitig blieben die positiven Effekte einer industrialisierten Landwirtschaft für die Region weit hinter den Erwartungen ihrer Befürworter*innen zurück. ${ }^{18}$ Die kleine Betriebsstruktur - typisch für das Flach- und Hügelland der Oststeiermark - erlaubte es den steirischen Landwirtschaftsbetrieben nie, im selben Ausmaß wie in anderen Regionen Europas in die Massenproduktion einzusteigen. ${ }^{19}$ Der Historiker Karl Stocker attestiert der Oststeiermark Mitte der 1980er Jahre eine »Anhäufung von wirtschaftlichen und sozialen Problemen, wie es sie kaum in einer anderen Region Österreichs in einer solchen Intensität gibt«. ${ }^{20}$

\footnotetext{
17 Vgl. Kaser und Stocker 1986; Posch 1978b.

18 Siehe dazu auch Ploeg 2010.

19 Vgl. Karner 2000.

20 Kaser und Stocker 1986, S. 267.
} 
Unterdessen gewann die Lebens- und Ernährungsreformbewegung in Österreich in den 1950er und 6oer Jahren verstärkt an Einfluss. Ernährungsreformerische Tendenzen gehen auf den im 19. Jahrhundert einsetzenden Ernährungswandel zurück, hin zu tierischen und verarbeiteten Nahrungsmitteln. »Das Nahrungsgefüge begann sich von einer wenig verarbeiteten, kohlenhydrat- und ballaststoffreichen hin $\mathrm{zu}$ einer fett- und eiweißreichen ballaststoffarmen Ernährung mit einem hohen Verarbeitungsgrad zu verschieben. ${ }^{21}$ Mitte des 19. Jahrhunderts begann sich die entstehende Lebensreformbewegung mit den möglichen negativen Folgen dieses Ernährungswandels auseinanderzusetzen. Über Vorträge, Vereine, Schriften und Schulungen - insbesondere durch den schwedischen Ernährungsreformer Are Waerland und das Schweizer Ehepaar Hans und Maria Müller - erreichten diese Ansätze die Steiermark. 1969 wurde der österreichische Demeter Bund (biologisch-dynamische Landwirtschaft basierend auf den anthroposophischen Grundsätzen Rudolf Steiners) gegründet. Darüber hinaus war es der seit 1963 jährlich erscheinende Mondkalender, den Maria Thun aus Hinweisen Steiners zur Aussaat entwickelt hatte, welcher weit über anthroposophische Kreise hinaus Verbreitung fand. So arbeitet auch Familie Bergmann in ihrer Gemüse-CSA nach dem Thunschen Aussaatkalender. ${ }^{22}$ Die Entwicklung ökologischer Anbausysteme lässt sich anhand der Geschichte ihrer Institutionen erkennen, allerdings sollte ihre Bedeutung nicht überbewertet werden. Es ist anzunehmen, dass Erfahrungen im ökologischen Landbau vielfach in undokumentierten Selbstversuchen gesammelt wurden, ohne engere Kontakte $\mathrm{zu}$ Institutionen und Netzwerken. ${ }^{23}$

Ernährungsbewusste, reformbewegte Verbraucher*innen betonten den in der Lebens- und Ernährungsreform wichtigen Zusammenhang von Produktionsmethoden, Nahrungsmittelqualität und Gesundheit. Ihre totale oder zumindest weitgehende Ablehnung von chemischen

21 Baumgartner 1998, S. 117.

22 Vgl. Vogt 2000, 2001b; Jurtschitsch 2010. Im Zuge meiner Forschungen ist mir diese Praxis vielfach begegnet; Kosnik 2019. 
Substanzen in der Nahrungsmittelerzeugung erhöhte die Nachfrage nach »naturbelassenen«, »ungespritzten« (daher ohne Chemie hergestellten) Lebensmitteln. ${ }^{24}$ Gleichzeitig spielten die vermehrt auf den Einsatz von Chemie zurückgeführten Krankheiten, Allergien und Spritzmittelvergiftungen in landwirtschaftlichen Familien, sowie die sich verschlechternde Futtermittelqualität und krankes Vieh, eine ausschlaggebende Rolle bei der Umstellung der Produktion auf ökologische Landbaumethoden. Ernährungsreform-orientierte Hausärzte, Tierärzte und Dorfpfarrer gaben oft die ersten Hinweise zu möglichen Alternativen. Insbesondere die Bäuerinnen fanden vielfach Interesse an einer Ernährungsumstellung, um die Gesundheit ihrer Familien zu fördern. Die Umstellung der Lebensmittelerzeugung erfolgte auf manchen Höfen als logische Konsequenz dieser Einstellungsänderung. ${ }^{25}$

Die Verbindung von Boden, Nahrung und Gesundheit hat sich als Themenkomplex im ökologischen Landbau erhalten. So formuliert der EU-Bericht zur ökologischen Landwirtschaft vom März 2019: ökologische Praktiken »address consumers demand for healthier food. The growing concern that excessive exposure to pesticides and overuse of antibiotics have a negative effect on health conditions is reorienting the society towards more natural alternatives. ${ }^{26}$

Dieselben Motive führen Interviewte in der vorliegenden Studie an, wobei Frauen zumindest teilweise nach wie vor die Rolle als Erhalterinnen der Gesundheit ihrer Familien übernehmen. Für Frau Adam etwa war Öko-Anbau von Anfang an eine Frage der gesunden Ernährung für sich und ihre Familie: "Ich esse gerne, ich koche gerne und das war die Ausgangsbasis für mich, mich selber gesund ernähren zu wollen« erklärt sie im Interview (20.8.2017). Frau Conrad bezeichnet die Nachfrage nach gesundheitsförderlicher magerer Milch als einen entscheidenden Faktor, Ziegenmilch entgegen den regionalen Normen zu produzieren. Außerdem geht sie gerne am Markt auf Fragen ihrer Kund"innen zu Gesund-

24 Vgl. Vogt 2000.

25 Vgl. Jurtschitsch 2010, 2009. Siehe die ähnliche Situation in Belgien: Vankeerberghen 2012.

26 European Commission 2019, S. 22. 
heit und Ernährung ein. Für die Familien Bergmann und Danninger hingegen waren es Krankheitsfälle in der Familie - Krebstod, chronische Erkrankungen und Vergiftungen durch Insektizide - welche einen wichtigen Einfluss auf die Entscheidung hatten, den Betrieb umzustellen. ${ }^{27}$

In Deutschland und Großbritannien entstand bereits um die letzte Jahrhundertwende eine Reformwarenwirtschaft, während Erfahrungen mit und Meinungen über ökologische Landbaumethoden durch zahlreiche Publikationen und Vorträge verbreitet wurden. ${ }^{28}$ In der Oststeiermark hingegen kam es, gleichzeitig mit anderen Regionen Österreichs, erst in den 1960er und 70er Jahren $\mathrm{zu}$ vermehrten Umstellungen auf alternative Landbaumethoden - zu einer Zeit, als Landwirt*innen bereits auf erprobtes Wissen und Erfolgsmodelle Anderer zugreifen konnten. Dabei dominierte in Österreich die sogenannte organisch-biologische Landbaumethode, wie die von Aurelia Jurtschitsch für Bio Austria durchgeführte Studie $\mathrm{zu}$ den »Bio Pionieren « Österreichs aufzeigt. ${ }^{29}$ Von der Ernährungsreformerin Maria Müller in Theorie und Praxis erarbeitet und von dem deutschen Arzt und Mikrobiologen Hans Peter Rusch wissenschaftlich fundiert, fand die Methode durch die Schulungs- und Vortragstätigkeiten Hans Müllers, sowie durch seine seit 1946 erscheinende Vierteljahresschrift Kultur und Politik weite Verbreitung. ${ }^{30}$

Ruschs Theorie der »lebendigen Substanz« propagierte ein alternatives Verständnis von Boden, das zwar weiterhin Bodenproduktivität zum Vorteil der Menschen in den Mittelpunkt stellte, dabei aber von einem komplexen Verständnis von Bodenbeziehungen ausging, welche

Eine wachsende Anzahl an Ethnografien beschäftigt sich mit den Zusammenhängen von Agrochemie und Gesundheitsschäden für Landwirt*innen, siehe Lock und Nguyen 2018.

28 In Deutschland z.B. Rudolf Steiners Landwirtschaftlicher Kurs (1924); in Großbritannien z.B. Sir Albert Howards The Influence of Soil Factors on Disease Resistance. Annals of Applied Biology, 1921, 7, S. 373-389.

29 Vgl. Jurtschitsch 2010; siehe auch Vogt 2000, 2001a, 2001b.

30 Vgl. Vogt 2000, 2001b; Wagner 2006; Lünzer 2002. 
durch Landwirtschaft nicht zerstört oder geschädigt werden sollen. Puig de la Bellacasa umschreibt dies mit dem Begriff der soil communities. ${ }^{31}$ Der Agrarsoziologe Gunter Vogt bezeichnet dieses »biologische Verständnis« von Bodenleben als einen Kernpunkt ökologischer Landbausysteme, ${ }^{32}$ das bis heute von großer Bedeutung ist, wie Wahlhütter u.a. in ihrer Studie zum Bodenverständnis von Landwirt"innen in Österreich feststellen. ${ }^{33}$ Puig de la Bellacasa unterstreicht die multi-species Dimension von soil life: »In this conception, soil is not just a habitat or medium for plants and organisms, nor is it just decomposed material, the organic and mineral end-product of organism activity. Organisms are soil. A lively soil can only exist with and through a multispecies community of biota that makes it«. 34

Die 1932 von Hans und Maria Müller in der Schweiz gegründete Landbau- und Volkshochschule wurde seit den 1960ern auch von zahlreichen österreichischen Landwirt*innen besucht, wobei Vogt den dort stattfindenden Wissensaustausch zwischen Praktiker*innen als wesentlich für die Weiterentwicklung des organisch-biologischen Landbaus betrachtet. ${ }^{35} 1960$ entstand in Österreich nach dem Vorbild von Hans Müllers Schweizerischer Bauern-Heimatbewegung die "Förderungsgemeinschaft für gesundes Bauerntum « als Interessensverband von Praktiker*innen und Theoretiker*innen. ${ }^{36}$ Laut Vogt fand in dieser Zeit ein grundlegender Wandel statt, von einer christlichkonservativen Ausrichtung hin zu einer ökologisch-sozialen: »Die bisherigen Grundsätze - Erhalt von Familie und Hof sowie Bewahrung von Heimat und Tradition - wurden durch Verantwortung für Natur und Verbraucherschaft ergänzt «. ${ }^{37}$

\footnotetext{
31 Vgl. Puig de la Bellacasa 2015, S. 704.

32 Vgl. Vogt 2001a.

33 Vgl. Wahlhütter u.a. 2016, S. 46.

34 Puig de la Bellacasa 2015, S. 701, Kursiv original.

35 Vgl. Jurtschitsch 2010, 1998; Vogt 2001b, 2000.

36 Vgl. Jurtschitsch 2010.

37 Vogt 2001b, S. 47-48.
} 


\section{Agrarkapitalismus und Landromantik - gegensätzliche Positionen im Agrardiskurs}

Seit den 1950er Jahren galt vielen Landwirt*innen der Oststeiermark Produktivismus als vielversprechendste Überlebensstrategie, wie Kaser und Stocker feststellen:

»Das wichtigste Gesetz dabei lautet, daß der Sinn der Produktion nicht mehr wie früher darin besteht, so viel am Hof zu produzieren, daß man davon leben kann, sondern möglichst billig zu produzieren, um die damit hergestellten Waren mit einem angemessenen Erfolg verkaufen zu können. Dabei muß egal sein, was man produziert, denn es geht in erster Linie darum, ein angemessenes Einkommen zu erwirtschaften. $\ll^{38}$

Demgegenüber stehen die in lebensreformerischen Ideen wurzelnden ökologischen Landbausysteme, denen eine moralische Ökonomie gemeinsam ist, welche Ideale wie Harmonie und Gemeinschaft einem individuellen Profitdenken vorziehen. So bezeichnet Hans Müller den gewinnorientierten Landwirt derogativ als »bäuerlichen Techniker «, ${ }^{39}$ im Gegensatz zum traditionell wirtschaftenden Bauern, den er als Dienenden beschreibt. In seiner Zeitschrift hält Müller fest: »Rechte Bauernarbeit ist immer dienen, ob sie der Dienstbote oder der freie Bauer tut. Dienst am Hofe - pflegen und hegen auf den Feldern oder in den Ställen ${ }^{40}{ }^{40}$ Laut Vogt leitet Müller Ideale wie Dienst und Verantwortung als bäuerliche Lebensmaximen aus seiner konservativ-christlichen Weltanschauung $a b$, »zum einen gegenüber der Familie als Lebensgemeinschaft und Tradition, zum anderen gegenüber der Natur als Heimat und Schöpfung ${ }^{41}$

38 Kaser und Stocker 1987, 228-229.

39 Kultur und Politik, Müller 1953, zitiert nach Vogt 2000, S. 197.

40 Kultur und Politik, Müller 1955, S. 27, zitiert nach Vogt 2000, S. 198.

41 Vogt 2000, S. 198. 
Agrarkapitalismus und Landromantik stehen sich als konträre politische Positionen im europäischen Agrardiskurs gegenüber, die weit in das 19. Jahrhundert zurückreichen. ${ }^{42}$ Ploeg stellt dazu fest:

»The problem with the historical debate is that it has frequently evolved into polarized and fixed positions that imbue the different sides of the equation with ontological properties. One camp has attributed peasant agriculture with an intrinsic superiority. The opposite position views peasant farming as intrinsically backwards. The dialectical relation between reality and potentiality (between > what-is<and > what-can-bes) has been neglected by both camps. ${ }^{43}$

Durch Bildungsarbeit der entsprechenden Institutionen (hier die Landwirtschaftskammer, dort lebensreformerische Volkshochschulen, beziehungsweise ihre Vereine und Zeitschriften) sollten die jeweiligen Standpunkte den Landwirt*innen näher gebracht werden. Tatsächlich existiert zwischen diesen Polen ein breites Spektrum an Diskursen und Praktiken realer Akteur*innen, die nicht auf Extreme verkürzt werden dürfen.

Während Staat und Wirtschaft nach der Grundmaxime agierten, dass nur eine industrialisierte Landwirtschaft die Bevölkerung ernähren könne, gingen die Anhänger*innen ökologischer Landbauweisen davon aus, dass der Anstieg an Quantität zwangsläufig mit dem Verlust von Qualität einhergehen müsse. In Anlehnung an E.P. Thompsons moral economy of provision ${ }^{44}$ ließe sich feststellen, dass für Befürworter*innen ökologischer Landbausysteme eine profitorientierte Landwirtschaft nicht länger ihre Aufgabe als Versorgerin der Bevölkerung mit nahrhaften Lebensmitteln erfüllen konnte.

Jurtschitsch zeigt auf, wie in den späten 1970er Jahren österreichische Printmedien und öffentliches Fernsehen vermehrt eine kritische Einstellung zur industrialisierten Landwirtschaft einnahmen. ${ }^{45}$ Es ent-

\footnotetext{
42 Vgl. Langthaler 2010.

43 Ploeg 2014, S. 1005.

44 Vgl. Thompson 1971.

45 Vgl. Jurtschitsch 2010.
} 
wickelte sich ein breiteres gesellschaftliches Bewusstsein für die Problematik von Rückständen chemisch-synthetischer Pestizide in Nahrungsmitteln. ${ }^{46}$ Mit Hilfe ökologischer Methoden sollte die Qualität der Erzeugnisse verbessert werden und die steigende Nachfrage den Produzent*innen gleichzeitig ein gutes Einkommen sichern. Während höhere Preise für Öko-Waren zu dieser Zeit noch kein Thema für die Produzent*innen waren, bedeutete der Verzicht auf zugekaufte Produktionsmittel eine deutliche Senkung der Produktionskosten. Nicht unbedeutend für die Verbreitung des Öko-Landbaus waren daher die Energiekrisen der 1970er Jahre, welche die Preise für chemisch erzeugten Stickstoffdünger steigen ließen und zahlreiche Landwirt*innen dazu veranlassten, eine weniger mechanisierte, Kunstdünger-freie Landwirtschaft in Betracht zu ziehen. ${ }^{47}$

Der gefühlte Vertrauensverlust - begründet darin, dass profitorientierte Unternehmen Quantität statt Qualität, beziehungsweise Profite auf Kosten von Gesundheit und Umwelt produzieren - setzt sich bis ins 21. Jahrhundert fort, wie Frau Adam im Interview beschreibt:

»Ich glaube, dass in den letzten Jahren einfach ein großer Vertrauensbruch stattgefunden hat, von Konsumentenseite, dass ich das Gefühl habe, es ist gerade voll viel Potential da für kleine Betriebe wie wir...es gibt schon einen starken Trend, finde ich, wo die Menschen qualitätsvoll sich ernähren wollen.« (Interview vom 20.8.2017)

Der bereits oben erwähnte EU-Bericht stellt ebenfalls fest: »The pursuance of quality food is a further driver. Organic food is sometimes associated with tastier and more nutrient-dense food, in line with the >flavour-over-appearance belief « ${ }^{48}$ Peasant farmers, ob ökologisch zertifiziert oder nicht, genießen in Österreich einen deutlichen Vertrauensvorschuss von Seiten der Konsument*innen, der von diesen Produzent"innen auch ökonomisch genutzt wird. So hat Frau Conrad die Erfahrung gemacht, dass nach Medienberichten über chemische Rück-

46 Vgl. Vogt 2000.

47 Vgl. Vogt 2000; Jurtschitsch 2010.

48 European Commission 2019, S. 8, eigene Hervorhebung. 
stände in Nahrungsmitteln die Nachfrage nach ökologischen Waren spürbar steigt, was auch der EU-Bericht bestätigt. ${ }^{49}$

\section{Öko-Entrepreneure und human-soil-relations}

Die Wachstums- und Intensivierungsbestrebungen im Landwirtschaftssektor führten seit den 1970ern $\mathrm{zu}$ einem Überschuss an landwirtschaftlichen Erzeugnissen. Ökologische Methoden hingegen gehen häufig einher mit einer vergleichsweise deutlich geringeren Produktion. ${ }^{50}$ Als eine Möglichkeit, das Überangebot zu reduzieren, wurde daher der ökologische Landbau als agrarpolitische Alternative nun erstmals auch von staatlicher Seite politisch und finanziell gefördert. 1983 erhielt das Österreichische Lebensmittelgesetz den Zusatz "Landwirtschaftliche Produkte aus biologischem Landbau und daraus hergestellte Folgeprodukte« als erstes Regelwerk für ökologische Produktionsmethoden. ${ }^{51}$ Die Erhaltung einer vielfältigen Landschaft war als Nebenprodukt der ökologischen Bewirtschaftung besonders für die wachsende Tourismusbranche der Steiermark von Bedeutung.

Seit Ende der 1970er Jahre zählten umweltbewusste Konsument* innen zur wachsenden Zahl der Abnehmer*innen von Öko-Produkten. Erstmals überstieg die Nachfrage das Angebot. Verkauft wurden ökologisch produzierte Waren größtenteils ab Hof, ohne besondere Kennzeichnung. Audrey Vankeerberghen stellt für Belgien fest, was auch für die Situation in Österreich galt: »At that time, there were two ways for buyers to identify organic goods: personal relationships of trust between producers and consumers, or private organic standards. ${ }^{52}$ Anfang der 1980er entstanden in Österreich

49 Vgl. European Commission 2019, S. 22.

50 Vgl. European Commission 2019, S. 6. Siehe dazu auch Einleitung zu diesem Band.

51 Vgl. Jurtschitsch 2010; BMCF 2017. Ab dem EWR-Beitritt Österreichs 1994 traten die EU-Richtlinien für ökologischen Landbau in Kraft und lösten damit frühere Regelungen $a b$.

52 Vankeerberghen 2012, S. 104. 
erste ökologische Verbraucher-Erzeuger Initiativen und Bio-Läden. »Der inhaltliche Schwerpunkt« schreibt Vogt über die Tendenzen im ökologischen Landbau »verschob sich vom Erhalt einer bäuerlichen Lebenswelt zur Entwicklung einer umweltschonenden, dauerfähigen Landbau- und Lebensweise «. ${ }^{53}$

1979 spaltete sich von der »Förderungsgemeinschaft für gesundes Bauerntum« der als reiner Anbauverband geplante »Bundesverband organisch-biologisch wirtschaftender Bauern Österreich« ab (später »Ernte für das Leben«). Dessen Mitglieder waren deutlicher an neuen Absatzmöglichkeiten, Vermarktungsstrategien und besseren Preisen interessiert. Die Mitgliedschaft war auch Voraussetzung für die Verwendung eines eigenen Siegels als Auszeichnung für eine ökologische Produktion. Der Verein wurde rasch zum mitgliederstärksten Verband Österreichs. Die Zentralisierungs- und Institutionalisierungsbestrebungen (und damit einhergehend die Etablierung von einheitlichen Produktionsstandards) kulminierten in der Gründung des zentralen Dachverbandes Bio Austria. ${ }^{54}$ Vankeerberghen erkennt dahinter eine EU-weite Entwicklung: »Originally a matter of diverse specification, often informal and based on trust, it became a matter of concern for the different organisations and associations within the organic movement, and then became a matter of legislation, enforced by commercial inspection companies authorised by individual European countries «. ${ }^{55}$

Mit dem EU Beitritt Österreichs 1995 sanken die Preise für landwirtschaftliche Produkte im erweiterten Markt. Mit Spezialprodukten wie Kernöl, Wein und Öko-Waren sollten den Produzent*innen einträgliche Nischen eröffnet werden. ${ }^{56}$ Gleichzeitig wurden LebensmittelHandelsketten als Abnehmer für Öko-Waren gewonnen. Für viele Produzent*innen tat sich damit ein lukrativer Markt auf, jedoch mussten Öko-Waren nun auch »regalfähig« werden. Kritiker*innen bemängelten, dass nun auch im Öko-Bereich die Lebensmittelqualität

\footnotetext{
53 Vogt 2001b, S. 49.

54 Vgl. Schermer 2005.

55 Vankeerberghen 2012, S. 105.

56 Vgl. Karner 2000; Sassatelli und Scott 2001; Schermer 2015.
} 
zugunsten von Quantität und Aussehen an Bedeutung verlor. Der Öko-Landbau hatte die Blase der Direktvermarktung und ErzeugerVerbraucher Verbände verlassen, „Wachsen oder Weichen« galt nun auch für den ökologischen Landbau, womit gleichzeitig die Konventionalisierungsdebatte einsetzte. ${ }^{57}$ Ploeg hält dazu fest:

»Started as an alternative praxis developed from a variety of sources that all differed from, and strongly criticized conventional farming, the techniques and logos have now been taken over by large-scale entrepreneurial and corporate farms (that consider organic agriculture to be an interesting economic opportunity, no more and no less). It has, in short, largely been conventionalized. ${ }^{58}$

Herr Danninger, der seit den 1990ern ökologische Tafeläpfel an den Lebensmittelhandel liefert (und der in Ploegs Begrifflichkeiten als entrepreneurial farmer gelten kann), kommentiert diese Entwicklung im Interview. Dabei bemerkt er, dass die neuen Konsumansprüche längst nicht mehr nur im Supermarkt von Bedeutung sind:

»Also damals [vor der Konventionalisierung, Anm. EK] haben wir unsere Äpfel auch verkauft, weil die Leute Bio-Äpfel haben wollten, die nach was schmecken. Und jetzt ist es nicht einmal im Bio-Laden mehr wirklich leicht, Äpfel mit Flecken zu verkaufen.« (Interview am 9.8.2018)

Staatliche Förderungen und neue Absatzmöglichkeiten motivierten viele Landwirt*innen seit Anfang der 1990er zum Umstieg auf ökologischen Landbau. Dominierte bis dahin peasant farming unter den ÖkoBetrieben, begann nun die Zeit des entrepreneurial farming auch im ökologischen Landbau - als den Bedürfnissen des Weltmarktes angepasste Rohstofflieferanten. Ploeg hält fest: „Entrepreneurial farmers are highly market-dependent (both for inputs and outputs), which is in stark contrast to peasants who generally try to distantiate their farming practices from markets through a multitude of often ingenious mechanisms «. ${ }^{59}$

57 Vgl. Groier 2013; Guthman 2004, 2014; Vankeerberghen 2012.

58 Ploeg 2018b, S. 264.

59 Ploeg 2018b, S. 2. 
Für viele der neuen Öko-Entrepreneure war die Erfahrung jedoch keineswegs nur positiv. Schon Ende der 1990er stellte eine Vielzahl von ihnen die ökologische Produktion wieder ein, aus unterschiedlichen Gründen: hohe Investitionskosten, der hohe und gleichzeitig wenig lohnende bürokratische Aufwand für Biokontrollen und Förderungen, Ertragseinbußen aufgrund der Umstellung und der erhöhte Arbeitsaufwand. $^{60}$

Die Entwicklung hin $\mathrm{zu}$ einer eco-entrepreneurial agriculture, in Anlehnung an Ploegs Begriff, blieb dabei immer partiell. Bis heute ziehen es zahlreiche Produzent*innen vor, peasant farmers zu bleiben, beziehungsweise zu werden - ein Phänomen, dass sich weder auf bestimmte globale Regionen noch auf den ökologischen Landbau beschränkt. ${ }^{61}$ Die Fallbeispiele unserer Studie zeigen dabei auf, dass es gerade auch die affektiven Beziehungen zu Bodenlebewesen, Tieren und Menschen sind, die mit einer produktivistischen Denkweise unvereinbar bleiben. Herr Adam, der bewusst viel händisch arbeitet und auf Vielfalt und samenfeste Sorten auf seinem Gemüsehof wert legt, stellt selbstkritisch fest:

»Das ist nicht wirtschaftlich. Und das ist mir schon bewusst in Wirklichkeit, aber die Wirtschaft ist für mich nicht der Punkt. Mein Punkt ist, meinen Boden zu verbessern und eine gute Ernährung zu kreieren. Und eine gute Ernährung ist für mich ein bisschen gleichwertig mit Medizin. « (Interview am 20.08.2017)

Das Zitat spiegelt Ansätze der Ernährungsreform wieder, die Lebensmittel als Heilmittel betrachtete. ${ }^{62}$ Am Hof von Familie Adam werden Boden und Pflanzen nicht gezwungen, an dem Ort oder zu dem Zeitpunkt zu wachsen, an dem es für die Betriebsleitung (oder den Weltmarkt) am profitabelsten ist. Frau Adam ergänzt: »Was uns wichtig ist, so wenig Bodenbewegung wie möglich machen, oder? Dem Boden die Möglichkeit

60 Vgl. Freyer u.a. 2001; Groier 2005.

61 Vgl. Ploeg 2018b.

62 Vgl. Baumgartner 1998. 
zu lassen, sich zu entwickeln und sich so anzulegen, wie es für ihn gesund ist und gut ist (Interview am 20.08.2017).

Im Sinne von Puig de la Bellacasas human-soil communities ist hier der Mensch nicht mehr nur Abnehmer und Nutznießer der Leistungen von Boden und Bodenlebewesen, sondern Teil einer Gemeinschaft. »In other words, within these conceptions, to properly care for the soil humans cannot be only producers or consumers in the community of soil making organisms but must work, and be, in relation to soil as a significant living world «. ${ }^{63}$ Der Boden, beziehungsweise die Bodenlebewesen sind eigenständige Akteure die beobachtet werden, um mit ihnen zusammen $\mathrm{zu}$ arbeiten und $\mathrm{zu}$ leben, um sich gegenseitig $\mathrm{zu}$ versorgen. Ploegs Begriff von co-production deutet in dieselbe Richtung:

»From the point of view of co-production, the resource base of the farm can be conceptualized as composed by living nature and the capacity to deal with it. Living nature is embodied in the land (and the soil biology it contains), in crops, water, animals, and the local ecosystem. Together with this comes the capacity of farmers to understand, deal with, develop and convert living nature into food. ${ }^{64}$

Co-production ist für Ploeg ein Charakteristikum des peasant farming:»By contrast, entrepreneurial and corporate agriculture tend to minimize the role of living nature because, within these structurally different contexts, it represents a nuisance and a limit. « ${ }^{65}$

Für die Viehwirtin Frau Conrad steht in ihren Erzählungen weniger die Beziehung zu Bodenlebewesen und Pflanzen im Vordergrund, sondern ihre Beziehung zu den Tieren:

»Man schreibt ja schon vor, die Tiere sind zu alt, sie gehören weg. Ich finde, wenn ich der Meinung bin, mein Ziegenbock ist mit acht Jahren nicht zu alt, ist es meine Entscheidung, ich möchte das nicht vorgeschrieben bekommen. Ich möchte eine Wertschätzung für das Tier, das mir ein Leben lang gedient

63 Puig de la Bellacasa 2015, S. 706, Hervorhebung original.

64 Ploeg 2018b, S. 20, Hervorhebung original.

65 Ploeg 2018b, S. 20, Hervorhebung original; siehe auch Ploeg 2010. 
hat, das finde ich auch wichtig, es muss nicht immer alles nur auf Gewinn aufgebaut sein.« (Interview am 05.07.2018)

Frau Conrads Sorge um das Wohl ihrer Tiere führte zu der paradoxen Situation, dass sie von den zuständigen Behörden eine Anzeige wegen falscher Tierhaltung erhielt, als sie sich weigerte, ein Kälbchen nach der Geburt sofort von seiner Mutter zu trennen. Puig de la Bellacasas Feststellung zu human-soil-relations als care-Arbeit scheint hier, erweitert auf more-than-human-relations, besonders zutreffend:

"Valuing care by refficiency< standards transforms its practice into a managed >conduct < to be monitored (Latimer, 2000). That is why, in contexts of managerial control that underestimates care's value and even penalize its practice, acts of care can be considered as a kind of resistance. " $" 66$

Gleichzeitig, und weitab von jeder Agrarromantik, sind sich die Landwirt*innen in unserer Studie immer bewusst, dass ihr Hof ein Einkommen erwirtschaften muss. In ihren Praktiken der Produktion, Verarbeitung und Vermarktung suchen sie allerdings nach Möglichkeiten, dies ohne Ausbeutung von Bodenlebewesen, Tieren oder Menschen, einschließlich ihrer eigenen Arbeitskraft, $\mathrm{zu}$ erreichen (siehe Kapitel Heistinger).

Seit den Anfängen ökologischer Landbaumethoden wird von Praktiker*innen der Wunsch nach Wertschätzung für diese Form der zeitund arbeitsintensiven Produktion geäußert, sowie eine faire Entlohnung für landwirtschaftliche care-Arbeit gefordert. ${ }^{67}$ Von staatlicher Seite wird diese care-Arbeit einer sorgsamen Landwirtschaft in Förderungen wie Flächenprämien für umweltschonend(er)e landwirtschaftliche Praktiken umgerechnet, als bürokratisch geregelte, standardisierte und überprüfbare Formen der Entlohnung - „valuing care by refficiency< standards«. Gabriele Sorgo stellt in ihrem Kapitel dar, wie unentlohnte, reproduktive (oft als unproduktiv deklarierte) care-Arbeit in einer marktorientierten Gesellschaft strukturell entwertet wird. Gleich-

66 Puig de la Bellacasa 2015, S. 708.

67 Vgl. Jurtschitsch 2010; Vogt 2000. 
zeitig baut die Gesellschaft weiterhin darauf auf, dass care-Arbeiten als kostenfreie »Liebesdienste« dauerhaft zur Verfügung stehen. ${ }^{68}$ Im Sinne einer human-soil-community drückt sich dieser Gedanke nicht nur in entwerteter Arbeit des Menschen, sondern auch des Bodens und anderer Lebewesen aus. So kommentiert Frau Adam: "Wir sind ganz gut im Kalkulieren. Aber dann gibt es trotzdem so Spitzenzeiten und dann haben sich die Pflanzen bemüht, wir haben uns bemüht und dann nimmt es uns keiner ab« (Interview am 20.08.2017).). Der Einsatz der Hofgemeinschaft, die über die menschliche Arbeitskraft hinausgeht, bleibt unentlohnt.

\section{Schlussbemerkung}

Die Aufgabe dieses Kapitels war es, die historischen Entwicklungen im ökologischen Landbau für die Forschungsregion Oststeiermark nachzuzeichnen, um die Fallbeispiele der vorliegenden Studie zu kontextualisieren. Dabei zeigt sich, dass die ökologische Landwirtschaft ein heterogenes Feld an Akteur*innen, Motivationen und Praktiken ist, das sich nicht schlicht auf die Position einer (agrarromantischen) Kritik an der industriellen, chemisch-technischen Landwirtschaft reduzieren lässt. Im Besonderen wurden Care Diskurse und Praktiken thematisiert, wie sie in unterschiedlichen Bezügen in der Geschichte des ökologischen Landbaus sichtbar werden. Die Erweiterung feministischer Care Diskurse durch Puig de la Bellacasas Konzepte von soil care erweist sich als besonders hilfreich, um Praxen und Vorstellungen eines Zusammenlebens von menschlichen und anderen Akteur*innen, soil-communities, als Versorgungsgemeinschaft $\mathrm{zu}$ betrachten. Divergierende Bedürfnisse werden wahrgenommen und dennoch, oder gerade dadurch, Grundnahrungsmittel abseits von Ausbeutungsverhältnissen (von der Ausbeutung des Bodens bis zur Selbstausbeutung) produziert.

68 Ausgehend von feministischen Diskursen seit den 1970ern wird faire Entlohnung für Versorgungsarbeit seit der Jahrtausendwende wieder verstärkt in den Sozial- und Kulturwissenschaften thematisiert; siehe etwa Binder u.a. 2019. 


\section{Wie aus Familiengeschichten sorgsame Landwirtschaft entsteht}

Andrea Heistinger

Wie in der Einleitung ausführlich beschrieben, ist der Handlungsdruck innerhalb der Agrar- und Ernährungswirtschaft geradezu unvorstellbar groß. Die vorindustrielle bäuerliche Landwirtschaft gibt es nicht mehr, ${ }^{1}$ die industrielle konventionelle Landwirtschaft hat sich als nicht zukunftsfähig erwiesen und selbst der biologische Landbau hat in den letzten 20 Jahren unter einem enormen sozialen und ökonomischen Konventionalisierungsdruck viel seiner Innovationskraft und Bedeutung als existenzsichernde Alternative für kleinere und mittlere landwirtschaftliche Betriebe verloren. Dazu auch eine aktuelle Zahl: Die ökologisch wirtschaftenden Testbetriebe Deutschlands haben im Wirtschaftsjahr 2018/2019 im Durchschnitt ein Einkommen von ca. $€ 38.000$ pro Arbeitskraft erzielt. Das sind zwar um $€ 10.000$ mehr als der Durchschnitt der konventionellen Betriebe, aber um $6 \%$ weniger als im Vergleich zum Vorjahr. ${ }^{2}$

Die globale Land- und Ernährungswirtschaft bedarf einer grundlegenden Transformation. Dabei geht es nicht um eine große Transformation, sondern um viele lokale und überregionale Transformationsprozesse, die ineinander greifen und sich gegenseitig verstärken können: Transformationsprozesse sowohl von politischer Seite, ${ }^{3}$ wie

1 Vgl. Hiß u.a. 2018.

2 Thünen Institut 2020.

3 Siehe dazu das im Mai 2020 veröffentlichte Strategiepapier der EU-Kommission »From Farm to Fork«. Es skizziert den notwendigen Wandel zu einem 
auch der Ernährungsgewohnheiten, der agrarischen Ausbildungen, direkt auf den Betrieben sowie neue Formen von Beziehungen, die Menschen zueinander und $\mathrm{zu}$ anderen Lebewesen unseres Planeten haben.

Die sozialwissenschaftliche Transformationsforschung definiert Transformation als eine besondere Form von Wandel. Denn »Neues und mithin Unvertrautes wird in Gesellschaften ständig verhandelt, ausgehandelt und schließlich in Vertrautes übergeführt. ${ }^{4}$ Der Unterschied zwischen Wandel und Transformation liege darin, dass »Umwälzungsprozesse am Wirken sind. (...) Wo Umwälzungen im Gange sind, wird Vertrautes brüchig, werden Routinen des Alltags in Frage gestellt und erhebliche Bestände des alltäglichen Orientierungswissens fragwürdig. ${ }^{5}$ Dies betrifft sowohl akademische und in Schulsystemen vermittelte Wissensbestände - zum Beispiel, wie man einen Betrieb ökonomisch erfolgreich führt - wie auch bislang bewährte Praxis-Erfahrungen, wie Kulturpflanzen angebaut oder wie bestimmte Betriebszweige gehandhabt werden. Und ebenso Fragen des sozialen Zusammenlebens. Letzteres wird am deutlichsten in der Öffentlichkeit wahrgenommen durch den Umstand, dass es für

»nachhaltigen Lebensmittelsystem «und benennt konkrete Ziele, um dies zu erreichen. So soll die Abhängigkeit von Pestiziden und antimikrobiellen Mitteln verringert, der übermäßige Einsatz von Düngemitteln reduziert, der Ökologische Landbau ausgedehnt, der Tierschutz verbessert und der Verlust an biologischer Vielfalt rückgängig gemacht werden. Auslöser für die klaren Worte und Ziele des Papers war vermutlich auch die COVID-19 Pandemie: „Die COVID_19Pandemie hat ein Schlaglicht auf die Bedeutung eines belastbaren und resilienten Lebensmittelsystems geworfen, das unter jeglichen Umständen weiter funktioniert und in der Lage ist, die Bürgerinnen und Bürger in ausreichendem Maße mit erschwinglichen Lebensmitteln zu versorgen. Sie hat uns auch die Wechselwirkungen zwischen unserer Cesundheit, unseren Ökosystemen, Versorgungsketten, Verbrauchsmustern und den Belastungsgrenzen unseres Planeten sehr bewusst gemacht. Es liegt auf der Hand, dass wir viel mehr tun müssen, um uns und den Planeten gesund zu hallten. «European Commission 2020, S. 2.

$4 \quad$ Hildenbrand 2015, S. 232.

$5 \quad$ Hildenbrand 2015, S. 231. 
junge männliche Hoferben zunehmend schwieriger geworden ist, eine Partner*in $\mathrm{zu}$ finden. Die geschlossenen Heiratskreise, die bis vor 20 oder 30 Jahren hier Orientierung und Sozialisation boten, haben sich vielerorts fast vollständig aufgelöst.

Die sinnverstehende Sozialforschung geht davon aus, dass jeder Wandel durch soziale Interaktionen hervorgebracht und es die - handelnden - Menschen sind, die diesen Wandel mit Bedeutung versehen. Gegenstand der sinnverstehenden Sozialforschung ist daher jener

»Prozess, innerhalb dessen das Verhältnis von Vertrautem und Fremdem in der sozialen Wirklichkeit für die Akteure in weiten Bereichen fragwürdig geworden ist, gleichzeitig aber ein Handlungsdruck besteht, Vertrautheit und Routine wiederherzustellen und ihr einen Sinn zu verleihen. ${ }^{6}$

Viele Menschen, die in der Landwirtschaft tätig waren, haben in den letzten Jahren und Jahrzehnten die Entscheidung getroffen, ihre Betriebe zu schließen und einer Erwerbsarbeit außerhalb der Landwirtschaft nachzugehen. Vor allem für junge Menschen war die soziale Wirklichkeit des Berufs Bauer/Bäuerin ${ }^{7}$ fragwürdig geworden und der ökonomische Druck zu groß, um den Beruf und das Familienunternehmen ihrer Eltern zu übernehmen. Sie schlossen die Höfe, die oft seit vielen Generationen als landwirtschaftliche Betriebe bewirtschaftet worden waren. Meist wird dies als "Betriebsaufgabe« bezeichnet. Dieser Begriff ist negativ konnotiert, im "Aufgeben « schwingt auch ein individuelles Versagen oder ein persönliches »Es ist mir nicht gelungen« mit. Mit der Schließung der Betriebe geht auch ein Wandel des beruflichen Habitus, der sozialen Praktiken innerhalb der Familie, die häufig dann keine Unternehmerfamilie/kein Familienunternehmen mehr ist,

6 Hildenbrand 2015, S. 232.

7 Dasselbe trifft für viele andere Berufe zu: Auch viele Wirte und Wirtinnen und Unternehmen in der Lebensmittelverarbeitung - Bäckereien, Fleischereien sowie Händler*innen im Lebensmittelbereich haben in den letzten Jahrzehnten ihre Betriebe geschlossen. Die Anzahl der Familienunternehmen ist auch in diesen Branchen gesunken. 
einher. Die Handlungsmuster, die die Familie prägen, ändern sich. ${ }^{8}$ Im Einzelnen mag dies ein Prozess des Wandels (im oben beschriebenen Sinn) sein. Gesamtgesellschaftlich ist dies ein großer Transformationsprozess: Jene regionalen Wirtschaftssysteme, die notwendig sind, um die lokalen Ressourcen (Boden, Wasser, Sonne, Luft) in Lebensmittel für jene Menschen zu transformieren, die in der Region leben, funktionierten nur mehr zu einem kleinen Anteil.

\section{Ausstieg aus der Landwirtschaft}

Die große gesellschaftliche Entwicklung ist die des Ausstiegs aus der Landwirtschaft. Zu diesem Ergebnis kommt man recht nüchtern, wenn man sich die Zahlen der landwirtschaftlichen Betriebe und ihre Abnahme über die letzten Jahrzehnte vor Augen führt. ${ }^{9}$ Das Phänomen wird als Strukturwandel in der Landwirtschaft bezeichnet oder als Prozess beschrieben: Wachsen oder Weichen. Dieses Wortbild bezieht sich auf die Zunahme der Hektar-Anzahl, die ein Betrieb bewirtschaftet (oder die Zunahme der Anzahl der auf dem Betrieb gehaltenen Tiere), bei einer gleichzeitigen Aufgabe anderer Betriebe. Doch trotz des Strukturwandels und trotz massiver Förderungen von Seiten der EU im Rahmen der Gemeinsamen Agrarpolitik (GAP) hat sich die Einkommenssituation in der Landwirtschaft in den letzten Jahren verschlechtert: Die Nettowertschöpfung in der österreichischen Landwirtschaft hat zwischen den Jahren 2000 bis 2015 um mehr als ein Viertel abgenommen. ${ }^{10} \mathrm{EU}$ -

Siehe dazu das Thema Handeln und Familienmuster im Kapitel »Sinn verstehen durch rekonstruktive Genogrammarbeit«.

9 In der EU schlossen zwischen den Jahren 2000 bis 2013 ein Viertel aller Landwirtschaftlichen Betriebe. Vgl. Agrar-Atlas, siehe www.boell.de (Zugriff am 22. Juni 2020). Im Jahr 1999 gab es in Österreich 217.508 Land- und Forstwirtschaftliche Betriebe im Jahr 2010 173.317, im Jahr 2013 166.317. Vgl. Landwirtschaftskammer Österreich 2016, S. 11.

10 Dies hat in erster Linie damit zu tun, dass die Ausgaben für Betriebsmittel und Dienstleistungen deutlich zugenommen haben, sowie die Ausgaben für Pachtzahlungen und Löhne, siehe Landwirtschaftskammer Österreich 2016, S. 8. 
weit betrachtet verdient ein Landwirt/eine Landwirtin durchschnittlich derzeit nur etwa halb so viel wie ein Arbeitnehmer/eine Arbeitnehmerin. ${ }^{11}$ Auch diese Einkommenssituation hat dazu geführt, dass viele Söhne und Töchter landwirtschaftlicher Familien es bevorzugen, Betriebe nicht zu übernehmen und einen Beruf außerhalb der Landwirtschaft zu erlernen und diesen als Vollzeitberuf auszuüben. Mit dieser Entwicklung einher geht in vielen Regionen ein Rückgang der Bevölkerung in ländlichen Regionen. Die regionale Bevölkerungsprognose 2030/2050 der Österreichischen Raumordnungskonferenz (ÖROK) zeigt, dass der demografische Wandel und der Bevölkerungsrückgang in vielen österreichischen Regionen ein zentrales Thema sein wird. War bereits in den letzten 50 Jahren die Geburtenbilanz in vielen ländlichen Regionen negativ, hat sich die Landflucht seit den 2000 er-Jahren nochmals verstärkt: $30 \%$ aller politischen Bezirke in Österreich und mehr als $40 \%$ aller Gemeinden sind mit einem Bevölkerungsrückgang konfrontiert. ${ }^{12}$ Für unsere Forschungsregionen - die Oststeiermark und das Waldviertel - lässt sich sagen, dass in der Oststeiermark seit den 1990er Jahren ein Bevölkerungsrückgang zu verzeichnen ist, während im Waldviertel dieser Prozess bereits in den 1960er Jahren begann. ${ }^{13}$ In erster Linie sind es jungen Frauen, die vom Land in die Stadt gehen und nicht mehr - zum Beispiel in der Lebensphase der Familiengründung zurückkehren. ${ }^{14}$ Dabei hat der »Exodus« der jungen Frauen vom Land nicht nur wirtschaftliche, sondern auch »lebensweltliche Gründe«, wie die Agrarsoziologin Theresia Oedl-Wieser beschreibt. ${ }^{15}$ Insbesondere weist sie auf ein Festhalten an starren traditionellen Geschlechterrollen hin, die die Entwicklungsperspektiven für Frauen am Land stark einschränken. Die Raumplanerinnen Gerhild Weber und Tatjana Fischer weisen darauf hin, dass mit der selektiven Abwanderung von Frauen eine negative Entwicklungsspirale für ländliche Regionen in Gang gesetzt

\footnotetext{
11 European Commission 2020, S. 2.

12 Dax u.a. 2016, S. 5.

13 Dax u.a. 2016, S. 22.

14 Oedl-Wieser 2017.

15 Oedl-Wieser 2017, S. 5.
} 
wird, die nicht nur einen Verlust an Know-How, an Tatkraft und Reproduktionsfähigkeit mit sich bringt, sondern letztlich auch dazu führt, dass die Bevölkerung überaltert, die Finanzkraft der öffentlichen Hand sinkt, lokale Infrastruktur abgebaut wird, Dörfer und ländliche Regionen ihr Attraktivität verlieren, das Gemeinschaftsleben stirbt, sich in diesen Regionen eine »No Future-Stimmung « breit macht und all dies die Dynamik einer weiteren Abwanderung stärkt. ${ }^{16}$

\section{Einstieg in die Landwirtschaft}

All diesen Faktoren zum Trotz wollen immer mehr junge Menschen sowie Menschen, die bereits einen beruflichen Werdegang in einer anderen Branche eingeschlagen hatten, in die Landwirtschaft einsteigen. ${ }^{17}$ Vor dem Hintergrund all dieser Entwicklungen ist insbesondere die Frage interessant, wer die Menschen sind, die landwirtschaftliche Betriebe neu gründen. Ausgehend von der These, dass es auch in den untersuchten Regionen Menschen gibt, die neu in die Landwirtschaft einsteigen und dass dieser Einstieg Merkmal eines gesellschaftlichen Transformationsprozesses ist, stellt unsere Forschung die Frage: Wer sind die Menschen, die diese Transformationsprozesse vorantreiben? Wie gelingt es ihnen Wirtschaftsformen zu finden, die für sie die biologische Landwirtschaft unter dem Druck des agrarindustriell organisierten Marktes wirtschaftlich erfolgreich macht? Welche Ressourcen bringen sie dafür aus ihren Familien-Systemen mit? Welche Familienmuster sind dafür hilfreich?

Insbesondere fragt die vorliegende Studie nach resilienten Formen und Handlungsmustern einer ökologischen Landwirtschaft, die Grund-

16 Weber \& Fischer 2012, S. 2.

17 Siehe dazu auch die Einleitung. Genaue Zahlen dazu sind schwierig zu erheben, ein Indikator für Österreich ist die Zahl der Hofsuchenden, die bei der Vermittlungsplattform »Perspektive Landwirtschaft« anfragen: Waren es im Jahr 2018 noch 82, hatten im Jahr 2019187 Einzelpersonen, Paare oder Familien ein Inserat für eine Hofsuche geschaltet. (Persönliche Information am 1.7.2020 der Geschäftsführung, https://www.perspektive-landwirtschaft.at). 
nahrungsmittel für Menschen produziert, während sie gleichzeitig den Lebensmittelproduzent*innen materiell, sozial und umweltethisch zufriedenstellende Lebensbedingungen ermöglicht. An welches überlieferte Wissen knüpfen die »neuen Bäuerinnen und Bauern« an und welches Wissen bringen sie mit? Schließlich: Wie generieren sie das (neue) Wissen, das sie für die Bewirtschaftung ihrer Höfe benötigen und wie entwickeln sie neue Techniken und Organisationsformen?

Die Vermarktungsmöglichkeiten für bäuerliche Produkte waren im Laufe des 20. Jahrhunderts ${ }^{18}$ bis in die Gegenwart ebenso veränderlich wie die zur Verfügung stehenden Technologien und die Ansprüche der Konsument*innen. Unsere zentrale These lautet daher: Neueinsteiger*innen und Quereinsteiger*innen entwickeln Produktionsweisen und erschließen Vermarktungswege, die es bislang so noch nicht gab. $^{19}$

Für die Auswahl der Fallbeispiele für unser Forschungsprojekt haben wir folgende Kriterien festgelegt: Haupterwerbsbetriebe, die zertifiziert-ökologische Grundnahrungsmittel erzeugen. ${ }^{20}$ Im Sinne einer »maximalen Kontrastierung« zur Gesamtbewegung in der Landwirtschaft - nämlich der Schließung von Betrieben - suchten wir als ersten Betrieb einen neu gegründeten Betrieb aus. ${ }^{21}$

\section{Eduard und Raphaela (Fall Adam): Von der Magerwiese zur intensiven Gemüsewirtschaft}

Eduard und Raphaela gründen im Jahr 2015 einen Öko-GemüsebauBetrieb. Ihre beiden Kinder sind gerade neun und drei Jahre alt. Sie

18 Siehe dazu ausführlich das Kapitel von Elisabeth Kosnik.

19 Auch der agrarische Ausblick der Landwirtschaftskammer stellt fest: »Die Gruppe der Neu-Einsteiger in die Landwirtschaft ist zwar sehr klein, kann aber in Bezug auf Öffentlichkeit und Ideenreichtum viel zur Gesamtentwicklung beitragen.«Siehe Österreichische Landwirtschaftskammer 2016:15.

20 Daher haben wir zum Beispiel Imkerei-Betriebe oder Kräuterbetriebe ausgeschlossen.

21 Zur Fallauswahl siehe Methodenkapitel. 
wandeln ca. $8.000 \mathrm{~m}^{2}$ Wiese in Gemüseland um. Das Land gehört Raphaelas Eltern und wird seit ca. 30 Jahren sehr extensiv und biologisch bewirtschaftet. Die Böden sind karge Sandböden. Rund um das Wohnhaus liegen einige Nebengebäude, die als Lagerräume dienen, sowie Wohnwägen - als Wohnmöglichkeit für die im Sommer zahlreichen Mitarbeiter*innen (WWOOFer*innen, ${ }^{22}$ Praktikant*innen, Lehrlinge). Eduard leitet den Gemüsebau, Raphaela die Vermarktung. Sie vermarkten ihr Gemüse auf zwei Wochenmärkten nahegelegener Kleinstädte, liefern an vier Foodcoops ${ }^{23}$ und ein Catering-Unternehmen sowie einen Reformladen in Wien. Zum Zeitpunkt des Interviews arbeiten sie gerade am Aufbau einer Community Supported Agriculture (CSA). ${ }^{24}$ Eduard bietet regelmäßig Workshops zum Anbau von Bio-Gemüse auf ihrem Betrieb an.

Mit 17 Jahren kommt Eduard aus seinem Geburtsland Mali nach Frankreich, wo er eine Landwirtschaftsschule und eine Gartenbauschu-

22 World Wide Opportunities on Organic Farms - freiwillige Helfer"innen auf ökologischen Höfen (www.wwoof.at).

23 Eine Foodcoop ist ein Zusammenschluss von Einzelpersonen und Haushalten, die selbstorganisiert Lebensmittel direkt bei Bauern, Gärtnereien oder Imkern aus der jeweiligen Region beziehen. In den letzten Jahren sind in Österreichvor allem in Städten, aber auch in einigen Landgemeinden - Foodcoops entstanden. Im Jahr 2020 gab es in Österreich 91 Foodcoops (www.foodcoops.at, abgerufen am 5.6.2020). Siehe auch Heistinger 2018.

24 Auch unter der Bezeichnung Solidarische Landwirtschaft (SOLAWI) bekannt. Basis ist eine Art Vertragslandwirtschaft: Eine Gruppe von Menschen nimmt die Erzeugnisse einer Gärtnerei/eines landwirtschaftlichen Betriebes verbindlich ab und deckt mit diesen fixen Beiträgen die Ausgaben der Betriebsführung - und sichert so auch das Einkommen für die ProduzentInnen. Durch einen vielfältigen Anbau kann ein CSA-Betrieb dutzende bis einige hundert Menschen über einen langen Zeitraum mit frischem Gemüse, Obst und Kräutern versorgen - manche schaffen sogar eine Canzjahresversorgung. Eine CSA ist eine Nutzen- und eine Risikogemeinschaft: Die vorhandene Ernte wird auf alle Mitglieder der CSA gleichmäßig aufgeteilt. Ist die Ernte gering-zum Beispiel aufgrund von Trockenheit oder Hagel - ist auch jeder Ernte-Anteil kleiner (wobei der Kosten-Anteil gleich bleibt). Das Konzept bietet vor allem neu gegründeten Betrieben einen ökonomischen Start-Vorteil. Siehe ausführlich Heistinger 2018, S. 136-165. 
le besucht. An dieser Schule lernen sich Eduard und Raphaela - die an der Schule ein Austauschsemester absolviert - kennen. Ein Lehrer der Französischen Schule organisiert für ihn ein Praktikum auf einem biologisch-dynamischen Gemüsebaubetrieb in Österreich, wo er ab dem Jahr 2005 auch für einige Jahre arbeitet, bevor er zunächst mit einem befreundeten Bauern und dann mit Raphaela einen eigenen Betrieb gründet. Raphaela ist die jüngste von vier Geschwistern. Sie ist Akademikerin und studierte Internationale Entwicklung.

Weder Eduard noch Raphaela haben den Anbau von ökologischem Gemüse in ihren Familien gelernt. Das Wissen, das sie benötigen, um Gemüse ertragreich anzubauen ist daher kein überliefertes Erfahrungswissen. Ebenso wenig hat der Erwerbsanbau von Gemüse in der Gemeinde, in der der Betrieb liegt, eine Geschichte. Hingegen erschließt sich eine Ressource für die Idee einen Gemüsebau-Betrieb in einer trockenen Region zu gründen und diese Idee auch in die Tat umzusetzen aus den Familienbiografien von Eduard und Raphaela: Sowohl Eduards Großvater wie auch sein Vater waren im westlichen Sahel für das größte Bewässerungsprojekt der französischen Kolonialmacht tätig. Sein Großvater als zwangsrekrutierter Bauer, sein Vater viele Jahre später als leitender Angestellter der Baumwollindustrie - nach einer Ausbildung zunächst in Mali, später in Frankreich. ${ }^{25}$ Die Technik der Auseinandersetzung mit Klima und Region wird aus dieser biographischen Erfahrung Eduards her erklärbar. Der Gewissheit, dass Pflanzen auch in einer Trockenregion Österreichs ertragreich wachsen können, folgt die Fähigkeit die regionale Bodenbeschaffenheit - und wie die Pflanzen darauf reagieren - zu beobachten und zu erspüren. Diese Techniken des Wahrnehmens, etwa was Gemüsepflanzen für eine ertragreiche Ernte benötigen, begünstigt somit unabhängig von der Region den bäuerlichen Erfolg und generiert neues Wissen. Diese familiäre Kompetenz kombiniert Eduard mit seiner Ausbildung und dem Wissen und der Erfahrung aus seiner mehrjährigen Anstellung auf einem ökologischen Gemüsebaubetrieb in der Region.

25 Diese Ausbildung hatte ihm der auch in Mali tätige Französische Don BoscoOrden ermöglicht. 
In der Familiengeschichte Raphaelas fällt auf, dass es in der Familie ihrer Großmutter Erfahrungen des Verlustes von Grund und Boden, des sozialen Abstiegs und des sich in einem neuen Land neu sozial und ökonomisch zu verwurzeln gibt sowie eine hohe Bildungsorientierung. Diese Erfahrungen verdichten sich in der Familie zum Muster »Als Familie unkonventionelle Lebensentscheidungen zu treffen«. In Bezug auf die persönliche Resilienz-Potentiale der beiden fällt auf, dass sowohl Raphaela wie auch Eduard bewusst an die Ressourcen aus ihren Familien anknüpfen. Eduard beschreibt die Geschichte seines Vaters und seines Großvaters als Erfolgsgeschichte. Auch Raphaela nimmt viele Erfahrungen und Kompetenzen ihrer Familie als Ressourcen wahr und beschreibt diese in den Gesprächen ausführlich und wertschätzend. Dieses positive und stärkende Anknüpfen an die eigenen Familienbiografien ist ein wichtiges Kapital für die Gründung eines Familienbetriebs und den Schritt in die landwirtschaftliche Selbständigkeit.

Die Betriebsneugründung von Eduard und Raphaela ermöglicht den beiden ihre jeweiligen familiären Handlungsmuster zu verweben - oder anders gesagt: in der Betriebsgründung kommen beide familiären Handlungsmuster zum Ausdruck. Zusätzlich bringen beide auch unterschiedliche Ressourcen für die Gründung des Betriebes mit: Während Eduard - durch seine Ausbildung und seine berufliche Tätigkeit vor der Betriebsgründung - das pflanzenbauliche Wissen mitbringt, bringt Raphaela das Land ein, auf dem der Betrieb angelegt werden kann, sowie Offenheit, Vertrauen und Mut, sich auf neue Lebenskonzepte einzulassen und einen landwirtschaftlichen Betrieb als Lebensgrundlage ihrer jungen Familie zu gründen (zum Zeitpunkt der Betriebsgründung sind ihre beiden Kinder bereits auf der Welt). In die Ausrichtung des Betriebs - Anbau von ökologischem Gemüse, Direktvermarktung und das Anbieten von Seminaren - fließen verschiedene Ressourcen aus beiden Herkunftsfamilien mit ein.

Im Sinne der maximalen Fallkontrastierung wurde als zweites Fallbeispiel ein Betrieb ausgewählt, der innerhalb der Familie übernommen wurde. 


\section{Martin und Andrea (Fall Bergmann): Vom Weltmarkthuhn-Betrieb zur Öko-Gemüse CSA}

Martin und Andrea bewirtschaften ihren ca. drei Hektar großen Betrieb seit dem Jahr 2007. Auf dem Betrieb leben sie mit ihren beiden Kindern, die 2015 und 2017 auf die Welt gekommen sind, sowie mit Martins Mutter. Auf rund 1,5 Hektar bauen sie Gemüse und Kartoffeln an. Der Betrieb hat eine umfangreiche Ausstattung an Gebäuden. Martin hat den elterlichen Betrieb sehr jung übernommen, nachdem sein Vater erkrankt und verstorben war. Bis zum Jahr 2012 war der Betrieb ein intensiver Geflügelbetrieb, der Bruteier für die Mast-GeflügelProduktion erzeugte. Die von einem holländischen Zuchtunternehmen angelieferten Küken wurden aufgezogen, ihre Eier abgenommen und ausgebrütet. ${ }^{26}$ Martin und Andrea erzählen im Interview: »Der Knackpunkt war eher der, dass wir gesagt haben, so kann es nicht weitergehen. In diese Richtung wollen wir nicht weitermachen. Und dann haben wir Alternativen gesucht. «Sie entschieden sich die Intensiv-Hühnermast zu beenden. Die erste Überlegung war, dass Martin eine Erwerbstätigkeit außerhalb der Landwirtschaft annehmen könnte. Schließlich brachte Andrea die Idee, wie sie den Betrieb stattdessen bewirtschaften können, aus ihrem Studium der Umweltpädagogik mit. Auf einer Exkursion hatte sie die erste Community Supported Agriculture Österreichs kennen gelernt. Andrea: »Und so ist die Idee dann eigentlich entstanden, dass wir das bei uns ja auch machen können. «Für Martin war diese Idee anfangs »ganz weit weg«. Eindrücklich beschreibt er die Transformation seines eigenen BetriebsVerständnisses: »Für einen Agraringenieur, der als Landwirtschaftsmanager ausgebildet worden ist, ist ein System, wo die Betriebswirtschaft ein bisschen in den Hintergrund rückt und andere Faktoren entscheidender sind, das ist nicht so gleich vorstellbar gewesen. «Sein innerer Transformationsprozess, erzählt

26 Die Legehennenzucht ist eine der intensivsten Tierhaltungen der industriellen Landwirtschaft. Die Hühner sind Hybridrassen, weltweit gibt es drei Konzerne, die diese Legerassen züchten und die Tiere werden über weite Strecken transportiert. Teil dieser Tierindustrie ist auch das Töten der männlichen Küken, da diese in diesem System »überflüssig« sind. 
Martin, habe aber bereits davor begonnen: Im Sterbejahr seines Vaters habe er mit diesem noch ein neues Wirtschaftsgebäude - für den Ausbau der Hühnerhaltung - errichtet. Für seinen Vater sei dies eine "perfekte Betriebssituation « gewesen, wie »er es sich vermutlich erträumt hat «. Ihn hingegen habe es »aber nicht befriedigt oder nicht genug das Feuer in mir genährt«. Es habe keinen fachlichen oder betrieblichen Grund gegeben, die Produktion von Bruteiern aufzugeben: »Das war eine Nische und wenn du da gut warst, hast du gut damit verdient, keine Frage." Einige Jahre nach dem Tod seines Vaters erlebt Martin ein Burnout. Er habe sich einfach nicht mehr motivieren können, in den Stall zu gehen: »Ich hab einfach nicht mögen, das war so eine müde Zeit. « Genau in dieser Krise Martins absolviert Andrea ihr Studium der Umweltpädagogik und kommt mit neuen Ideen, einem anderen Naturverständnis und dem konkreten Vorschlag, einen CSA-Betrieb zu gründen, nach Hause. Noch im gleichen Sommer - des Jahres 2011 - besuchen die beiden andere Höfe als Inspiration. Einen Betrieb in Oberösterreich, der seit fast 40 Jahren Gemüse für die Selbstversorgung und die Direktvermarktung anbaut und neue Anbautechniken (Mischkultur und Permakultur) entwickelt hat, sowie von Kolleg*innen gegründete CSA-Betriebe. Die Kontakte zu ihnen stammen von Andrea über ihr Studium. Auf die Frage, wie er sich das gemüsebauliche Wissen angeeignet hätte, meint Martin: »Ich habe den ersten Fenchel angebaut, bevor ich ihn jemals selber gegessen habe." Grundsätzlich wären sie gerne für eine Saison als Praktikant*innen auf einen anderen Betrieb gegangen. Das würden er Neu-Einsteiger*innen empfehlen, meint Martin: »Wenn wir die Zeit gehabt hätten, wäre es schön gewesen auf einen anderen Gemüsebaubetrieb zu gehen (...), ich sehe das als gutes Fundament, um dann selbst später einen Betrieb aufzumachen. «Überhaupt meint er, dass gerade für den Anbau von Gemüse in Form eines CSABetriebes die Praxis besonders wichtig sei:

»Das glaube ich nicht, dass das über die Fachschulen laufen kann, sondern wenn, dann nur über die Betriebe, wenn man sie wirklich hautnah erlebt. Weil es ist ein totaler Spezial Know-How-Bereich. Und die Innovationen passieren aufden Betrieben und nicht in den Schulen." 
Im Jahr 2012 stellen Andrea und Martin den Betrieb auf Bio um, im Jahr 2013 starten sie mit dem Konzept als CSA-Betrieb. Als eine essentielle Ressource, um von der industriellen Hühner-Produktion aussteigen zu können, benennt Martin die niedrige Schuldenbelastung des Betriebs: »Wenn wir nicht diese niedrige Schuldenbelastung gehabt hätten, hätten wir es uns gar nie leisten können, aus dem Auszusteigen."

Die Entscheidung der beiden Betriebsleiter*innen, die intensive Hühnerhaltung aufzugeben und auf einen CSA-Betrieb umzustellen, erscheint aufs erste als radikaler Bruch mit der Geschichte des Betriebs. Bei einer sequentiellen Analyse des Genogramms der Eltern und Großeltern der Betriebsleiter*innen wird hingegen sichtbar, dass das SichEinlassen-Können auf neue Wirtschaftsweisen und das Eröffnen neuer Betriebszweige sowie die Weitergabe des eigenen Erfahrungswissens und der Erfahrungs-Austausch mit anderen Betriebsleiter*innen ein Muster ist, das auch für die Eltern- und Großelterngeneration von Martin zutrifft. Auch sie konnten sich jeweils als erste in der Region auf radikal Neues einlassen - den Anbau damals neuer Kulturen, neuer Anbaumethoden sowie neuer Vermarktungswege. Durch die familiäre Offenheit für neue Ideen und Bewirtschaftungsweisen entstehen neue Perspektiven für die Bewirtschaftung des Betriebes, neue Einkommensmöglichkeiten für den Betrieb und diese stärken die eigene Arbeitsfähigkeit und Motivation. Bedeutsam für die Transformation des Betriebes waren die Erfahrungen und Kontakte, die Andrea durch ihre Ausbildung mit auf den Betrieb gebracht hat. Sie selbst bringt kein direktes landwirtschaftliches Wissen auf den Betrieb mit - ihr Vater ist Handwerker, ihre Mutter Büro-Angestellte - doch auch ihre Großeltern waren Bauern und Bäuerinnen. Möglicherweise ist es auch diese Kombination, die sie einen frischen und unvoreingenommenen Blick auf den Betrieb und die Möglichkeiten, die sich hier bieten, einnehmen lässt.

Als maximale Kontrastierung zum zweiten Fallbeispiel wählten wir einen ökologischen Betrieb, der neu gegründet worden war. 


\section{Marianne und Heinz (Fall Conrad): Von der Lohnarbeit zur Landwirtschaft}

Marianne und Heinz kaufen den bereits aufgelassenen landwirtschaftlichen Betrieb im Jahr 2002 und gründen einen ökologischen Ziegenund Kuhbetrieb mit eigener Hofkäserei und Direktvermarktung. Der Betrieb umfasst 20 Hektar, 160 Ziegen und 30 Stück Kühe und deren Nachzucht. Marianne und Heinz stammen aus einem westlichen Bundesland Österreichs und haben Berufe außerhalb der Landwirtschaft erlernt. Marianne ist gelernte Hotelfachfrau und Heinz Maschinenschlosser. Die Familie hat an ihrem damaligen Wohnort mit der Ziegenhaltung angefangen: »Wir haben zuerst zwei Ziegen gehabt, dann haben wir 13 Ziegen gehabt und dann haben wir noch Kühe dazu gehabt und dann hat sich das Ganze entwickelt«, beschreibt Marianne den Ausbau ihrer landwirtschaftlichen Tätigkeit. Im alpinen Berggebiet war die Aussicht auf einen eigenen Hof jedoch gering. In der lokalen Zeitung sei ein Hof in der Oststeiermark inseriert gewesen. »Wir haben ja überhaupt nicht die Steiermark ausgesucht. Wir wären eher so Kanada, Australien - so in diese Richtung gewesen «, erzählt Marianne über ihre Pläne. Sie suchten nach einem Hof, der aus einer zusammenhängenden Fläche bestehe, maschinell bearbeitbar sei - vor allem für die Heuarbeit - und keine Nachbarn hätte. Wegen der Weidehaltung der Ziegen hatten sie zu Hause schon schlechte Erfahrungen mit Nachbarn gemacht. Sie wollte die Tiere im Freien halten, daher war die Abgelegenheit des Hofes für sie ein großes Kriterium. Sie konnte sich nicht vorstellen, die Tiere nur im Stall zu halten:

»Da muss ich es so machen, wie die Großen. Da muss ich sagen, okay, ich stell einen Großbunker hin, alle Tiere bleiben brav drinnen und ich tu so großbauernmäßig. Das ist für mich nicht die Landwirtschaft, die ich mir vorstelle. Wir haben uns eigentlich für Bio entschieden, weil ich einfach für artgerechte Tierhaltung bin. Und auch für Wertschätzung für Natur und Tier.«

Da sie für die Hofbesichtigung die Tiere nicht alleine hätten lassen können, sei ihr Mann damals alleine in die Steiermark gefahren: 
"Dann ist mein Mann hergekommen und hat sich das angeschaut und hat dann geschrieben, das ist super, das kann man alles mit dem Traktor fahren, das ist voll klass. Acht Tage später waren wir mit Sack und Pack und Finanzierung da. Also gesucht, gefunden, gekauft. Das gibt es ja sonst nicht."

Der Prozess der Wissens-Aneignung über die Käse-Herstellung war für Marianne intensiv und erstreckte sich über viele Jahre. Bereits an ihrem alten Wohnort habe sie begonnen, sich damit zu beschäftigen. Zunächst besuchte sie verschiedene Kurse. Nicht nur in ihrer unmittelbaren Nähe, sondern auch in Deutschland und der Schweiz. An der zu ihrem Wohnort nächstgelegenen Ausbildungsstätte hätte sie damals keinen Kursplatz bekommen. Hier wäre sie nur aufgenommen worden, wenn sie bereits in einer Sennerei angestellt gewesen wäre. Dazu meint sie im Interview kritisch: »Aber dann brauch ich ja den Kurs nicht, dann brauch ich ja die Landwirtschaftsschule nicht machen, dann hätte ich sie (Anmerkung: die Kompetenz dazu) ja schon. "Marianne war von Anfang an sehr genau und hat viel Zeit in das Erlernen des Käsens investiert. Sie meint: »Weil ich denke mir, entweder macht man es ordentlich oder gar nicht. "Zudem habe sie von den verschiedenen Käserei-Kursen sehr profitiert und für sich und die Vielfalt an verschiedenen Käsen, die sie anbietet, viel herausholen können. "Und außerdem ist es auch interessant, weil die Schweiz ist in Punkto Käsemachen ein Hauseck anders als Österreich, und auch die Bayern. Es ist ein Unterschied zwischen Vorarlberg und Steiermark, komplett anders«. Zusätzlich zu den Kursen ist für Marianne gute Fachliteratur wichtig. Es gäbe am Markt sehr viel schlechte Literatur zum Thema Käsen, bei denen bei den Rezepten kleine Fehler enthalten wären, die aber dann auf das Endprodukt eine große Auswirkung hätten. Auf die Frage, wie sie die Qualität guter Fachliteratur ausmache, meint sie: »Das siehst du sofort am Rezept. Jemand, der Kuchen backt, liest das auch sofort. Wenn ich Kuchen backe, weiß ich, das funktioniert so nicht, das muss ich ein bisschen umändern. "Zusätzlich zu den Kursen sei zu Beginn für sie wichtig gewesen, dass sie sich bei einem Bekannten ihres Mannes immer wieder Tipps holen hätte können: »Die praktischen Tipps, die kannst du dir halt auf keinem Kurs holen." Besonders wichtig sei auch gewesen, dass er ihr nicht nur Angaben - zum Beispiel über die Zeit, wie lang man den Käsebruch 
rühren müsse - gemacht habe, sondern konkret gezeigt hätte, wie sich die Käsemasse nach einem bestimmten Arbeitsschritt anfühlen müsse: »So muss sich jetzt der Druck anfühlen, dann passt das«. Gerade auf den Käsereikursen in Österreich sei es - im Gegensatz zu Deutschland - üblich, dass die Referent"innen »entweder nicht vermitteln könnten oder etwas bewusst zurückhalten« würden.

Marianne hat zunächst begonnen, ihre Käse an verschiedene Hotels und Gastwirtschaften in der Nähe ihres neuen Hofes zu vermarkten. Nach ein paar Jahren ist sie wieder davon abgekommen, da sie sich hier nicht frei fühlte: »Du bist dann auch wieder in diesem System drinnen, (...) du bist gezwungen, das zu machen, was man dir sagt. Das möchte ich nicht.«Die Einschränkung durch die fixen Speisekarten der Hotels sei ihr zu groß gewesen. Mittlerweile vermarktet sie den Käse zu $100 \%$ direkt und zwar auf vier verschiedenen Bauernmärkten in der Landeshauptstadt. »Ich möchte einfach kreativ sein und meine Sachen machen. Und das kann ich halt, wenn ich direkt verkaufe, besser «. Besonders ausführlich erzählt Marianne, wie wichtig es für ihre Produktion ist, dass sie direkt im Kontakt mit den Kund"innen ist: "Du kannst es dem Kunden erklären und weißt sofort, was er will und bekommst sofort eine Rückmeldung und du weißt, passt es oder passt es nicht. "Auch auf das Wetter und die damit zusammenhängenden Essgewohnheiten könne sie gut reagieren:

»Du weißt, jetzt ist Sommer, jetzt brauch ich das und das. Man bekommt ein Gefühl dafür. Gerade mit meinen Produkten kann ich ja schneller etwas herzaubern. Mach ich halt im Winter Nuss und Kürbis. Im Sommer mach ich halt dann eben Grillkäse, Halloumi-mäßig. Was einfach speziell auf das Wetter passt.«

Auch »gewinnmäßig« sei die Direktvermarktung das Beste für den Betrieb.

Das Fallbeispiel der Familie Conrad zeigt eindrücklich, welche Ressourcen Menschen mitbringen (müssen), um einen landwirtschaftlichen Betrieb mit Tierhaltung aufbauen zu können. Neben der Liebe zu Tieren ist dies die Fähigkeit und die Bereitschaft beharrlich und kontinuierlich zu arbeiten und für die Versorgung der Tiere Verantwortung zu übernehmen. Da die Tierhaltung mit höheren Investitionskos- 
ten verbunden ist als der Gemüsebau (wie im ersten Fallbeispiel), war es für die beiden Betriebsgründer*innen essentiell, dass Heinz von Beginn an in der Region in seinem erlernten Beruf einen Arbeitsplatz hatte denn nur so war es überhaupt möglich, von der Bank einen Kredit für den Kauf des Hofes zu bekommen. ${ }^{27}$ Dass Heinz nun gemeinsam mit seiner Frau den Hof betreibt, ist - aus seiner Familiengeschichte heraus - als sozialer Aufstieg zu verstehen. Marianne wiederum bringt aus ihrer Familiengeschichte - und vermutlich vor allem von ihren weiblichen Rollenvorbildern - ein Arbeitsverständnis mit, das einerseits von einer starken Kundenorientierung geprägt ist, anderseits von der Fähigkeit, eigene Wege $\mathrm{zu}$ gehen und $\mathrm{zu}$ improvisieren. Sie scheint es gewohnt zu sein, ihren Weg auch gegen Widerstände (der Behörden, von Kolleg*innen) zu gehen und diese zu überwinden. ${ }^{28}$ Ein möglichst selbstbestimmtes bäuerliches Leben und möglichst autonomes Handeln ist ein Handlungsmuster, das beiden wichtig zu sein scheint. Eine große Unabhängigkeit ist Marianne wichtig, auch wenn viel zu Arbeiten der Preis dafür ist. Wie ihre Mutter als Frisörin und ihre Großmutter als Schneiderin lebt Marianne gewissermaßen von »ihrer Hände Arbeit«. Möglicherweise haben beide keine familienbiografische Vorlage dafür, dass es für den Aufbau eines Betriebs auch eine Möglichkeit - und für bestimmte biografische Momente möglicherweise auch eine Notwendigkeit ist - Mitarbeiter*innen am Betrieb zuzuziehen. So ist zur Zeit die - gerade erst 13 Jahre alte Tochter - die einzige, die das Käsen übernehmen könnte, sollte Marianne ausfallen. Dies könnte zu einem Risiko

27 Bätzing betont, dass Erwerbskombinationen für die Stärkung der Regionalwirtschaft grundlegend sind, weil sie die Flexibilität des ländlichen Wirtschaftens ermöglichen. Ohne erreichbare Nebenerwerbsmöglichkeiten wären die Betriebe gezwungen, nach agrarindustriellen Bedingungen für den globalen Markt zu produzieren. Bätzing 2020, S. 236-241. Auch die Agrarsoziologinnen Heide Inhetveen und Mathilde Schmitt sehen in der Erwerbskombination die Möglichkeit für Menschen, die einen bäuerlichen Betrieb im Nebenerwerb führen, ihre bäuerliche Orientierung aufrecht zu erhalten und bezeichnen dies als Merkmal einer bäuerlichen Überlebenskultur. Siehe dazu Inhetveen und Schmitt 2010:111.

28 Siehe dazu auch das Kapitel von Elisabeth Kosnik. 
für die Entwicklung des Betriebes werden, wenn es nicht gelingt, familienfremde Arbeitskräfte einzubeziehen.

Als viertes Fallbeispiel wählen wir einen Betrieb aus, der wiederum in der Familie übernommen, aber bereits von der Elterngeneration auf ökologischen Landbau umgestellt wurde.

\section{Daniela und Anton (Fall Danninger): Vom ererbten Hobbybetrieb zum Haupterwerbsbetrieb}

Daniela und Anton bewirtschaften einen Betrieb, der seit dritter Generation in Familienbesitz ist. Antons Großeltern kaufen den Betrieb in den 1960er Jahren und führen ihn von Wien aus. Zu dieser Zeit hat der Betrieb in erster Linie als Sommer-Landsitz der bürgerlichen Familie eine Bedeutung. Nach eigenen »Bio-Versuchen« Mitte der 1980er Jahre übernehmen Antons Eltern den Betrieb und stellen ihn auf die ökologische Wirtschaftsweise um. Beide Eltern waren bereits von der ökologischen Wirtschaftsweise überzeugt. Auch sie bewirtschaften den Betrieb im Nebenerwerb und von Wien aus, wo sie beide berufstätig sind. In seiner Kindheit verbringt Anton, der in der Großstadt aufwächst, viele Wochenenden und Sommerferien am Betrieb. "Das war immer lässig«, erzählt er. Im Jahr 1985 haben die Eltern einen schweren Autounfall - Anton ist zu diesem Zeitpunkt erst 17 Jahre alt. »Da musste ich sowieso einspringen. Meine Schwester auch «, erzählt Anton. Da er in dieser Zeit gemerkt habe, dass ihm die »Arbeit am Hof recht gut gefällt«, habe er sich nach der Matura entschieden, eine Ausbildung zum landwirtschaftlichen Facharbeiter zu machen. Vor der Umstellungsphase hätte er zwei Vergiftungen durch ein Insektizid gehabt und daraufhin den ersten ökologischen Obstbaubetrieb Österreichs besucht. Hier lernt er auch seine erste Partnerin Isabella kennen, die im Zuge ihrer ObstbauAusbildung hier ein Praktikum macht. Isabella, die von einem landwirtschaftlichen Betrieb stammt, studiert Biologie. Im Jahr 1992 kommt ihre erste Tochter zur Welt, 1996 der erste und 2000 der zweite Sohn. Erst im Jahr 1996 übernimmt Anton den elterlichen Betrieb - der damals verschuldet war - und Anton und Isabella, die wie er vom biologischen Landbau überzeugt ist, stellen ihn auf Vollerwerb um. 
Aktuell umfasst der Hof mit zugepachtetem Boden rund 7 ha Obstbaufläche. Das Obst (Äpfel, Birnen und Quitten) wird lokal über einen Bauernladen vermarktet, sowie über Bioläden, ein Seminar-Hotel, ÖkoGroßhändler und eine österreichische Supermarkt-Kette. Daniela, Antons spätere Frau, die ebenso wie Isabella Biologie studiert hat, arbeitet im lokalen Naturpark und bietet Eselwanderungen an. Bei der Ernte helfen "Pensionisten und Hausfrauen « aus der Umgebung, die sehr verlässlich seien und die Arbeit gerne machen würden: »Man weiß genau, wo sie sind, weil sie so viel lachen (...) und die hört man durch die ganze Anlage«. Anton erzählt, dass er froh sei, dass er »die Ernte nicht busweise organisieren « müsse - womit er meint, keine Ernte-Arbeiter"innen aus dem benachbarten Ausland organisieren müsse. Wobei Daniela erzählt, dass ihre Erntehelfer*innen schon älter seien und kaum jüngere aus der Gegend nachkommen würden. Überhaupt fehle am Hof »die Elterngeneration«, die bei der Arbeit unterstützen könne. Eine große Erleichterung sei neuerdings die Mitarbeit des jüngsten Sohnes Lorenz.

Anton kann kaum auf familiäres Know-How zum Obstbau zurückgreifen. Er erzählt: »Praktisch als nicht am Land aufgewachsener, ganz normaler Maturant hatte ich von Landwirtschaft null Ahnung. Ja, es war ein Hineinwachsen. Meine Oma ist leider zu früh verstorben, um ihr Wissen weiterzugeben. Ah, das war verdammt viel Lehrgeld, viel ausprobieren, viel fragen. Ich hatte gottseidank ein paar Freunde (...), die mir viele Sachen gezeigt haben, erklärt haben, und dann ist es wirklich ausprobieren und versuchen. « Zum BioObstbau habe er sich sein Wissen aus ganz unterschiedlichen Quellen angeeignet: Auf den ersten Ökologischen Obstbautagungen in Deutschland, durch den Austausch mit andern Bio-Obstbauern aus der Region und aus anderen Regionen Österreichs, sowie aus Deutschland. Später erst sei er auch von einem von der Landwirtschaftskammer finanziertem Berater für ökologische Landwirtschaft beraten worden. Ein Unterschied zu jener Zeit, in der sie mit dem Bio-Obstbau begonnen hätten, sei, dass es nun kaum mehr einen Spielraum für Versuche gebe: »Damals gab es ja auch nicht viel Forschung zum Thema biologischer Obstbau, da haben wir einfach alle probiert, was gegangen ist." Anton weist auch darauf hin, dass es nun in Österreich, Deutschland, Südtirol und Slowenien viele Versuchsanstalten gebe, die sich auch mit dem biologischen 
Anbau beschäftigen würden. »Man kann sich aus allen (...) etwas herauspicken.« Jedoch sei der Unterschied: »Du bist dann reiner Produzent (...), wirtschaftlich optimierter Produzent. Das ist der Unterschied zu damals, wo du dich noch selber gespielt hast.«

Bei der Übernahme sei der Betrieb »hoch verschuldet « gewesen und auch Investitionen seien zu tätigen gewesen. Anton erzählt, er habe »nur übernommen«, damit der Betrieb »nicht verkauft« wird. »Es ist ein Mordsstress, eben diese Wirtschaftlichkeit, aber es fängt an, sich wirtschaftlich zu rechnen. Mit dem negativen Aspekt, dass es irgendwie (...), der Reiz der Landwirtschaft dem wirtschaftlichen Aspekt untergeordnet wird. «Daniela erzählt, dass sie und ihr Mann »um jeden Millimeter « feilschen würden zwischen Wirtschaftlichkeit und technischen Fragen des Obstbaus einerseits (Antons Interesse) und andererseits anderer Qualitäten des Betriebes, wie Lebensräume für Wildtiere oder nicht unmittelbar produktive Pflanzen und Tiere am Betrieb (Danielas Interesse). Diese seien aber notwendig, da sie den Betrieb auch interessant machen würden für zum Beispiel Schulklassen. Daniela: »...dass ich diejenige bin, die wieder Aktionstage macht am Hof, die Schulen an den Hof bringt, die dann im Herbst so schauen, wie gepflückt wird, und eine Apfelverkostung machen (...). Das sind so die Sachen, wo ich das Gefühl habe, da kommt man wieder am Boden an."

\section{Sorgsame Landwirtschaft und Resilienz - Gemeinsamkeiten und Unterschiede der Fallbeispiele}

Die Protokollierung der Lebenspraxen von vier Ökobauern und fünf Ökobäuerinnen und die Rekonstruktion ihrer Genogramme liefert eine genaue Beschreibung ihrer spezifischen, subjektiven Antworten auf allgemeine Handlungsprobleme bäuerlicher Betriebe der Region. Jede Betriebsgeschichte und jede Familienbiographie ist Ausdruck der vorliegenden Bewährungsanforderungen. Jeder Fall repräsentiert unterschiedliche Modi der Problembewältigung und des Umgangs mit Krisen. Die Produktionsweise und die betriebliche Dynamik eines landwirtschaftlichen Betriebes sind ein Ausdruck der Biografien der Betriebsleiter*innen. 
Die untersuchten erfolgreichen Ökobetriebe setzen individuell gefundene Wirtschaftskonzepte um, die nicht im Sinne von Modellen generalisierbar sind. Dennoch sind aus diesen gemeinsame Handlungsmuster herauslesbar: Alle Betriebsleiter*innen zeichnet aus, dass sie bereit sind, in ihrem unmittelbaren Umfeld noch nicht bekannte - geschweige denn etablierte - Wirtschaftskonzepte umzusetzen. Alle vier Betriebe können daher als Pionier-Betriebe bezeichnet werden. Gerade in diesem Zusammenhang fällt auf, dass die Betriebsleiter*innen, die ansonsten in der Privatwirtschaft verbreitete Praxis, Wissen exklusiv für sich zu behalten, nicht pflegen und betonen, wie wichtig der Austausch mit anderen Betrieben, aber auch mit Konsument*innen und anderen Akteur*innen ist. Im Gegenteil haben sie großes Interesse, Wissen unter Kund*innen und Kolleg*innen zu verbreiten und sich in Communities auszutauschen. Möglicherweise auch deswegen, da eine Konkurrenz auf Absatzmärkten bei regionalem Vertrieb und Ablehnung des Wachstumsdogmas nicht zu befürchten ist. Ein weiterer Grund dafür mag sein, dass sie von der Qualität ihrer Produkte überzeugt sind, auf Qualität (statt Quantität) setzen und diese mit Überzeugung vermarkten. Im Rahmen kleiner regionaler Betriebe erzeugt ein non market trade Vorteile - vor allem der Austausch von Wissen und Erfahrungen über Produktionsmethoden, die die eigenen betrieblichen Ressourcen (wie die Bodenfruchtbarkeit der Betriebe) schonen oder über kostengünstige Methoden der Herstellung von Geräten, über gute Erfahrungen zu Lieferanten oder zum Aufbau von neuen sozialen Strukturen wie einer CSA, die viel betriebswirtschaftliches Organisationswissen - etwa wie man eine neu entstehende Gemeinschaft organsiert - benötigt. Dieses Wissen entsteht neu auf den Betrieben. Für kleine und regionalspezifisch wirtschaftende Betriebe gilt, dass der profitfreie Austausch von Expertisen die Gewinne aller erhöht.

Drei der vier Betriebsleiter-Paare erzählen, dass für sie Freundinnen und Freunde, die ihnen landwirtschaftliches Know-How vermittelt hätten, besonders zu Beginn für sie wichtig gewesen wären. Sie konnten also ihre freundschaftlichen und familiären Beziehungen als Ressourcen für die Betriebsgründung oder für die Konzeption und das In- 
die-Welt-bringen von neuen Betriebskonzepten nutzen. ${ }^{29}$ Für Martin und Andrea ist der gute Kontakt zu den Eltern auch betriebswirtschaftlich wichtig. So hat Andreas Vater, der Schlosser ist, mit Martin gemeinsam neue Gerät konstruiert zum Setzen von Jungpflanzen in Heu - was eine große zeitliche Arbeitsersparnis bedeutet.

Alle Betriebsleiter*innen betonen, wie wichtig für sie persönlich, aber auch für die Betriebe der Austausch mit ihren Kund*innen ist, die positiven Rückmeldungen zu den Produkten stärken das Vertrauen in die eigene Kompetenz und können - da sie die eigene Handlungsfähigkeit bzw. das Vertrauen in die eigene Handlungsfähigkeit stärken auch als Praktiken der Resilienz bezeichnet werden.

An die eigene Geschichte anknüpfen, an die eigene Biografie anknüpfen, an die Biografie des Ortes, das sind resiliente Handlungsmuster. Sorgsame Landwirtschaft knüpft an und verbindet, lässt los, interpretiert neu, kann sich anpassen, ist reaktionsfreudig. An die eigene Biografie anzuknüpfen heißt immer auch einen Bezug zu schaffen zu einem Kollektiv: Zur eigenen Herkunftsfamilie und ihrer Geschichte oder zum sozialen Milieu, in dem man aufgewachsen ist - dazu zählen neben den Eltern, Großeltern und Verwandten auch andere Akteur*innen. Regionale Muster der Daseinsbewältigung ${ }^{30}$ und wie sich die eigenen Eltern und Großeltern darin eingerichtet haben, welchen Handlungsmustern ihre beruflichen und betrieblichen Entscheidungen gefolgt sind, all das sind Ressourcen, an die die Betriebsleiter*innen anknüpfen können. Die Betriebsleiter*innen knüpfen so unmittelbar an der eigenen Geschichte an, an ihrer Wissensgeschichte und verwandeln sie in etwas Neues. So können sie auch neue Wissensbestände und neue Erfahrungen aus ihren Ausbildungen oder aus dem Austausch mit Kolleg*innen in das eigene Tun einweben. Gleichzeitig führt so neues Wissen nicht weg vom eigenen Wissen und von der eigene Geschichte vom Eigenen überhaupt - sondern wird zu einem eigenen Pol, der die

29 Zu ähnlichen Ergebnissen kommt auch eine Untersuchung zur Betriebsübergabe außerhalb der Familie. Siehe: Heistinger 2012.

30 Siehe dazu das Kapitel »Sozialen Sinn verstehen durch rekonstruktive Genogrammarbeit«. 
handelnden Menschen sogar wieder neu in die eigene Geschichte hineinführen kann. An die eigene Biografie anzuknüpfen, die Ressourcen aus der eigenen Familiengeschichte neu beleben zu können, führt zu Resilienz und Widerstandskraft. Dazu braucht es Offenheit und Kommunikation und Freiräume zur Reflexion über die eigene Geschichte: Was davon ist jetzt für mich und meinen Betrieb hilfreich und eine wichtige Ressource? Was ist in der alten Form nicht mehr hilfreich? Wie kann ich es neu kontextualisieren und wovon will ich mich auch abgrenzen? Die eigene Geschichte immer wieder neu zu beleben, neu zu interpretieren, bedeutet, die bisherigen Erfahrungen immer wieder neu im Moment der Gegenwart - zu kontextualisieren, in Beziehung zu gehen mit der eigenen Geschichte und der Umwelt, den Menschen aus der eigenen Vergangenheit und der eigenen Gegenwart. Dabei spielt es keine Rolle, ob die Familie in der Region, in der sich der Betrieb befindet gelebt hat oder nicht. Im Gegenteil: Die Menschen aus unseren vier Fallbeispielen - die jeweils etwas Neues in der Landwirtschaft wagten bringen Bereitschaft zu Mobilität sowie Erfahrungen des Ortswechsels aus ihrer Familienbiographie mit. Diese haben sich als wichtige Ressource für den Aufbau des Betriebes in der Region erwiesen.

Die Forschungsergebnisse zur sorgsamen Landwirtschaft sind insbesondere anschlussfähig an den Diskurs zur Agrarökologie, der innerhalb des Ökologischen Landbaus seit etwa 20 Jahren geführt wird. Diese versteht sich nicht als rein objektive Naturwissenschaft, sondern bezieht bäuerliches Wissen und Erfahrungswissen aus der Landwirtschaft mit ein. Agrarökologische Methoden sind im Vergleich zu den Methoden der industriellen Landwirtschaft wissens- und arbeitsintensiver.

Ein wesentliches Ergebnis unserer Forschung besteht in der Erkenntnis, dass es kein spezifisch lokales Wissen gibt, das an einem Ort gefunden und dort tradiert wird. ${ }^{31}$ Vielmehr zeigen die einzelnen Fälle, dass das handlungsgenerierende Wissen individuell erworben wird und von Generation zu Generation wechselt. Wissen wird erst durch das Sammeln von Erfahrungen an einem Ort anwendbar und zu embodied knowledge. Da die Herausforderungen durch Markt und 
Klima ebenso veränderlich sind wie die zur Verfügung stehenden Technologien und die Ansprüche der Konsument*innen, muss stets neues Wissen generiert werden. Überliefertes - auch konventionelles landwirtschaftliches Wissen und das Wissen über die Auswirkungen dieser Produktionsmethoden auf die eigenen Körper und Böden wird mit neuem Wissen auf kreative Weise verwoben.

Für Expertise und Handlungskompetenz werden in der Professionsforschung folgende vier Faktoren als Voraussetzung genannt: ${ }^{32}$ Umfangreiches Wissen und gutes Gedächtnis, Problemlösefähigkeit und Entscheidungsstärke, Verfügbarkeit von Routinen und die Einbettung in Expert*innengemeinschaften. Die von uns befragten Personen weisen diese Fähigkeiten auf. Eine weitere wesentliche Fähigkeit eint die Bauern und Bäuerinnen unserer Fallbeispiele: Die Fähigkeit zum Erkennen von Problemen. Oder anders gesagt: Das Neue liegt im Erkennen von Problemen, die andere so nicht sehen. Bio Landwirt"innen können Probleme nicht nur innovativ lösen, sondern haben davor aufgrund ihrer spezifischen familiären Ressourcen Faktoren verknüpft, die bisher noch nicht in dieser Konstellation erkannt wurden. Neue innovative Betriebsgründungen oder Umgründungen verdanken sich einer Kombination aus Vorwissen, Neugier, Experimentierfreudigkeit und guter Vernetzung. Dazu kommen Pflanzen oder Tiere, die in der Region gut gedeihen. Weiters braucht es die Bestärkung von Expert*innen oder anderen Menschen, denn im unmittelbaren Lebensund Betriebsumfeld wird Innovationen teils auch mit Skepsis und Ablehnung begegnet. Daher sind soziale Netzwerke - analoge wie digitale - und der überregionale Wissensaustausch für die Betriebe besonders wichtig. ${ }^{33}$ Bedeutsam ist zudem, dass die neuen Betriebsgründer*innen eine Kombination unterschiedlicher Ausbildungen und Erfahrungen vorweisen können. Wie z.B. auch Studien aus Italien zeigen, ${ }^{34}$ verfügen neue Betriebsgründer*innen über eine gute Bildung die allerdings nicht notwendigerweise eine landwirtschaftsbezogene

32 Vgl. Gruber u.a. 2006, S. 194.

33 Siehe dazu auch das Kapitel von Elisabeth Kosnik.

34 Milone \& Ventura 2019. 
Grundausbildung sein muss. Sie sind kommunikativ, können sich Information auch informell besorgen, haben fremde Länder bereist und stehen den herkömmlichen Vermarktungsformen kritisch gegenüber. Wesentliche Faktoren für die Entscheidung gegen konventionelle Landwirtschaft, die in den Gesprächen genannt wurden, waren einerseits der Wunsch nach autonomer Betriebsführung im Gegensatz zum Diktat der Weltmarktorientierung und andererseits eine Haltung der Sorge gegenüber der Umwelt. Regionale Einbettung ist nichts Stabiles, sondern ein lebendiger Zusammenhang, der durch den beschleunigten Weltmarkt noch viel veränderlicher geworden ist. 



\section{Wirtschaften im Zusammenhang: Sorge, Sympathie, Sinn}

Gabriele Sorgo

Als wir das vorliegende Projekt konzipierten, lag unser Interesse auf dem Zusammenspiel des persönlichen Engagements und des Arbeitseinsatzes bäuerlicher Akteur*innen einerseits mit den regionaltypischen sozialen und ökologischen Ressourcen andererseits. Als zentrale Theoriemodelle für die Makroanalyse agrarsoziologischer Daten hatten wir Karl Polanyis Theorie der "Einbettung « ${ }^{1}$ und das Konzept der »Gabe« von Marcel Mauss ${ }^{2}$ gewählt. Denn menschliche Zuwendungen an Zeit, Aufmerksamkeit und materiellen Gaben repräsentieren soziale Beziehungen, betten also ein, und überschreiten die Grenzen zwischen Menschen, Tieren und Dingen, die gewöhnlich als isoliert betrachtet werden. Zuwendung erzeugt Beziehung - und Beziehung überschreitet Grenzen, auch jene zwischen den Spezies. Im Verlauf der Erhebungen wurde diese theoretische Basis um die Begriffe der Resilienz ${ }^{3}$ und der Relationalität erweitert. Die Studien von Ika Darnhofer stellen hierzu im Bereich der Agrarsoziologie die bei weitem spannendsten und interdisziplinär anschlussfähigsten Forschungsansätze dar, denen wir viel verdanken. ${ }^{4}$

Ziel unseres Vorhabens war es, zu zeigen, dass auch Geräte, Landschaften und Pflanzen von Menschen in ein lebensweltliches Be-

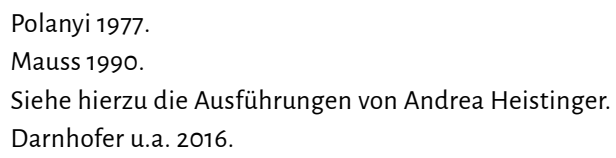


ziehungsgeflecht eingewoben werden, das nur zu einem geringen Teil nach marktwirtschaftlichen Kriterien funktioniert und wohl gerade deshalb die Grundlage des guten Lebens ${ }^{5}$ darstellt. Diese Gedanken sind keineswegs neu, sondern finden sich schon des längeren in modernen ökonomischen Theorien, die der profitorientierten Marktwirtschaft dienen sollen, wenn auch bisher ohne Einbindung der Tierund Pflanzenwelt. ${ }^{6}$ Eine Evaluierung so genannter »weicher Faktoren « des unternehmerischen Erfolgs, wie von Organisationsentwickler*innen oft empfohlen, stellt jedoch keinen Interessensschwerpunkt dieser Studie dar. ${ }^{7}$ Vielmehr gehen wir der Frage nach, inwieweit die Motivation ökologisch wirtschaftender Bauern und Bäuerinnen für ihre durchaus riskanten betrieblichen Entscheidungen sich aus ihren biographischen Erfahrungen und ihren Familiengeschichten herleitet. Jedes menschliche Individuum wird in Beziehungen hineingeboren und während des Heranwachsens von ihnen geprägt. Verknüpft man Stephen Gudemans wirtschaftsanthropologische Perspektive einer stets vorhandenen Verschränkung profitorientierter mit sozial motivierten Austauschprozessen ${ }^{8}$ zusätzlich mit der artenübergreifenden relationalen Ontologie von Donna Haraway, so wird das hegemoniale, profitorientierte Theoriemodell der Ökonomie gewaltig relativiert. Eine andere, humanere Perspektive eröffnet sich, die jedoch die herkömmlichen betriebswirtschaftlichen Zugriffe auf die Wirklichkeit nicht erkennen und auch nicht anerkennen wollen. Seit drei Jahrzehnten fordert Haraway mit ihrem Aufruf zum artenübergreifenden Denken angesichts des bedrohten Planeten mehr Demut ein. ${ }^{9}$ Sie weist darauf hin, dass sämtliche Beziehungen, soziale wie biologische, von denen und in denen ein Individuum ausschließlich leben kann, der Existenz menschlichen Lebens vorausgehen. Sich die Menschen nur als abgeschlossene, selbstbezogene Systeme vorzustellen, betont Haraway,

\footnotetext{
$5 \quad$ Nussbaum 1999, S. 57 f.

6 Vgl. Krippner u.a. 2004.

7 Vgl. Schönborn 2008, S. 100.

8 Gudeman 2016.

9 Haraway 2018.
} 
mache blind für die Tatsache, dass wir unsere Existenz sowohl vergangenen als auch gegenwärtigen Beziehungen und Kooperationsformen mit unzähligen Lebewesen verdanken. ${ }^{10}$ Einige dieser Kooperationsformen sind dem Feld der Ökonomie zuzuordnen, die meisten müssen jedoch unter anderen Gesichtspunkten betrachtet werden. Zusammen bilden sie ein Bündel an Relationen, das Menschen und ihre Wirtschaftsformen als relationale Phänomene begreifbar macht. Die Erforschung des menschlichen Mikrobioms relativiert z.B. Vorstellungen von einem klar gegenüber seiner Umwelt abgegrenzten menschlichen Organismus. Vielmehr sind Menschen Holobionten ${ }^{11}$ : Eine Versammlung von Milliarden von Kleinstlebewesen, die zusammenarbeiten und sich austauschen, damit ein menschlicher Stoffwechsel tadellos funktioniert. ${ }^{12}$ Bakterien des Verdauungstraktes, ihre Vielfalt und ihre Wechselwirkungen beeinflussen sogar die menschliche Psyche. ${ }^{13}$ So gesehen ist es dringend notwendig, auch in sozialwissenschaftlichen Forschungen den Bodenbakterien, die unsere Lebensmittel wachsen lassen, mehr Aufmerksamkeit zu schenken. Genau das machen die von uns interviewten Bauern und Bäuerinnen. Das einst Bedeutungslose und durch disziplinäre Grenzen Aussortierte, rückt nun endlich in den Fokus der Forschung. Die Wissenschaften benützen große Theorien, um die Komplexität des Lebendigen gedanklich erfassen zu können. »Profitorientierung« oder "Subsistenzorientierung « erscheinen dann als zwei diametral entgegengesetzte Wirtschaftsformen, die anhand von klar definierten Merkmalen unterschieden werden. Doch diese Dramatisierung der Differenz kann zu falschen Ergebnissen führen. Forschung sollte zwar immer theoriegeleitet stattfinden, doch die Theorien dürfen für Widersprüche und ambivalente Ergebnisse, die sich nicht so einfach in die erstellten Kategorien einfügen lassen, nicht blind machen. Das reale Leben der Menschen ist weitaus komplexer.

\footnotetext{
10 Haraway 2003, S. 21.

11 Grassberger 2019, S. 200f.

12 Collen 2015.

13 Valles-Colomer u.a. 2019.
} 


\section{Geben, Nehmen, Werden}

Mit dem Wissen, dass menschliche Individuen sich ihren sozialen und materiellen Beziehungen verdanken, erscheinen auch vermeintlich banale Interaktionen in einem anderen Licht. Man gibt den Blumen Wasser und schenkt den Nachbarskindern Himbeeren oder einem Besucher ein paar gute Tipps für den eigenen Garten. Der Alltag besteht aus vielen solchen kleinen Geschenken, die unter Menschen Verbindlichkeit und Vertrauen erzeugen. Unsere ursprüngliche Hypothese lautete, dass naturnah wirtschaftende Betriebe diese nicht-gewinnmaximierenden Handlungen häufiger einsetzen als mehr agrarindustriell ausgerichtete und dass sie deswegen auch der Region statt nur dem eigenen Unternehmen Gewinn bringen. Die derzeit vorherrschende agrarindustrielle Nutzung von Boden und Tieren ist eine Wirtschaftspraxis, die auf Dauer zu viel »nimmt « und sowohl den Boden und die Artenvielfalt als auch die sozialen Zusammenhänge schädigt. Die Agrarindustrie folgt einem modernen marktrationalen Konzept von Landbau, das sich aus einigen wenigen Parametern (Bodenqualität, Klima, Dünger, Maschineneinsatz, Wasser, Lagerung, Transport) zusammensetzt, die so austariert werden, dass sie die Quantität an Lebensmitteln kurz- und mittelfristig erhöhen, langfristig jedoch gefährden, wie der Weltagrarbericht von 2008 darlegen konnte. ${ }^{14}$ Dabei leben in einer Hand voll fruchtbarem Humus mehr Mikroorganismen als Menschen auf der Erde. Die Beziehungen und Wechselwirkungen zwischen ihnen sind noch lange nicht ausreichend erforscht, obwohl das Überleben der Menschheit von ihnen abhängt.

Auf der Suche nach kurzfristigem Gewinn reduziert die erdölbasierte, hochtechnologische Landwirtschaft langfristig die Mikroorganismen des Bodens und lässt die Fruchtbarkeit sinken. Die kultivierten Pflanzensorten werden auf einige wenige hochgezüchtete Sorten reduziert. Parallel mit der Zunahme der Monokulturen verließen die jungen Menschen im 20. Jahrhundert das Land (und tun es bis heute). Die verbleibenden Bauern und Bäuerinnen wurden häufig aufgrund

VgI. IAASTD 2008. 
der marktwirtschaftlich erzwungenen Rationalisierungen zu hochverschuldeten Ressourcenlieferanten eines weltweiten Agrarsystems. Ihre Beziehungen zum Boden, zu den Tieren und auch zu den Menschen, für die sie Lebensmittel erzeugen, können Agrarunternehmer*innen heute nicht mehr selbst bestimmen, sondern sie unterliegen den Auflagen des globalen Nahrungsregimes. ${ }^{15}$ Um die Unterschiede zwischen agrarindustrieller und biobäuerlicher Herangehensweise wissenschaftlich differenzierter $\mathrm{zu}$ erfassen, ist es aus unserer Sicht unbedingt angebracht, soziologische und anthropologische Theorien auf den Umgang mit Pflanzen und Tieren auszudehnen. Menschen sind nicht nur soziale, sondern im umfassenden Sinn relationale Wesen, sie sind eher Prozesse, die durch Beziehungen ins Leben gerufen und am Leben erhalten werden. ${ }^{16}$ In den euroatlantischen Industriegesellschaften haben Menschen aber unter dem Einfluss kapitalistischer Produktions- und Konsumbedingungen die Gewohnheit angenommen, sich die Beziehung zu sich selber und zur Umwelt nach dem Muster eines neutralen Erfassens von dinglichen Gegebenheiten vorzustellen. ${ }^{17}$ Daraus resultiert eine Handlungspraxis, die selbst verdinglichte Gestalt annimmt. Bäuerliches Handeln wurde oft $\mathrm{zu}$ teilnahmslosem Handeln. ${ }^{18}$ Früchte werden aufgrund von Verträgen mit Handelspartner*innen $\mathrm{zu}$ früh geerntet und Jungtiere von den Muttertieren getrennt, weil die Logik des Marktes dies verlangt. Die zahlreichen bloß kalkulatorischen Tauschprozesse des Alltags prägen auf Dauer die Deutungsgewohnheiten der Menschen moderner Industriegesellschaften, sodass sie die lebenswichtigen Beziehungen zur Umwelt ausblenden. Nichtsdestotrotz müssen Menschen sich als

Der Begriff food regime stammt von Harriet Friedman und Philipp McMichael (1989). Van der Ploeg (2018b, S. 245) bevorzugt food empires und definiert sie so: »Food empires are globally operated networks with clear centres of command. They control large, and expanding parts of the production, processing, distribution and consumption of food, although they are not necessarily involved in the physical realities associated with these processes.«

16 Vgl. Donati 2011.

17 Vgl. Honneth 2005, S. 36.

18 Vgl. Müller 1998, S. 167f. 
soziale Wesen dennoch stets um gelingende materielle und soziale Austauschprozesse mit der Umwelt bemühen. Das Feld der dafür notwendigen Interaktionen muss aber heute angesichts des botanischen, zoologischen, psychologischen und anthropologischen Wissens unbedingt weiter gefasst werden als derzeit in der Agrarsoziologie üblich. ${ }^{19}$ Nahrung - Erzeugung, Herstellung und Verzehr - gilt nach Mauss als soziales Totalphänomen ${ }^{20}$, weil sie menschliche Belange in materieller, rechtlicher, wirtschaftlicher, religiöser, ästhetischer und sozialer Hinsicht beeinflusst. Sich Ernähren, der Akt der Konsumption, stellt eine Interaktion auf vielen Ebenen dar. Ein durchschnittlicher Körper beherbergt vor allem im Darmtrakt unzählige Lebewesen, die sich von ihrem Wirt unterscheiden und ein eigenes Leben führen. Wo endet ein Körper und wo fängt er an? Das hochentwickelte Gehirn kann uns nicht davor bewahren, dass wir essen müssen und dabei zugleich auf vielfältige Weise von unserer Umwelt vereinnahmt, durchdrungen und verbraucht werden. Dieses Wissen um die menschliche Leiblichkeit, die mehr ist als nur ein Körper, hat Akteure*innen in der Landwirtschaft immer wieder dazu angespornt, agrarindustrielle Produktionsstile abzulehnen. Die interviewten Akteur*innen dieses Forschungsprojektes leben in spezifischen familiären, regionalen, sozialen, ökologischen und wirtschaftlichen Beziehungsgeflechten und zeichnen sich dadurch aus, dass sie diese Einbettung auch reflektieren. Weit entfernt von jeder Sozialromantik tauchen immer wieder Wendungen in ihren Erzählungen auf, die dies zum Ausdruck bringen. Sie wissen, dass sie in Food webs ${ }^{21}$ leben und haben Respekt davor.

\footnotetext{
19 Vgl. Darnhofer u.a. 2016.

20 Mauss 1990, S. 17-18.

21 Alle Lebewesen befinden sich in Food webs, die aus der Verknüpfung von Nahrungsketten bestehen und den komplexen Zusammenhang und das Miteinander-Verbunden-Sein auf diesem Planeten repräsentieren. Vgl. Puig de la Bellacasa 2017, S. 69-94.
} 


\section{Austausch, Abhängigkeiten, Einbettung}

Die deutlich spürbaren Folgen des Klimawandels schaffen es gegenwärtig zum ersten Mal in der Geschichte, dass sich breite Bevölkerungsschichten über die Folgen der modernen Produktionsbedingungen den Kopf zerbrechen. Die Mondlandung vermittelte 1969 distanzierte Bilder des Planeten Erde, die damals wohl zum ersten Mal als gemeinsamer Lebensraum aller Menschen vorstellbar wurde. Nun scheint es, dass der Klimawandel dieses Bewusstsein sinnlich spürbarer macht. Denn er vermittelt nicht die Souveränität, dass die Menschen sich über das Irdische erheben könnten, sondern unterwirft sie eher den Naturvorgängen und lässt den Zusammenhang auch als Abhängigkeiten fühlbar werden. Das kann eine Chance für eine gesellschaftliche Transformation sein. Um die Qualität der materiellen, sozialen und symbolischen Eingewobenheit der Menschen so $\mathrm{zu}$ beschreiben, dass auch neue Dimensionen der umweltlichen Einbettung sichtbar werden, wählte Haraway in ihrer jüngsten Publikation ${ }^{22}$ das Wort "sympoietisch «, das die Umweltwissenschaftlerin Beth Dempster ${ }^{23}$ vorgeschlagen hat. Dempster wollte mit ihrer Wortschöpfung aus den griechischen Begriffen sym - »mit« - und poiesis - „Erschaffung«, die Abhängigkeiten und die Austauschprozesse zwischen lebenden Organismen ins rechte Licht rücken. Denn alle Lebewesen dieses Planeten existieren miteinander und es gibt mehr, das sie verbindet, als trennt. Die großen klassischen Theorien verlocken dazu, die alltäglichen Mikroprozesse arbeitender Menschen entlang von Kategoriensträngen wie Natur/Kultur, Mensch/Tier, Arbeit/Spiel, Produktion/Reproduktion, Stadt/Land, männlich/weiblich usw. zu sortieren. Für eine am (Über-)Leben orientierte Wirtschaft wäre es aber besser, sämtliche ökonomisch relevanten Handlungen als sozial und regional sowie zeitlich gebundene Strategien zur Bestreitung des je individuellen Lebensunterhaltes zu erfassen, welche diese Dichotomien der analytischen Wissenschaften ständig überschreiten. Darauf hat die feministisch-ökonomische Geografin

22 Haraway 2018, S. 47-83.

23 Dempster 1998. 
J. K. Gibson-Graham nachdrücklich hingewiesen. ${ }^{24}$ Die Erhebungen in der Oststeiermark waren konzeptuell von vorneherein vom Widerspruch zwischen den Ansprüchen des ökologischen Landbaus und den niedrigen Preisen der agrarindustriellen Konkurrenz geprägt. Wie können Betriebe in diesem Widerspruch Wirtschaftsstile entwickeln, die umweltschonende Arbeitspraktiken mit angemessenen Preisen verbinden? Betriebe müssen sich im ökonomischen Umfeld bewähren und verfügen über je völlig unterschiedliche Böden, Menschen und finanzielle Rücklagen. Gibson-Graham schlägt vor, näher bei den erhobenen Daten zu bleiben und die "starken « Theorien nur vorsichtig an das Datenmaterial anzulegen. Der Alltag wirtschaftender Menschen, meint sie, ist eine »chaotische Landschaft ${ }^{25}$ aus verschiedensten Praktiken, an deren Komplexität Theorien herangetragen werden, die den Weizen von der Spreu trennen helfen sollen. Dies mag der besseren Kommunikation unter Wissenschaftler*innen dienen, unterbindet aber das Aufbrechen ihrer Denktraditionen. Wenn eine Biobäuerin ihren Kräuterfrischkäse zehn Jahre lang an ein Fünfsternehotel liefert, heißt das noch lange nicht, dass sie ihren Betrieb agrarindustriell strukturiert und dass ihr Vorgehen auch allen anderen Käseproduzent*innen als Strategie weiterempfohlen werden sollte. Das Moment der Flexibilität und das unvorhersehbare taktische Vorgehen so genannter resilienter Betriebsführer*innen geraten aus dem Blick. Theoretische Scheuklappen können dazu verleiten, das Einmalige und Unnachahmliche zu übersehen. Gerade die so genannten »neuen Bauern und Bäuerinnen ${ }^{26}$ stellen keine einheitliche Gruppe in Europa dar, obwohl zahlreiche agrarsoziologische Studien das vermitteln wollen und einen Kriterienkatalog dazu entwickelt haben. ${ }^{27}$ Diese Studien liegen nicht falsch, folgen jedoch den klassischen Vorgangsweisen der Soziologie, die eine Typenbildung vornimmt, die vielleicht angesichts eines derart raschen Wandels ökonomischer Bedingungen und angesichts großer

\footnotetext{
24 Gibson-Graham 2014.

25 Gibson-Graham 2014, S. 148.

26 Van der Ploeg 2018b.

27 Milone \& Ventura 2019; Van der Ploeg 2018b.
} 
regionaler Unterschiede wenig verlässliche Aussagen über die Zukunft bäuerlicher Betriebe bietet. Die agrarsoziologischen Forschungen der 1990er Jahre lieferten z.B. eher pessimistische Ergebnisse vom »Niedergang der lokalen Ökonomien ${ }^{28}$ und gingen von einer intrinsischen Verbindung traditioneller Bauerngesellschaften mit lokalen Ökonomien aus. Christa Müller schilderte in ihrer ausgezeichneten Studie den Mentalitätswandel bäuerlicher Produzent*innen, die ihr traditionelles umwelt- und suffizienzorientiertes Denken zugunsten einer profitorientierten Anschauung aufgaben. Müller unterscheidet zwischen einer Außenwirtschaft und einer Innenwirtschaft der bäuerlichen Familienbetriebe und kommt zu dem Schluss, dass die erzwungene Abhängigkeit vom Weltmarkt letztlich die noch verbleibende Subsistenz - die Innenwirtschaft - »entökonomisierte ${ }^{29}$ Damit meint sie, dass diese Innenwirtschaft mehr oder minder zu einem Hobby der Bäuerinnen wurde. Doch mit ihrer Wortwahl hat sie den Denkstil der modernen Betriebswirtschaftslehre übernommen und die dörfliche Realität der wirtschaftswissenschaftlichen Dichotomie bezahlt/unbezahlt unterworfen. Zwischen den Eigenschaftswörtern bezahlt und unbezahlt erstreckt sich ein Raum von Möglichkeiten, die erst benannt werden müssen. Um wesentliche Beiträge zum Gemeinwohl nicht unsichtbar werden zu lassen, ist es notwendig, die wissenschaftliche Beschreibung der Realität anzupassen statt umgekehrt. Sonst wird mit der Übernahme dieser vereinfachenden Dichotomie einmal mehr unsichtbar, dass die Subsistenzwirtschaft ohne finanziellen Profit gleichwohl einen bedeutenden ökonomischen Beitrag leistet, wie feministische Theoretikerinnen schon seit den 1960er Jahren darlegen. ${ }^{30}$ Die Begriffe der rein profitorientierten Betriebswirtschaft erwecken den Eindruck, dass die häusliche Produktion nichts zum Auskommen beiträgt, weil im Supermarkt billigere Konfitüren, Suppen und Würste angeboten werden. Dies entspricht jedoch nicht der Wahrheit. Häusliche Produktion mag kein Geld einbringen, sie kann es aber 
sparen, außerdem ist sie sozial und symbolisch wirksam und sorgt für eingebettete Nahrungsmittel, die Hersteller*innen ebenso wie Essende in Beziehung setzen und mit Sinn versorgen. Solche Beziehungen stellen die Grundlage jeder funktionierenden Marktwirtschaft dar. Werbung für Markenwaren versucht z.B. genau diese Einbettung so manchen industriell erzeugten Produkten künstlich hinzuzufügen. Bezeichnungen wie »Mit Liebe gekocht« oder »Nach Großmutters Rezept« oder »Ein gutes Stück Heimat« etc. simulieren nicht vorhandene Beziehungen und sollen bei den Konsument*innen Vertrauen erzeugen. Diese Werbungen beweisen, dass es um Werte geht, die ökonomisch relevant sind. Menschen brauchen diese sinnstiftenden Beziehungen ebenso wie pestizidfreie Feldfrüchte. Daniel Miller hat daher sogar die Einkaufstätigkeiten und das Auswählen der Waren als kulturschaffende Tätigkeiten bezeichnet, weil dabei aus vereinzelten fremden Dingen Bausteine für das soziokulturelle Konstrukt "Haushalt « entstehen, das sinnstiftend wirkt. ${ }^{31}$ Erst recht gilt das für häusliche Nahrungsmittelherstellung. Übertragen auf die bäuerlichen Betriebe heißt das, dass in der Spätmoderne nun auch die unbezahlte häusliche Herstellung von Lebensmitteln, die in der klassischen Wirtschaftstheorie bis in die 1960er Jahre der Reproduktion der bezahlten Arbeitskräften $\mathrm{zu}$ dienen hatte, dabei aber noch sichtbar war, nun in unsichtbare Reproduktionsarbeit verwandelt wurde und dadurch gemäß dieser Theorie nicht mehr zu ökonomisch verrechenbaren Tätigkeiten zählte. ${ }^{32} \mathrm{Ab}$ den 1970er Jahren verlor die Rolle der Hausfrau ihre gesellschaftliche Anerkennung und die »doppelte Vergesellschaftung « ${ }^{33}$ der Frau wurde in allen Schichten zur Selbstverständlichkeit. Doch eine Wirtschaftstheorie, die Natur und Hausarbeit als unendlich verfügbare Güter voraussetzt, die einerseits nichts wert sein sollen, während die Wirtschaftsleistung doch andererseits ohne sie nicht

$31 »[$...] consumption is used to extract culture as the selfconstruction of humanity from the intractable but essential institutions of the modern world, such as the market or bureaucracy.« Miller 1995, S. 34.

32 Kosnik 2019 und 2018.

33 Becker-Schmidt 2003. 
zustande käme, ist natürlich falsch. ${ }^{34}$ Seit den 1970er Jahren ignorieren neoliberale Wirtschaftstheorien sowohl Subsistenzarbeit als auch Konsumarbeit völlig. Dies führt einerseits zu steigenden Bedürfnissen nach regionalen Lebensmitteln - weil Lebensmittel eben doch mehr sind als nur Kalorien mit Geschmack - doch andererseits auch zu steigenden Arbeitszeiten auf naturnah wirtschaftenden bäuerlichen Betrieben, die jetzt mit niedrigen Weltmarktpreisen mithalten und zusätzlich unbezahlte affektive Arbeit leisten müssen. Affektive Arbeit bindet unter industriekapitalistischen Bedingungen die mehr oder minder fremden Waren und zwar ganz besonders Lebensmittel in sinnstiftende Beziehungsnetze ein und hilft, sie in die Weltauslegung und in die Lebenswelten der Konsument"innen $\mathrm{zu}$ integrieren. Die erfolgreichen Biomarken »Ja Natürlich« und »Zurück zum Ursprung«, die in Österreich von Supermarktketten entworfen wurden, werben mit Beziehungen. Fleisch, Eier und Milchprodukte werden mit ihrer Einbettung, d.h. mit Herkunftsnamen und Bildern ihrer Produzent*innen in idyllischer Natur verkauft. Der Anteil unbezahlter Arbeit, die letztlich "aus Liebe« zum Boden (ohne nationalistische Ideologie) und $\mathrm{zu}$ den essenden Mitbewohner*innen verrichtet werden, ist jedoch auf Biobetrieben sehr hoch. Denn Biobetriebe, die an große Handelsketten liefern, unterliegen denselben Wettbewerbsgesetzen wie konventionelle Betriebe und daher setzt der Markt sie deutlich stärker unter Druck, möglichst billig zu produzieren. So wird der ursprüngliche Gedanke des Wirtschaftens im Einklang mit der Natur durch die Gesetze des Marktes pervertiert. Biomonokulturen und Biomasttierzuchtanstalten entstehen. Sorgsame Landwirtschaft verwehrt sich diesen Vertriebsschienen, steht aber dennoch in Konkurrenz mit

34 Die häusliche Arbeit der Frauen fand bis in die 1960er Jahre Anerkennung. Lohn wurde jedoch vorrangig den Männern als »Familienernährern « ausgezahlt, um das Machtgefälle zwischen den Geschlechtern aufrecht zu erhalten. Der Spätkapitalismus verleugnet den Wert häuslicher Subsistenzarbeit und Sorgearbeit vollends und verdrängt die Geschlechterfrage, während er die Frauen (durch niedrige Löhne und unbezahlte Sorgearbeit) doppelt ausbeutet. Vgl. Soiland 2016. 
billigen Lebensmitteln. Der persönliche Einsatz und die Bereitschaft, je nach Saison sehr viel zu arbeiten sind hier sehr hoch. Die moderne Betriebswirtschaftslehre hält jedoch weiter daran fest, dass unbezahlte Arbeiten für Menschen, Regionen und Nahrungsmittelqualität keine Rolle spielen. Da heute jedoch belegt werden kann, dass Ökonomie nicht auf das Feld der geldbasierten Austauschprozesse beschränkt ist, verdeckt ein Begriff wie »Entökonomisierung« im Grunde, dass es sich um willkürliche kulturelle Entscheidungen handelt, was bezahlt wird und was nicht. Denn wirtschaftliches Handeln wird hier auf eine einzige ökonomische Theorie reduziert, die demnächst den Planeten in einen Kollaps zwingen könnte. Umso wichtiger ist es, diese mächtige Theorie, die behauptet, dass es bei erfolgreichen Betrieben nur um rationales Kalkül und finanziellen Profit ginge, zu entthronisieren. Die Organisationsentwicklung hat längst vorgezeigt, wie sehr der Bestand von großen Firmen von deren sozialen Klimata und Firmenkulturen abhängen kann. ${ }^{35}$

Im agrarsoziologischen Forschungsfeld wies Robert Hettlage schon 1989 darauf hin, dass bäuerliches Wirtschaften von Theoretiker*innen häufig als konservativ beharrend und als irrational dargestellt würde. ${ }^{36}$ Dies ist ein Schicksal, das Bauern und Bäuerinnen mit den Hausfrauen teilen. Doch solche Aussagen bringen die mittlerweile stark kritisierte Überheblichkeit von Wissenschaftler*innen zum Ausdruck, die das Modell des modernen Wirtschaftskapitalismus niemals zu hinterfragen gelernt haben. Die ökonomischen Diskurse des 20. Jahrhunderts ignorierten die Abhängigkeit der industriellen Expansion und des Finanzkapitalismus von der Subsistenzwirtschaft jeglicher Art, sei sie bäuerlich oder haushälterisch. Allein Kenneth Galbraith hat schon sehr früh mit seinem Begriff der »Konsumarbeit « nachdrücklich darauf hingewiesen, dass die Industrie ihre Gewinne der unbezahlten, meist weiblichen Arbeit in Haushalten verdankt, das heißt also der weitgehend unbeachtet gebliebenen, völligen sozialen und kulturellen Umgestaltung der Gesellschaft und ihrer Ausrichtung auf die Industrialisierung der Lebens-

35 Becker \& Langosch 2016.

36 Hettlage 1989, S. 300. 
mittelherstellung. ${ }^{37}$ In Zeiten der Wachstumskritik kann der Anthropologe Gudeman ${ }^{38}$ jedoch das Desinteresse der Wirtschaftswissenschaften gegenüber den Praktiken in Haushalten nur mehr als befremdend und kurios beurteilen, denn seine Forschungen zeigen deutlich, dass Subsistenzwirtschaft und Kapitalismus mindestens gleichberechtigte Formen des Wirtschaftens darstellen.

»I see economy by its institutions or spheres, ranging from the house to meta-finance. Each sphere secures and distributes wealth distinctively from sharing to risk-taking, although the spheres and distributional modes may be combined. The spheres might be likened to a division of labor. The power of capital as well as closely held knowledge and social relationships takes place within this structure. ${ }^{39}$

Es ist also an der Zeit, die längst vorliegenden wissenschaftlichen Erkenntnisse als Grundlage wirtschaftspolitischer Entscheidungen heranzuziehen und sorgsame Formen des Wirtschaftens ernst zu nehmen, von denen in Zeiten des peak soil ${ }^{40}$ wahrscheinlich das Überleben der Menschheit im 21. Jahrhundert abhängen wird. ${ }^{41}$

\section{Resilienz und Bricolage}

Die globale Beschleunigung von Transaktionen und die daraus resultierende Instabilität von Märkten haben in den letzten zwei Jahrzehnten Resilienz zu einem Schlüsselgriff der Organisationsentwickler*innen werden lassen. Parallel dazu nimmt der Begriff aber auch in der Psychologie und in den Umweltwissenschaften einen prominenten Rang ein, geht es doch um die allseits erwünschte Fähigkeit, mit unvorhersehbaren oder unberechenbaren Widerständen, Notlagen und Verlus-

\footnotetext{
37 Galbraith 1974.

38 Gudeman 2016, S. 2.

39 Gudeman 2016, S. 5.

40 Vgl. Politische Ökologie 119 (2010).

41 Vgl. Shiva 2008.
} 
ten zurecht zu kommen, ohne dass Gesundheit oder Betrieb Schaden nehmen. Forschungsprojekte aus unterschiedlichsten Disziplinen stellen daher die Frage, wie Resilienz herzustellen sei, oder wie und unter welchen Bedingungen man resilientes Verhalten lernen könne. Die Agrarsoziologin Ika Darnhofer ${ }^{42}$ konzipiert auf der Grundlage ihrer Forschungen über bäuerliche Familienbetriebe Resilienz im Rahmen einer relationalen Soziologie und mit Rückgriff auf die von Gilbert Simondon ${ }^{43}$ beeinflussten Theorien des Philosophen Gilles Deleuze als ein "Werden ${ }^{44}{ }^{44}$ Sie verabschiedet Perspektiven, die Resilienz bisher als festschreibbare und eventuell wiederholbare Lernprozesse einzugrenzen versuchten. Vielmehr eröffnet sie ein interdisziplinäres Spektrum an Herangehensweisen. Vor allem ihre Übertragung Claude LeviStrauss' Metapher vom "wilden Denken ${ }^{45}$ auf bäuerliches Wirtschaften erweist sich als äußerst hilfreich, um das komplexe und kreative Handeln mancher Betriebsführer*innen im ökologischen Landbau besser zu verstehen.

Im Rahmen eines »wilden Denkens«, das er dem »domestizierten« und ergebnisorientierten Denken der rationalen europäischen Wissenschaftler*innen entgegenstellte, verwendete Lévi-Strauss die Bezeichnung bricolage. Ein Begriff, der mit »Bastelarbeit« oder auch »Pfusch« $\mathrm{zu}$ übersetzen ist und daher eine gewisse Geringschätzung zum Ausdruck bringt, die aus heutiger Sicht als eurozentristische Überheblichkeit kritisiert werden muss. Der Kulturanthropologe hielt z.B. die kunstvollen Erzählstrukturen, die brasilianische Stammeskulturen aus der Verknüpfung mythologischer Bausteine entstehen lassen, nicht für planvolles Vorgehen sondern für Bastelei oder mythopoietisches Schaffen. Als Strukturalist versuchte er aus den Relationen zwischen einzelnen Bausteinen der mythologischen Erzählungen kulturübergreifende Regeln zu abstrahieren, um allgemeine Gesetze für den Mythenbau festzustellen. Als ihm das aber nicht zufriedenstellend gelang, bezeichne-

\footnotetext{
42 Darnhofer u.a. 2016, S. 116.

43 Simondon 2007, S. 29-45.

44 Iliadis 2013.

45 Lévi-Strauss 1989.
} 
te er diese mythopoietischen Gebilde als unvorhergesehene Ergebnisse von Improvisationen. Das heißt, er erkannte kein strategisches, regelgeleitetes Vorgehen darin, sondern nur ein Experimentieren auf gut Glück ${ }^{46}$ - eine Vorgangsweise, die in Europa damals wie heute nicht besonders viel Anerkennung findet. Das »wilde Denken«, das er den Bororo oder den Nambikwara im Amazonasgebiet zuschrieb, ist nicht nur von rationalen Absichten geleitet, sondern vermischt ständig rationale Vorhaben mit Kompromissen oder Umwegen, die aus Gründen gewählt werden, die sich jeder Verallgemeinerung entziehen: Neugier, Spaß am Tun, Lust an Varianzen, Inspiration durch aktuelle Ereignisse, Wetterlagen oder Notfälle, was auch immer. Der Bastler oder die Bastlerin passt seine oder ihre Pläne an die Möglichkeiten und Ressourcen an, die zur Verfügung stehen und geht mit beschränkten Materialien kreativ um. ${ }^{47}$ Solche Improvisationen sind auch für kleinbäuerliche Biobetriebe mit beschränkter technologischer Ausstattung typisch. ${ }^{48}$ Die von uns untersuchten Betriebsführer*innen mussten sich das Know-How über Tiere, Pflanzen oder Käseerzeugung sowie die Anbaumethoden in Auseinandersetzung mit den örtlichen Gegebenheiten und der vorhandenen oder nicht vorhandenen betrieblichen Ausstattung auf sehr individuellen Wegen erwerben. Sie waren von Anfang an Bastler*innen einer Existenz, die so weder von ihnen selbst, ihren Herkunftsfamilien noch von den Behörden vorher angedacht war. Im Gegenteil: Viele Schwierigkeiten entstanden dadurch, dass behördliche Auflagen an nicht mehr praktikablen oder agrarindustriellen Vorstellungen von Tierhaltung und Pflanzenzucht festhielten und Innovationen gegenüber hinderlich wirkten.

Auch die Beziehungen zu anderen Bauern und Bäuerinnen wurden nicht immer positiv geschildert. Manche konventionell wirtschaftende Betriebsführer*innen halten ökologische Betriebsideen für unrentabel und verweigern auch den erfolgreichen Betrieben Anerkennung. Das äußert sich in abfälligen Bemerkungen und Witzen

47 Bies 2014, S. 212.

48 Darnhofer 2016, S. 118; Darnhofer 2014. 
unter den Männern im Dorf. Diese skeptischen Nachbarn führen selbst meist die seit den 1950er Jahren von den Landwirtschaftskammern der Landjugend regelrecht dogmatisch eingehämmerten Praktiken zur Effizienzsteigerung ${ }^{49}$ weiter. Da das Risiko eines Umstieges ins ökologische Wirtschaften tatsächlich hoch ist, beobachten sie eine ökologisch ausgerichtete Betriebsführung nicht nur mit Neugier, sondern fürchten manchmal auch die In-Frage-Stellung ihrer eigenen Entscheidungen, die dem Zwang zum Wachstum geschuldet sind. Die Tatsache, dass ökologische Betriebe oft so lange wie möglich mit alten Maschinen weiterarbeiten und in ihrer technologischen Ausstattung bewusst auf einem sehr niedrigen Niveau verharren, führt hin und wieder zu verächtlichen Blicken von Anrainern, die nur die Anschaffung neuer Maschinen als Zeichen des Erfolgs lesen können. Besondere Fähigkeiten, die etwa zum Einsatz modernster digitaler Medien im Kundenkontakt und bei der Vernetzung mit gleichgesinnten Expert*innen für Landbau führen, werden dabei übersehen. Die Betreiber"innen ökologischen Landbaus müssen es aushalten, in ihren Dörfern von einigen Mitbewohner"innen als Außenseiter*innen betrachtet und entgegen aller Evidenz als nicht ernst $\mathrm{zu}$ nehmende oder sogar realitätsferne Menschen beurteilt zu werden. Das macht ein Leben und Wirtschaften auf dem Land nicht leichter. Obwohl die Landwirtschaftskammer das »neue Leben auf dem Land« fördern will, verbreitet sie in der Beratung dennoch häufig wirtschaftsrationale Betriebskonzepte. Selbst wenn Vertreter*innen der Kammer ökologischen Landbau oder CSA-Konzepte als Lösung für betriebliche Probleme empfehlen, so geschieht dies im Kontext der klassischen Betriebswirtschaftslehre, die Trends aufnimmt, ohne das effizienzorientierte Weltbild zu ändern. Der "Geist des Kapitalismus ${ }^{50}$ bleibt einstweilen in diesen bäuerlichen Organisationen der vorherrschende. ${ }^{51}$ Welche Eigenschaften und Ressourcen es aber für

49 Vgl. Kaser u.a. 2003, S. 329-338.

50 Vgl. Boltanski \& Ève 2003.

51 Die Autorin wurde z.B. für eine Weiterbildungsveranstaltung von Bäuerinnen eingeladen. Nachdem sie den Veranstalter*innen das Konzept ihres Vortrags 
sorgsame Landwirtschaft braucht, bzw. welche Persönlichkeiten und Kommunikationsfähigkeiten nötig sind, wissen institutionell tätige Berater*innen nur selten. Sorgsame Landwirtschaft ist kein Konzept, das sich in einer Broschüre zusammenfassen oder in Workshops unterrichten ließe. Alle befragten Betriebsführer*innen müssen knapp kalkulieren, dennoch kommt in den Gesprächen klar zum Vorschein, dass Geld in einem Bündel an Motivationen zwar eine bedeutende Rolle spielt, jedoch den Rahmen der persönlichen Weltanschauung nicht sprengen darf. Die stärksten Motive entspringen einem Weltbild und persönlichen Erfahrungen, die man in der Beratung nicht einfach weiterreichen kann. So gesehen bräuchten die "neuen Bauern und Bäuerinnen« auch neue Institutionen, die nicht auf den Erhalt alter Strukturen und jener Vorstellungen vom bäuerlichen Leben fixiert sind, die sich in den 1960er Jahren etabliert haben. Immerhin - so manifestiert sich ein "wildes Denken« - haben sie sich zu vernetzen gelernt. Da die herkömmlichen Fachberatungen der Landwirtschaftskammer ihnen wenig Neues vermitteln können, haben sie begonnen, selbst Netzwerke aufzubauen, die aber regionsübergreifend und z.T. auch international sind. Die erfolgreichen Betriebsführer*innen haben Praktika, Auslandsreisen und verschiedene berufliche Experimente hinter sich und sind den Behörden im Wissenserwerb bezüglich ökologischer Landwirtschaft weit voraus. Dieser Umstand bestätigt die Hypothese, dass Beziehungen Innovationsprozesse fördern, gleich ob es sich um Beziehungen $\mathrm{zu}$ Menschen oder $\mathrm{zu}$ nicht-menschlichen Lebewesen oder sogar zu Dingen handelt. Beziehungen erzeugen Wertschätzung und fördern die Generierung von neuem Wissen, das aus unpersönlichen Top-down-Strukturen und Lehrbüchern ohne interdisziplinärem Ansatz nicht gewonnen werden kann. Innovationen entstehen eben

mit Kritik an der Werbekampagne »Genusslandschaft « zugesandt hatte, wurde sie wieder ausgeladen. Das Marketing wird von Kammerbeiträgen teuer bezahlt, doch das Etikett »Cenusslandschaft« stellt keine kulturellen oder sozialen Beziehungen zur Region her, sondern setzt von Werbefachleuten am Schreibtisch erfundene Vertriebskonzepte um, die am Megatrend Erlebniskonsum ausgerichtet sind. 
immer durch »Bastelei«, das heißt durch nicht unbedingt zweckrationale Verknüpfung von Faktoren und durch das Verlassen der alten ausgetretenen Wege. Ein funktionierender ökologischer Kleinbetrieb ist gefordert, sich ständig anzupassen: Dem Wetter, den gesetzlichen Vorgaben, den wechselnden Interessen der Kund*innen und den Bedürfnissen der Mitarbeiter*innen. Diese Anpassung stellt jedoch keine Unterwerfung dar, wie sie das globale Nahrungsregime fordert, sondern sie entspringt einer inneren Bereitschaft mit der Umwelt in Beziehungen zu treten.

\section{Sorgsamkeit, relationale Güter, Lebens-Mittel}

Das Wörterbuch der Gebrüder Grimm unterscheidet Sorge von Sorgsamkeit. $^{52}$ Es beschreibt Sorgsamkeit als eine spezifische Qualität, die verschiedenste Tätigkeiten auszeichnen kann. Sorgsames Handeln stellt eine Vorbeugung ernster Sorgen dar. Somit ist Sorgsamkeit nichts das bedrückt oder belastet, sondern hat im Gegenteil noch mehr als die Sorge mit dem guten Leben zu tun. Sorgsamkeit impliziert eine Haltung der Aufmerksamkeit und Offenheit gegenüber Mitmenschen und Umwelt.

Der Sorgecharakter vieler biobäuerlicher Tätigkeiten rückte erst im Verlauf der Erhebungen und der Auswertung der Interviews ins Blickfeld. Vielfältige Austauschprozesse verbinden einzelne Menschen mit Gemeinschaften und ökologischen Systemen, sodass eine fürsorgliche Praxis rekonstruiert werden kann, welche die Unterscheidung zwischen Natur und Kultur oft aufhebt. Die Interviewpartner*innen selbst empfinden das auch so. Sorgsamkeit überschreitet die Grenzen zwischen den Spezies. Gerade in Biobetrieben muss oft entschieden werden, ob man dem Boden, den Pflanzen oder den Tieren auf Kosten des finanziellen Gewinnes mehr Zeit schenkt. Bei jeder Investition muss abgewogen werden, inwiefern sie sich nicht nur auf der ökonomischen sondern auch auf der ökologischen und emotionalen Ebene lohnen wird, oder 
ob das ökonomische Kalkül etwa dem Wohlbefinden der Tiere oder der Qualität der Früchte nachgereiht werden sollte. Die interviewten Akteur*innen äußerten solche Überlegungen häufig, denn sie verdinglichen weder die tierischen und pflanzlichen Lebewesen noch die Menschen, obwohl die Entscheidungsspielräume knapp sind. So wie die für diese Studie interviewten Personen sich und ihre Arbeit beschreiben, müssen wir sie als intrinsisch motiviert bezeichnen. Sie wollen nicht in erster Linie nur Geld verdienen, sondern sie wollen mit sinnvoller und selbstbestimmter Arbeit ihren Lebensunterhalt bestreiten und dabei ein gutes Leben haben. Das bedeutet, dass sie die nicht-menschlichen Lebewesen mit Respekt behandeln, dem die Effizienz nachgereiht wird. Soziologische Studien haben bäuerliche Sozialstrukturen oft dichotomisch den urbanen gegenübergestellt und den ersteren Irrationalität und traditionales Denken, letzteren hingegen Rationalität und technikaffines Denken unterstellt. ${ }^{53}$ Sich der Marktrationalität zu widersetzen und mit weniger als 20 Hektar seine Produkte in Konkurrenz zum Weltmarkt absetzen zu wollen, könnte durchaus als irrational bezeichnet werden. Doch Rationalität hängt davon $a b$, in welchem System man sich beheimatet fühlt. Ganz anders als die Soziolog*innen konnten Kulturanthropolog"innen die eher ablehnenden Haltungen gegenüber Neuerungen in bäuerlichen Gesellschaften als durchaus rational in Bezug auf Wertesysteme einstufen, die Gewinnmaximierung nicht an die erste Stelle setzten. ${ }^{54}$ Der Behauptung, dass Menschen aus bäuerlichen Strukturen beharrlich am Althergebrachten festhalten würden, stellten sie sogar die Beobachtung entgegen, dass sich Mitglieder einfacher bäuerlicher Gesellschaften durch eine besondere Experimentierfreudigkeit auszeichnen. ${ }^{55}$ Denn im relationalen Weltbild von Subsistenzbäuer*innen sehen Experimente anders aus, als moderne Wissenschaftler"innen das erwarten würden. »The traditional agriculturalist subsists not merely in a complex environment, he contribu-

\footnotetext{
53 Hettlage 1989, S. 299.

54 Hettlage 1989, S. 300.

55 Johnson 1972.
} 
tes much of that complexity through his own labor. « ${ }^{56}$, formulierte der Anthropologe Allen Johnson im Hinblick auf die fast intime Verbundenheit armer Menschen mit dem Boden und den Pflanzen, die ihr karges Überleben sichern sollten. Aus heutiger Sicht erkannte Johnson damals die komplexen Beziehungen zwischen Landbearbeiter*innen und ihrer Umwelt und verlangte Wertschätzung für diese Art der Sensibilität, statt sie nur als vormodern und irrational einzustufen. Vielmehr müsste man marktrational agierende Bauern und Bäuerinnen der Gegenwart als einfallslos bezeichnen, wenn sie außer der Vergrößerung der Betriebe und dem Einsatz immer größerer Maschinen keine neuen Ideen haben. Tatsache ist jedoch, dass das Diktat des Marktes, dem sie sich durch die Aufnahme hoher Kredite unterworfen haben, kaum neue Ideen zulässt. Sorgsame Landwirt*innen haben sich zur rechten Zeit gegen einengende finanzielle Abhängigkeiten und für mehr Rücksicht auf die Natur entschieden. Der Begriff der sorgsamen Landwirtschaft scheint geeignet, um diese besondere Relationalität zu beschreiben, die die so genannten »neuen Bauern und Bäuerinnen« durch Umsicht, Rücksicht und Voraussicht herstellen. Aus rein wachstums- und gewinnorientierter Sicht könnte ihnen zwar vorgeworfen werden, dass ihr Arbeitsaufwand $\mathrm{zu}$ hoch und die Gewinne zu klein seien. Allerdings ignoriert diese Rechnung, dass ökologische Betriebe sinnvolle Arbeit anbieten und dem Gemeinwohl keine schädlichen Nebeneffekte wie erhöhten $\mathrm{CO}^{2}$-Ausstoß und Pestizide aufbürden. Reich wird man wahrscheinlich nicht. Der Arbeitsaufwand und die Risiken sind tatsächlich hoch. Wenn Spätfröste z.B. zwei Jahre hintereinander die Obsternte vernichten, dann kann das den Betrieb stark belasten, notfalls müssen die Betriebseigner*innen etwas dazuverdienen. Und wenn die Kund"innen Äpfel mit kleinen Schorfflecken nicht mehr akzeptieren wollen, kann das zu jährlichen Einbußen führen, auf die dann kreativ reagiert werden muss. Durch gezielte Werbung in der Region oder Angebote an Schulen, wo man den hervorragenden Geschmack der Früchte ins Bewusstsein bringt, steigt der Absatz vielleicht wieder. Dazu braucht es viel Kreativität und Flexibilität. Der Gewinn sammelt sich außerdem 
nicht nur bei den Bauern und Bäuerinnen, sondern manifestiert sich in der Bodengesundheit, dem Tierwohl und der hohen Qualität der Nahrungsmittel, die nicht teurer verkauft werden als Bioprodukte von Eco-entrepreneurs ${ }^{57}$ (siehe Kapitel Kosnik). Und zudem kann ein CSABetrieb auch als Zentrum eines Netzwerks fungieren, in dem man neue Menschen kennenlernt. Denn im Unterschied zur industriellen Landwirtschaft, wo die Böden immer unfruchtbarer, die Maschinen immer größer und die Menschen, die sie steuern, immer einsamer werden, bereichert sorgsame Landwirtschaft die Region durch positive Externalitäten. ${ }^{58}$ Dennoch erhält sie wie der größte Teil der Sorgetätigkeiten in dieser Gesellschaft weiterhin zu wenig Anerkennung.

Im Deutschen hat sich mittlerweile Care als Synonym für Pflegeoder Sorgearbeit eingebürgert, die entweder bezahlt oder unbezahlt durchgeführt wird. ${ }^{59}$ Joan Tronto und Berenice Fischer definierten den Begriff caring work in den 1990er Jahren mit Bezugnahme auf Karl Marx' »Reproduktionsarbeit«.

"In the most general sense, care is a species activity that includes everything we do to maintain, continue, and repair our world so that we may live in it as well as possible. That world includes our bodies, our selves, and our environment, all of which we seek to interweave in a complex, life-sustaining web. ${ }^{60}$

Tronto bezieht also ausdrücklich die Sorge um die Umwelt und die nichtmenschlichen Lebewesen mit ein. Feministische Debatten um die ungleiche Verteilung unbezahlter Arbeit zogen seit den 1960er Jahren präzise historische und soziologische Analysen der Hausarbeit

In Anlehnung an den Begriffentrepreneurial agriculture von Ploeg (2018b) für agrarindustrielle Lebensmittelproduktion.

58 Gorz 2004, S. 20. Gorz versteht darunter gelingende Selbstregulierung zwischenmenschlicher Beziehungen, die auf Empathie und Anerkennung beruhen. Sie ist nicht quantifizierbar und nicht austauschbar, stellt jedoch die Voraussetzung für profitable Produktionsstrukturen dar und wird unbezahlt von Unternehmen verwertet.

59 Winker 2015, S. 17.

60 Fisher \& Tronto 1990, S. 40. 
und der Pflegetätigkeiten nach sich, die Tronto $\mathrm{zu}$ der essentiellen Erkenntnis führten, dass Care mit Bedürfnisbefriedigung $\mathrm{zu}$ tun hat und immer Beziehungen stiftet. "Care is about meeting needs, and it is always relational. «" ${ }^{61}$ Die Analogien zwischen Pflegearbeit, Subsistenzarbeit und bäuerlicher Arbeit haben Bennholdt-Thomsen u.a. schon vor vier Jahrzehnten herausgearbeitet. ${ }^{62}$ Sorgsame Landwirtschaft ist sowohl reproduktiv als auch produktiv und führt vor Augen, wie gefährlich diese Unterteilung ist. Denn eine rein auf Produktion ausgerichtete Landwirtschaft zerstört auf Dauer die Grundlagen des Wirtschaftens durch negative Externalitäten (Zerstörung des Humus, Verunreinigung des Wassers, Bodenverdichtung etc.). Im sozialen Bereich erzeugt die Missachtung der Pflegearbeit als Quelle volkswirtschaftlichen Reichtums große soziale Ungleichheiten zwischen den so genannten produktiven und reproduktiven Branchen und vergrößert außerdem den Gender Pay Gap aufgrund der geschlechtsspezifischen Zuteilung unbezahlter oder schlecht bezahlter Pflegearbeit.

Bäuerliche Tätigkeiten waren besonders in der untersuchten Region der Oststeiermark bis in die 1960er Jahre mit einer starken Beziehung der Arbeitenden zu Erde, Tieren und sozialer Gemeinschaft verknüpft. Diese Gemeinschaft war außerdem oft zugleich die Gemeinschaft der Konsument*innen, denn Fleisch, Korn, Milchprodukte und etwa Kartoffeln wurden auch von den Familien selbst verzehrt. Dies trifft auch auf andere österreichische Regionen mit kleinbäuerlichen Betrieben und geringem Technologieeinsatz zu. Ziel der bäuerlichen Arbeit war der Erhalt des Betriebes und der Familie. Zwar hing der Erfolg vom Verkauf der Produkte ab, doch bei den meisten Tätigkeiten auf dem Hof standen vor der Vermehrung des Geldes der Betrieb selbst und das gute Leben der von ihm Abhängigen an erster Stelle. Eine Betriebsvergrößerung oder Ertragssteigerung wurde erst $a b$ den 1960er Jahren zwingend. ${ }^{63}$ Damals begann unter dem Druck zur Anpassung an Weltmarktbedingungen auch in den entlegenen Gebieten Ös-

\footnotetext{
61 Tronto 2015, S. 4.

62 Bennholdt-Thomsen u.a. 1983.

63 Vgl. Kaser u.a. 2003, S. 333.
} 
terreichs mit kleinen Betrieben die Spezialisierung der Landwirtschaft. Die Entwicklung komplexer Maschinen und pharmazeutischer Produkte sowie spezielle Tierzüchtungen ließen Investitionen nun auch bei kleinem Betriebskapital nicht nur rentabel sondern sogar überlebensnotwendig erscheinen. Kaser und Stocker ${ }^{64}$ zeigen - ebenso wie Müller für Deutschland - den Mentalitätswandel, der in der bäuerlichen Bevölkerung Österreichs in der 2. Republik parallel zur Abwanderung in die Städte stattfand. ${ }^{65}$ Die Forschungen von Heide Inhetveen und Mathilde Schmitt ${ }^{66}$ betonen aber eine doppelte bzw. widersprüchliche Mentalität: Einerseits wollen Landwirt*innen kleinerer Betriebe nicht völlig abhängig von den Marktmechanismen werden, andererseits entwickeln sie dennoch eine gutes unternehmerisches Gespür. Wie Andrea Heistinger in ihrer Analyse der Interviews ausarbeitet, so entwickeln sich sorgsame Einstellungen aus den je einmaligen Lebenserfahrungen der einzelnen Personen. Sie treten nicht zufällig auf, sondern wurzeln in spezifischen familiären Erlebnissen und Strategien aus der Vor- und Nachkriegszeit. Sie kommen also aus einem lebendigen Feld, das auf jede heranwachsende Generation einwirkt. Es ist ein Feld aus vielfältigen Beziehungen, das Umgangsweisen mit Krisen und die Resultate des Handelns speichert. Der Beschluss von Martin Bergmann, die profitorientierte und profitable Geflügelzucht des Vaters zu schließen und auf einen CSA-Betrieb mit Bioprodukten umzustellen, erfolgte z.B. nicht gegen die Entscheidungen seiner Vorfahren, sondern folgte in gewissem Sinn ihren wohlüberlegten Handlungsweisen. Denn die ökonomischen Bedingungen hatten sich geändert und dem jungen Mann war bewusst, dass er an einem Scheideweg stand. Das lebendige Beziehungsfeld aus dem heraus er seine Entscheidung traf, weist sowohl eine historische Dimension als auch die Dimension der Sorge auf. In beiden Dimensionen hoffen die Gebenden nicht auf eine Gegengabe. Die Eltern geben in dem meisten Fällen etwas an die Kinder weiter ohne Wunsch nach Bezahlung. Unbezahlt Sorgende rechnen zwar mit einem

64 Kaser \& Stocker 1987.

65 Vgl. Hofreither 1997, S. 641-651.

66 Inhetveen \& Schmitt 2010, S. 111-136. 
Nutzen, jedoch nicht (nur) für sich selbst, sondern für Mitmenschen, das Gemeinwohl oder die Mitwelt im weiteren Sinn inklusive nichtmenschlicher Lebewesen und ihrer nachfolgenden Generationen. Zwar handelt es sich um Reziprozitätsbeziehungen, jedoch geht es nicht um Verrechnung. Denn die Beziehungen sind intrinsisch motiviert und daher ad hoc lohnend. Die Bezugnahme auf ein »wir«, zu dem im Fall ökologischen Landbaus auch die zoologischen und botanischen Mitwesen zählen, erzeugt Beziehungen, die sich bei diesen Betrieben in der materiellen Qualität der Nahrung niederschlagen und die unverkäufliche Voraussetzung für Ernährungszufriedenheit bilden. Durch solche spezifischen sozialen Beziehungen und Interaktionen entsteht ein immaterielles "Drittes«, das der Soziologe Pierpaolo Donati als relationales Gut bezeichnet. ${ }^{67}$ Vorschriften, Auflagen oder materieller Zwang können dieses Gut nicht einfordern. Der Markt kann relationale Güter zwar verwerten aber nicht produzieren, sondern nur in der Werbung vortäuschen. Eine kluge Verknüpfung von Markt und staatlichen Maßnahmen kann die Entstehung relationaler Güter jedoch fördern. Denn sie stellen den besonderen Gewinn einer Region dar, in der sorgsame Landwirtschaft betrieben wird. Donati nennt folgende Bedingungen für ihre Entstehung: Die Teilnehmenden haben persönliche Kontakte und Interesse füreinander, sie achten auf die Bedürfnisse der Involvierten, die das relationale Gut nur miteinander herstellen und genießen können. Relationale Güter können nicht produziert werden sondern emergieren in einem Beziehungsfeld. Sie benötigen eine gewisse Dauer, weil Beziehungen keine punktuellen Phänomene sind, sondern historisch wachsen müssen. Wären keine Menschen beteiligt, spräche man von einem Ökosystem, einer Lebensgemeinschaft von unterschiedlichen Organismen und ihrer unbelebten Umwelt. Da aber Menschen und ihre kulturelle Dimension hinzukommen, sieht die Sympoiese anders aus. Sorgende Landwirtschaft schafft lebendige Felder des Austauschs, denen echte Lebens-Mittel entspringen, die materiell, sozial und symbolisch satt machen. 
In der sorgsamen Landwirtschaft stehen Menschen zwar in einem profitorientierten Austausch aber sie respektieren und unterstützen immer auch einen Gabenfluss, der im Gegensatz zu den sozial unwirksamen Deals des Marktes das gute Leben in seinen körperlichen, emotionalen und kulturellen Dimensionen garantiert. 



\section{"Es muss net alles immer nur auf Gewinn auf'baut sein." Zusammenfassung und Ausblick}

Elisabeth Kosnik, Andrea Heistinger, Gabriele Sorgo

Wie aktuelle Studien belegen, liegt Österreich sowohl bei der Produktion als auch beim Konsum ökologischer Produkte im EU-Spitzenfeld. ${ }^{1}$ Jede fünfte Landwirtschaft in Österreich wird mittlerweile ökologisch bewirtschaftet. Gleichzeitig dominieren wenige Supermarktketten den Vertrieb ökologischer Waren in Österreich. ${ }^{2}$ Ökologische Betriebe unterliegen längst dem Wachstums- und Rationalisierungstrend, was zunehmend zu einer Kritik an dieser »Konventionalisierung « führt, wie in den Kapitel von Andrea Heistinger und Elisabeth Kosnik nachgezeichnet wird. Diese Entwicklung hin zu einer konventionalisierten eco-entrepreneurial agriculture - in Anlehnung an den Begriff der entrepreneurial agriculture des Agrarsoziologen Jan Douwe van der Ploeg - ist allerdings kein flächendeckender Trend. ${ }^{3}$ Auch, oder gerade, im ökologischen Bereich gibt es Bäuerinnen und Bauern, die dem Trend des»Wachsen oder Weichen« kritisch gegenüberstehen und nach alternativen Wegen der Produktion und Distribution suchen. Diese Landwirt*innen standen im Fokus der vorliegenden Studie. Dabei sollte Öko-Landwirtschaft in ihren ökonomischen, sozialen, lokalen und ökologischen Dimensionen betrachtet werden, wobei auch nicht-menschliche Akteur*innen - im

1 Vgl. European Commission 2019.

2 Vgl. Bio Austria Statistik.

3 Vgl. Ploeg 2018b. 
Sinne von foodwebs, wie Gabriele Sorgo in ihrem Kapitel darstellt - miteinbezogen werden. Dabei zeigt sich, dass es gerade die affektiven Beziehungen zu Bodenlebewesen, Tieren und Menschen sind, die mit einer produktivistischen Denkweise unvereinbar sind. Die seit der Covid19 Pandemie rasant gestiegene Nachfrage nach regionalen Lebensmitteln, sowie der steigende Anteil an Direktvermarktung, scheinen diesen Produzent*innen Recht zu geben. ${ }^{4}$

Die Ergebnisse des vorliegenden Bandes basieren auf einem zwischen 2017-2019 durchgeführten transdisziplinären Forschungsprojekt. Im Mittelpunkt stand dabei die Frage, wer die Landwirt*innen sind, die neue Wege der Produktion und Distribution im ökologischen Sektor gehen. Gleichzeitig sollte dabei die Frage betrachtet werden, wie eine sozial und ökologisch nachhaltige und zugleich lebenswerte Landwirtschaft für die Bewirtschafter*innen aussehen könnte. Erforscht wurden dazu zertifiziert ökologische Vollerwerbsbetriebe, die Grundnahrungsmittel für Menschen produzieren und diese, zumindest teilweise, abseits von Großkunden regional vertreiben. Die qualitativen Erhebungen wurden auf vier ökologischen Landwirtschaftsbetrieben in strukturschwachen, ländlich geprägten Regionen im Osten Österreichs durchgeführt.

Methodisch basiert die Forschung auf dem sinnverstehenden Ansatz der Soziologie, der davon ausgeht, dass Menschen einerseits handlungsfähige Akteur*innen sind, ihr Handlungsspielraum aber andererseits durch orts- und zeitspezifische Bedingungen geprägt ist. Die Herangehensweise stützt sich auf die Einarbeitung historischer und familiensoziologischer Daten. Die Datenerhebung erfolgte durch qualitative Interviews mit den Betriebsleiter*innen, ergänzt durch mehrfache Besuche auf den vier untersuchten Höfen. Insbesondere wurden die Familiengeschichten der Landwirt*innen erhoben, basierend auf der familiensoziologisch-historischen Methode der Genogrammanalyse nach Bruno Hildenbrand. ${ }^{5}$ Im Rahmen des Projektes wurden daher nicht nur

4 Vgl. European Commission 2020; Bio Austria Statistik; Bio Austria Presseaussendung (veröffentlicht am 07.09.2020).

5 Vgl. Hildenbrand 2018. 
die Betriebsleiter*innen interviewt, sondern darüber hinaus ihre (insgesamt neun) Familiengeschichten bis zur Großelterngeneration - daher bis an den Anfang des 20. Jahrhunderts - rekonstruiert.

Die Betriebe (theoretical sampling) wurden gemäß einer im Verlauf des Forschungsprozesses festgelegten Kontrastierung ausgewählt. Dass es sich bei allen Fallbeispielen um Betriebsleiterpaare handelt, die zusammen mit ihren Kindern am Betrieb leben, war keine von uns gewählte Voraussetzung, sondern stellt eines der Ergebnisse der vorliegenden Forschung dar. Dies ist in Anbetracht der fortschreitenden Abwanderung junger Menschen und insbesondere von jungen Frauen aus ländlichen Gebieten in ganz Europa bemerkenswert. ${ }^{6}$ Ziel der Methode im Kontext unseres Forschungsprojekts war es, Dispositionen gegenüber Herausforderungen innerhalb von Familien zu rekonstruieren und davon erfolgreiche Strategien für Arbeits- und Alltagsleben ökolandwirtschaftlicher Betriebsleiter*innen abzuleiten. Auf diese Weise können historische, sozio-ökonomische, ökologische und regionale $\mathrm{Be}$ dingungen zu den individuellen Vorgangsweisen in Beziehung gesetzt werden. Gleichzeitig wird dadurch aufgezeigt, dass es keinen homogenen Öko-Sektor gibt. Die Akteur*innen, ihre Handlungsstrategien und Motivationen, sind vielfältig.

Als Forschungsgebiet diente primär das ländlich geprägte Flachund Hügelland der als Oststeiermark bezeichneten Region. Dieses Gebiet hat durch seine geographische Lage als historisches Grenzgebiet im Osten eine Sonderentwicklung erfahren. Die Industrialisierung erreichte die Region, verglichen mit anderen europäischen Gebieten, erst spät, wurde dann aber umso energischer vorangetrieben. War die Oststeiermark aufgrund der abgeschiedenen Lage und der fehlenden Verkehrserschließung weit bis ins 20. Jahrhundert auf Selbstversorgung und einen regionalen Wirtschaftskreislauf angewiesen, setzte ab der Mitte des 20. Jahrhunderts eine Entwicklung ein, die Karl Polanyi als Entbettung der wirtschaftlichen Verhältnisse bezeichnet. ${ }^{7}$ Diese Entwicklung wurde von den Großeltern-, bzw. Elterngenerationen der er-

6 Vgl. Weber und Fischer 2012; Leibert und Wiest 2016.

7 Vgl. Polanyi 1977. 
erbten Höfe unter den Fallbeispielen mitgetragen. Auf den Landwirtschaften wurde Produktion und Distribution rationalisiert, die kleinen und vielfältigen Betriebe verschwanden zusehends und die Bevölkerung wanderte in urbane Regionen $\mathrm{ab}$ - ein Trend, der sich bis heute fortsetzt.

Heute hat die Region vollen Verkehrsanschluss und ist gänzlich mobilisiert, aber auch Kommunikationstechnologien, insbesondere das Internet, bieten den Höfen neue Möglichkeiten. Wie die Forschungsergebnisse aufzeigen, stehen die Betriebsleiter*innen trotz dieser Voraussetzungen den globalen Lebensmittelsystemen - von der Primärerzeugung, über multinationale Betriebsmittelkonzerne und global agierende Lebensmittelkonzerne, hin zu Lebensmittelspekulationen an den Agrarbörsen usw. - kritisch bis ablehnend gegenüber. Manche ökologische Landwirt*innen der Pioniergeneration in Österreich - wie Familie Danninger, die seit den 1990er Jahren Supermärkte mit ihren Produkten beliefern - betrachten die Eingliederung der ökologischen Produktion in diese Lebensmittelsysteme heute kritisch. Die Landwirt"innen unserer Forschung investieren hingegen bewusst in langfristige Beziehungen abseits dieser Systeme - in Menschen sowie in andere Mitlebewesen wie Nutztiere, Pflanzen und Bodenlebewesen. Sie setzen mit ihren Alltagspraxen Ansätze um, die von Kritiker*innen einer konventionellen Landwirtschaft seit vielen Jahrzehnten eingefordert werden. ${ }^{8}$ Ihre gemeinwohlorientierten, vernetzten, holistischen Handlungspraktiken und Denkweisen umschreiben die Autorinnen in diesem Band mit dem Begriff der sorgsamen Landwirtschaft (caring agriculture).

In einer Mitteilung an das Europäische Parlament vom Mai 2020 stellt die Europäische Kommission fest, dass der »Ruf nach kürzeren Lieferketten während des Covid-19-Ausbruchs lauter geworden « ist. ${ }^{9}$ Die Mitteilung unterstreicht die Bedeutung der ökologischen Landwirtschaft für ein nachhaltiges Lebensmittelsystem und von kurzen Lieferketten, welche die Resilienz regionaler Lebensmittelsysteme fördern.

8 Vgl. Meadows u.a. und Club of Rome 1972.

9 European Commission 2020, S. 3. 
Die Landwirt*innen unserer Studie haben diesen Trend übernommen und setzen auf Direktvermarktung - wie Bauernmärkte, ab Hof Verkauf und CSAs - oder beliefern Foodcoops sowie regionale Gastgewerbe und Läden. Familie Bergmann etwa hat sich ganz bewusst dazu entschieden, ausschließlich nach lokalen Mitgliedern für ihre CSA zu suchen. Durch den persönlichen Kontakt konnten sich die Direktvermarkter*innen einen stabilen Kundenstock schaffen.

Die jüngere Generation von Landwirt*innen versucht sich bewusst vom Mainstream abzuheben und autonom handlungsfähig zu bleiben. ${ }^{10}$ Generell jedoch betonen alle Landwirt*innen in unserer Studie ihr Bedürfnis nach einem selbstbestimmten Leben, weshalb fast alle unter ihnen Kredite genauso zu vermeiden versuchen, wie Verflechtungen mit vor- und nachgelagerten Industrien, was sie im Sinne Ploegs als peasants auszeichnet. ${ }^{11}$ Gleichzeitig spielen Selbstverwirklichung, Kreativität, die Möglichkeit, ihre Fähigkeiten sinnvoll einzubringen und die Freude an der Arbeit mit der Natur eine wichtige Rolle. Damit beschreiben Betriebsführer*innen ihre Vorstellungen von einem guten Leben, von sinnvoller Arbeit und von hochwertigen Lebensmitteln. So erzählt Herr Bergmann (der auf einer konventionellen Landwirtschaft aufgewachsen ist und in einer Landwirtschaftsschule ausgebildet wurde) von der genussvollen Erfahrung, zum ersten Mal in seinem Leben mit den eigenen Händen direkt in der Erde zu arbeiten, nachdem der Hof auf ökologische Gemüsewirtschaft umgestellt wurde (Interview am 2.3.2018).

Ausgehend von den Fallanalysen kann aufgezeigt werden, dass für die Betriebsleiter*innen eine ökologisch verträgliche Produktionsweise im Mittelpunkt steht, die Tierwohl, Bodenfruchtbarkeit, Biodiversität und Schadstoffminimierung fördert. Entgegen den Rationalisierungsbestrebungen seit dem 20. Jahrhundert weigern sich diese Akteur*innen der Öko-Landwirtschaft, ihre Höfe - den Boden wie ihre Nutztiere - als austauschbare Rohstoffe zu betrachten. Die Ziegenbäuerin Frau Conrad meint dazu: "Es muss net alles immer nur auf Gewinn auf'baut

10 Vgl. Milone und Ventura 2014; Kaser u.a. 2003.

11 Vgl. Ploeg 2018b. 
sein«(Interview am 5.7.2018). Die Methoden des Landbaus und der Tierhaltung gehen bei allen Interviewpartner*innen über die gesetzlichen Öko-Standards der Europäischen Union hinaus. Motiviert, die Gesundheit von Boden, Pflanzen, Tieren und Menschen zu fördern, betreiben die Befragten eine sorgsame Landwirtschaft.

Aus dieser Sicht wird erkennbar, dass die klassische wirtschaftstheoretische Unterscheidung von produktiver und reproduktiver Arbeit in Bezug auf eine sorgsame Landwirtschaft nicht haltbar ist. In einer sorgsamen Landwirtschaft wird der Mensch nicht nur als Abnehmer und Nutznießer der Leistungen von Boden und Bodenlebewesen verstanden, sondern als Teil einer Gemeinschaft, was Begriffe wie Puig de la Bellacasas human-soil communities in ähnlicher Weise beschreibt wie Ploegs co-production. ${ }^{12}$ Seit den Anfängen ökologischer Landbaumethoden wird von Praktiker*innen der Wunsch nach ökonomischer und sozialer Wertschätzung für diese Form der zeit- und arbeitsintensiven Produktionsweise geäußert, sowie eine faire Entlohnung für diese landwirtschaftliche care-Arbeit gefordert. ${ }^{13}$ Die Unsichtbarkeit der reproduktiven Sorgetätigkeit stellt ein grundsätzliches Problem unserer Gesellschaft dar, wie die Kapitel von Kosnik und Sorgo aufzeigen. Mit Hilfe qualitativer Forschungsmethoden lassen sich so geschaffene Mehrwerte jedoch erkennen. Denn Subsistenzarbeit heißt auch, langfristige Beziehungen herzustellen und Menschen und ihre Umwelten im Sinne der foodwebs - als Gemeinschaften zu verstehen.

Von den Behörden fühlen sich die Betriebsleiter*innen jedoch oft behindert, gerade, wenn es darum geht, gänzlich neue Methoden - etwa artgerechte Tierhaltung oder eine Tierwohl-orientierte, stressfreie Schlachtung - anzuwenden (Kapitel Heistinger, Kapitel Kosnik). Von staatlicher Seite wird diese care-Arbeit einer sorgsamen Landwirtschaft in Förderungen wie Flächenprämien für umweltschonend(er)e landwirtschaftliche Praktiken umgerechnet, als bürokratisch geregelte, standardisierte und überprüfbare Formen der Entlohnung »valuing care by >efficiency< standards«, wie Puig de la Bellacasa den

12 Vgl. Puig de la Bellacasa2015; Ploeg 2018b.

13 Vgl. Jurtschitsch 2010; Vogt 2000. 
Umstand umschreibt. ${ }^{14}$ Der Verwertung von care-Arbeit sind Grenzen gesetzt, insofern Sorgearbeit kaum Renditen bringen kann. Gleichzeitig baut die Gesellschaft darauf auf, dass care-Arbeiten dauerhaft kostengünstig zur Verfügung stehen. Eine sorgsame Landwirtschaft muss, genau wie andere Pflege- und Sorgearbeiten, Wege finden, um in einer marktorientierten Gesellschaft $\mathrm{zu}$ überleben. Die bisher üblichen Lösungswege - die Ansprüche zu verringern oder den Weg der Selbstausbeutung zu wählen - werden von den Bewirtschafter*innen bewusst abgelehnt, jedoch sind auch sie immer wieder dazu gezwungen, diese anzuwenden. Stattdessen wollen sie die ihnen zur Verfügung stehenden Ressourcen nutzen, um sich Freiräume zu schaffen, für einen lebenswerten Arbeitsalltag in der Landwirtschaft. Hier sind politische Veränderungen gefragt. Die Last und das Risiko, ein globales Lebensmittelsystem umzustrukturieren, kann nicht allein die Aufgabe bescheiden wirtschaftender Öko-Landwirt*innen sein. So liegt etwa die (nicht entgoltene) Bildungsarbeit Großteils bei ihnen, Bürokratie und Konsument*innen über den Wert einer sorgsamen Landwirtschaft zu unterrichten.

Wie Heistinger darstellt, gibt es aber auch Ressourcen, welche die Familien in vielerlei Hinsicht resilient machen, wie eine familiär erworbene Offenheit für (Betriebs-)Veränderungen, vielfältige, (auch informelle) Bildungswege und Berufserfahrungen, auch abseits der Landwirtschaft. Die Kombination unterschiedlicher Erfahrungen kann helfen, die Probleme der Landwirtschaft aus anderen Perspektiven zu betrachten, was in der Folge die Entwicklung neuer Lösungsstrategien begünstigt. Die neuen Landwirt*innen denken interdisziplinär. Sie können in einer komplexen Welt die Puzzlestücke finden, die sich zu einer erfolgreichen Betriebsstrategie zusammensetzen lassen. Die untersuchten Öko-Betriebe setzen dabei individuell gefundene Handlungspraxen um, die nicht unbedingt generalisierbar sind. Denn Innovationen sind regional angepasst und mit bestimmten Persönlichkeiten und deren familiären Ressourcen verknüpft. 
Heistinger arbeitet in ihrem Kapitel heraus, dass es kein spezifisches, abgrenzbares lokales Wissen gibt, das an einem Ort gefunden und nur dort tradiert wird. Regionale Einbettung ist nicht starr, sondern ein lebendiger Zusammenhang, der durch den beschleunigten Weltmarkt noch viel veränderlicher geworden ist. Da die Herausforderungen durch Markt und Klima ebenso wandelbar sind wie die zur Verfügung stehenden Technologien und die Ansprüche der Konsument*innen, muss stets neues Wissen generiert werden. "Die Innovationen passieren auf den Betrieben und nicht in den Schulen « stellt Herr Bergmann im Interview dazu fest (Interview am 2.3.2018). Die Betriebsleiter*innen sind regional und überregional gut vernetzt, bedienen sich der neuesten Kommunikationstechnologien und experimentieren mit neuen Techniken. Dabei haben sie großes Interesse daran, ihr Wissen unter Kund"innen und Kolleg*innen zu verbreiten und sich untereinander auszutauschen. Der freie Austausch von Wissen und Erfahrungen erzeugt auf diese Weise Vorteile für kleinstrukturierte, regionalspezifisch wirtschaftende Familienbetriebe.

In allen Fallbeispielen erhielten die Höfe neue Impulse von außen, als Partner*innen hinzukamen, bzw. die Familie einen Betrieb neu übernahm. Die Untersuchung der Familiengeschichten von Betriebsleiter*innen lässt die enge Verknüpfung von ökologischer Landwirtschaft mit persönlichem Erfahrungswissen und gemeinwohlorientierten Handlungsmustern sichtbar werden. Ihnen gemeinsam ist, dass sie ihre eigenen theoretischen Überlegungen und Überzeugungen sowie Inspirationen aus ihrem sozialen Umfeld und all jene Kompetenzen, die sie in ihrem bisherigen (Berufs-)leben erworben haben in ihrer landwirtschaftlichen Praxis neu zusammenführen. Sie schöpfen aus ihrer eigenen Geschichte und knüpfen Beziehungen zu Boden, Pflanzen und Tieren, sowie zu jenen Menschen, die sie mit ihren Produkten versorgen. Nicht selten müssen auch Ablehnung im direkten sozialen Umfeld - in der unmittelbaren Nachbarschaft oder innerhalb der eigenen Berufsgruppe - und behördliche Inflexibilität ertragen werden. Um diesen Widerständen gut begegnen zu können spielen die Bestärkung und Anerkennung durch Familienmitglieder eine wichtige Rolle, aber auch durch jene Menschen, die sie mit Lebensmitteln 
versorgen. Auch die Aufmerksamkeit für ihre neuen ökologischen und sozialen Praktiken, etwa von Expert*innen oder Vertreter*innen der Landwirtschaftskammern, stärkt ihre Resilienz.

Weitere Forschungen $\mathrm{zu}$ den Praktiker*innen einer sorgsamen Landwirtschaft sind notwendig, um ihre Rolle in der Gesellschaft genauer zu beleuchten, sowie ihre speziellen Bedürfnisse zu ergründen. Neue, kreative Ansätze der Analyse sind hier gefragt, die es erlauben, vielschichtige Dimensionen zu erkennen, wie sie in einer alternativen Lebensmittelproduktion und Distribution gegeben sind. In ihrem feministisch-kritischen Manifest Gens stellen Laura Bear u.a. fest: „Capitalism is at its core a diverse, intimate network of human and nonhuman relations ${ }^{15}$ und rufen dazu auf, die vielfältigen Beziehungsnetzwerke, die hinter dem stehen, was oft unhinterfragt unter dem Begriff des Kapitalismus zusammengefasst wird, zu erforschen. Mit einer System-Aufstellung zur Landwirtschaft begeht auch Heistinger neue kreative Wege in der Analyse. Zusammen mit der Künstlerin Susanne Schuda nähert sie sich der Frage »Wie können die Ressourcen des Agrarsystems in einander nährende Beziehungen kommen? « ${ }^{16}$ und zeigt dabei die Komplexität der Beziehungsnetzwerke zwischen menschlichen und nicht-menschlichen Akteur*innen in einem globalen Lebensmittelsystem auf.

Mit unterschiedlichen disziplinären Herangehensweisen beleuchten die Texte in diesem Band die verborgenen Annahmen über Sorgetragen in der Landwirtschaft und erkunden die ökologischen, sozialen, ökonomischen, politischen und affektiven Praxen einer sorgsamen Landwirtschaft als Beziehungen von Multi-Spezies Gemeinschaften, die nicht alleine Menschen zum Vorteil gereichen. Dabei werden die vielschichtigen lokalisierten Beziehungsgeflechte zwischen Menschen, Tieren, Pflanzen und Böden als mehr-als-menschliche Kollektive sichtbar. Damit soll der Band auch einen Beitrag zum Verständnis der Komplexität von Praktiken der Sorge leisten, im Sinne Puig de 
124 Elisabeth Kosnik, Andrea Heistinger, Gabriele Sorgo

la Bellacasas »als eine materielle Praxis des Verbindens und der politischen Intervention, die die unbeachteten und vernachlässigten Dinge mit einbezieht ${ }^{17}{ }^{17}$ als sozio-ökonomische Praktiken, politischgesellschaftliche Teilhabe und Umweltgerechtigkeit.

17 Gesing u.a. 2018, S. 36. 


\section{Literatur}

Atlas der Österreichischen Raumordnungskonferenz (=ÖROK). Abgerufen am 26.03.2020 von www.oerok-atlas.at/\#indicator/12.

Bätzing, Werner (2020). Das Landleben. Geschichte und Zukunft einer gefährdeten Lebensform. München: C. H. Beck.

Bauchmüller, Michael (2020). Landwirtschaft. Die Entfremdung. Süddeutsche Zeitung vom 16.01.2020, Seite 4.

Baumgartner, Judith (1998). Ernährungsreform. In Diethart Kerbs \& Jürgen Reulecke (Hg.), Handbuch der Deutschen Reformbewegungen. 1880-1933 (S. 301-313). Wuppertal: Peter Hammer Verlag.

Bear, Laura u.a. (2015). Gens. A Feminist Manifesto for the Study of Capitalism. Abgerufen am 01.08.2020 von https://culanth.org/fieldsights/ gens-a-feminist-manifesto-for-the-study-of-capitalism.

Becker, Horst \& Ingo Langosch (2016). Produktivität und Menschlichkeit: Organisationsentwicklung und ihre Anwendung in der Praxis. Berlin \& Boston: De Gruyter Oldenbourg.

Becker-Schmidt, Regina (2003). Geschlecht als Kategorie. Die doppelte Vergesellschaftung von Frauen. Abgerufen am 22.01.2020 von https:// www.fu-berlin.de/sites/gpo/soz_eth/Geschlecht_als_Kategorie/Di e_doppelte_Vergesellschaftung_von_Frauen/becker_schmidt_ohne .pdf.

Bendix, Regina F. u.a. (2017). Sustaining Interdisciplinary Collaboration: A Guide for the Academy. Champaign, Illinois: University of Illinois Press.

Bennholdt-Thomsen, Veronika u.a. (1983). Frauen, die letzte Kolonie: Zur Hausfrauisierung der Arbeit. Reinbek bei Hamburg. Rowohlt. 
Bies, Michael (2014). Claude Lévi-Strauss und das wilde Basteln. In Sandro Zanetti (Hg.), Improvisation und Invention. Momente, Modelle, Medien (S. 205-215). Zürich/Berlin: diaphanes.

Binder, Beate \& Sabine Hess (2019). Politiken der Für_Sorge - Für_Sorge als Politik. Einige einleitende Überlegungen. In Beate Binder u.a. (Hg.) (2019). Care. Praktiken und Politiken der Fürsorge. Ethnographische und geschlechtertheoretische Perspektiven (S. 9-32). Leverkusen: Barbara Budrich.

Binder, Beate u.a. (Hg.) (2019). Care. Praktiken und Politiken der Fürsorge. Ethnographische und geschlechtertheoretische Perspektiven. Leverkusen: Barbara Budrich.

Bio Austria Presseaussendung (veröffentlicht am 14.2.2020). Pro Tag 115 Fußballfelder zusätzliche Bio-Fläche in Österreich. Abgerufen am 25.11.2020 von https:/www.ots.at/presseaussendung/OTS_202002 14_OTSO100/bio-austria-pro-tag-115-fussballfelder-zusaetzliche-bi o-flaeche-in-oesterreich-bild.

Bio Austria Presseaussendung (veröffentlicht am 07.09.2020). Umsatz mit Bio-Lebensmittel in Österreich wächst und wächst. Abgerufen am 13.07.2021 von https://www.ots.at/presseaussendung/OTS_202009 07_OTSO066/bio-austria-umsatz-mit-bio-lebensmitteln-in-oesterr eich-waechst-und-waechst-bild.

Bio Austria Statistik. Abgerufen am 13.11.2020 von https://www.bio-au stria.at/bio-bauern/statistik/.

BMGF (Bundesministerium für Gesundheit und Frauen) (Hg.) (2017). Biologische Landwirtschaft. 35 Jahre Bio-Regelungen in Österreich. Wien: BMGF. Abgerufen am 31.03.2020 von https://www.verbraucherges undheit.gv.at/lebensmittel/bio/Festschrift-Bioregelungen.pdf?6igf gd.

Boltanski, Luc \& Chiapello, Ève (2003). Der neue Geist des Kapitalismus. Konstanz: UVK.

Bonß, Wolfgang (2015). Karriere und sozialwissenschaftliche Potenziale des Resilienzbegriffs. In Martin Endreß \& Andrea Maurer (Hg.), Resilienz im Sozialen. Theoretische und empirische Analysen (S. 15-32). Wiesbaden: VS Verlag für Sozialwissenschaften. 
Bundesministerium Landwirtschaft, Regionen und Tourismus (Stand 12.06.2020). Benachteiligte landwirtschaftliche Gebiete. Abgerufen am 25.11.2020 von https://www.bmnt.gv.at/land/laendl_entwicklung/b erggebiete-benachteiligte_gebiete/benachteiligte_geb.html.

Collen, Alanna (2015). 10 \% Human. How Your Body's Microbes Hold the Key to Health and Happiness. London: Conville \& Walsh Ltd.

Darnhofer, Ika (2014). Resilience and why it matters for farm management. European Review of Agricultural Economics 41, 461-484.

Darnhofer, Ika u.a. (2016). The Resilience of Family Farms: Towards a Relational Approach. Journal of Rural Studies 44, 111-122.

Dax, Thomas u.a. (2016). Regionen mit Bevölkerungsrückgang. ExpertenImpulspapier zu regional- und raumordnungspolitischen Entwicklungsund Anpassungsstrategien im Auftrag des Bundeskanzleramts. Abgerufen am 07.07.2021 von https:/www.oerok.gv.at/fileadmin/user_uploa d/Bilder/2.Reiter-Raum_u._Region/1.OEREK/OEREK_2011/PS_Be voelkerung/Experten_Impulspapier_Analyse_strategische_Orienti erungen_20160718.pdf.

Dempster, Beth L. (1998). Sympoietic and Autopoietic Systems: A New Distinction for Self-organizing Systems. Masters Thesis, Environmental Studies in Planning, University of Waterloo, Ontario, Canada. Abgerufen am 26.03.2020 von https://pdfs.semanticscholar.org/4429/ 9317a2oafcd33boa11d3b2bf4fc196088d45.pdf.

Donati, Pierpaolo (2011). Relational Sociology. A New Paradigm for the Social Sciences. London \& New York: Routledge.

Donati, Pierpaolo (2015). When Relational Subjects generate relational goods. In Donati, Pierpaolo Donati \& Margaret S. Archer, The Relational Subject (S. 198-228). Cambridge: Cambridge University Press.

Eberhart, Helmut (1987). Die Zeitschrift »Landjugend«. Ein Beitrag zur Rezeptionsforschung. In Klaus Beitl (Hg.), Gegenwartsvolkskunde und Jugendkultur. Referate des 2. Internationalen Symposions des Instituts für Gegenwartsvolkskunde der Österreichischen Akademie der Wissenschaften vom 4. bis 8. Juni 1985 in Mattersburg (S. 138-157). Wien: Österreichische Akademie der Wissenschaften. 
Eberhart, Helmut (1991). Bäuerliche Alltagskultur zwischen Autarkie und marktorientierter Produktion. Schweizerisches Archiv für Volkskunde 87, 28-45.

European Commission (2019). Organic Farming in the EU. A fast growing sector. EU Agricultural Markets Briefs 13, March 2019. Abgerufen am 02.12.2020 von https://ec.europa.eu/info/sites/info/files/food-f arming-fisheries/farming/documents/market-brief-organic-farmi ng-in-the-eu_mar2019_en.pdf.

European Commission (2020). »Vom Hof auf den Tisch«-eine Strategie für ein faires, gesundes und umweltfreundliches Lebensmittelsystem. Brüssel am 20.05.2020. Abgerufen am 02.12.2020 von https://ec.europa.eu /info/sites/info/files/communication-annex-farm-fork-green-deal _de.pdf.

Farkas, Reinhard (1998). Alternative Landwirtschaft/Biologischer Landbau. In Diethart Kerbs \& Jürgen Reulecke (Hg.), Handbuch der Deutschen Reformbewegungen. 1880-1933 (S. 301-313). Wuppertal: Peter Hammer Verlag.

Federici, Silvia (2015). Aufstand aus der Küche. Reproduktionsarbeit im globalen Kapitalismus und die unvollendete feministische Revolution. Münster: edition assemblage.

Fisher, Berenice \& Tronto, Joan C. (1990). Toward a Feminist Theory of Caring. In Emily K. Abel \& Margaret Nelson (Hg.), Circles of Care. Albany, NY: SUNY Press.

Francis, Charles u.a. (2003). Agroecology: The Ecology of Food Systems. Journal of Sustainable Agriculture, 22 (3), 99-118.

Freyer, Bernhard u.a. (2001). Der biologische Landbau in Österreich. Entwicklungen und Perspektiven. Agrarwirtschaft 50 (7), 400-409.

Friedmann, Harriet \& McMichael, Philipp (1989). Agriculture and the State System: The Rise and Decline of National Agriculture, 1870 to Present. Sociologia Ruralis 29 (2), 93-114.

Galbraith, Kenneth John (1974). Wirtschaft für Staat und Gesellschaft. München/Zürich: Droemer Knaur.

Gesing, Friederike u.a. (2018). NaturenKulturen-Forschung. Eine Einleitung. In NaturenKulturen. Denkräume und Werkzeuge für neue politi- 
sche Ökologien, hg. Friederike Gesing u.a. (Hg.), 7-50. Bielefeld: transcript.

Gibson-Graham, J. K. (2014). Rethinking the Economy with Thick Description and Weak Theory. Current Anthropology 55 (S9 Crisis, Value, and Hope: Rethinking the Economy), 147-153.

Gorz, André (2004). Wissen, Wert und Kapital: Zur Kritik der Wissensökonomie. Zürich: Rotpunktverlag.

Grassberger, Martin (2019). Das leise Sterben. Warum wir eine landwirtschaftliche Revolution brauchen, um eine gesunde Zukunft zu haben. Wien/Salzburg: Residenz Verlag.

Grimm, Jacob \& Grimm, Wilhelm (1991). Deutsches Wörterbuch. $16=$ Bd. 10, Seeleben - Sprechen. Fotomechan. Nachdr. d. Erstausg. 1905. München: dtv.

Groier, Michael \& Markus Schermer (Hg.) (2005). Bio-Landbau in Österreich im internationalen Kontext. Band 2: Zwischen Professionalisierung und Konventionalisierung. Forschungsbericht 55. Wien: Bundesanstalt für Bergbauernfragen.

Groier, Michael \& Norbert Gleirscher (Hg.) (2005). Bio-Landbau in Österreich im internationalen Kontext. Band 1: Strukturentwicklung, Förderung und Markt. Forschungsbericht 54. Wien: Bundesanstalt für Bergbauernfragen.

Groier, Michael \& Schermer, Markus (Hg.) (2005). Bio-Landbau in Österreich im internationalen Kontext. Band 2: Zwischen Professionalisierung und Konventionalisierung. Forschungsbericht 55. Wien: Bundesanstalt für Bergbauernfragen.

Groier, Michael (2005). Entwicklung, Struktur und Förderung des biologischen Landbaus. In Michael Groier \& Norbert Gleirscher (Hg.), Bio-Landbau in Österreich im internationalen Kontext. Band 1: Strukturentwicklung, Förderung und Markt. Forschungsbericht 54 (S. 9-90). Wien: Bundesanstalt für Bergbauernfragen.

Groier, Michael (2013). Wie weit darf Bio gehen? Analyse von Konventionalisierungsrisiken im Bereich der biologischen Landwirtschaft Österreichs. Forschungsbericht 69. Wien: Bundesanstalt für Bergbauernfragen.

Gruber, Hans u.a. (2006). Professional Learning: Erfahrung als Grundlage von Handlungskompetenz. Bildung und Erziehung 59, 193-203. 
Gudeman, Stephen (2016). Anthropology and Economy. Cambridge: Cambridge University Press.

Guthman, Julie (2004). The trouble with »organic lite« in California. A rejoinder to the »conventionalization« debate. Sociologia Ruralis 44, 301-316.

Guthman, Julie (2014). Agrarian Dreams. The Paradox of Organic Farming in California. Oakland: University of California Press.

Grossarth, Jan (2017). Große Sorge ums Essen. FAZ vom 18.01.2017, abgerufen am 22.07.2021 von https://www.faz.net/aktuell/wirtsch aft/landwirtschaft-fordert-wegen-ernterueckgang-einen-systemw echsel-14690355.html.

Haraway, Donna (2003). Das Manifest für Gefährten. Wenn Spezies sich begegnen - Hunde, Menschen und signifikante Andersartigkeit. Berlin: Merve.

Haraway, Donna (2018). Unruhig bleiben: die Verwandtschaft der Arten im Chthuluzän. Frankfurt/New York: Campus Verlag.

Harris, Mark (2005). Riding a Wave: Embodied Skills and Colonial History on the Amazon Floodplain. Ethnos 70 (2), 197-219.

Heistinger, Andrea (2012). »Ich habe mir meine Erben selbst gesucht«. Ergebnisse eines Forschungsprojekts zu Möglichkeiten eines Einstiegs in die Landwirtschaft in Österreich. Zeitschrift für Agrargeschichte und Agrarsoziologie 60(2), 100-116.

Heistinger, Andrea (2018). Basiswissen Selbstversorgung aus Biogärten. Individuelle und gemeinschaftliche Wege und Möglichkeiten. Innsbruck: Löwenzahn.

Hettlage, Robert (1989). Über Persistenzkerne bäuerlicher Kultur im Industriesystem. In Christian Giordano \& Robert Hettlage (Hg.), Bauerngesellschaften im Industriezeitalter. Zur Rekonstruktion ländlicher Lebensformen (S. 287-333). Berlin: Dietrich Reimer.

Hildenbrand, Bruno (2005). Fallrekonstruktive Familienforschung. Anleitungen für die Praxis. Opladen: Leske + Budrich.

Hildenbrand, Bruno (2012). Leben als Prozess der Bewältigung von Krisen. In Rosemarie Welter-Enderlin \& Bruno Hildenbrand (Hg.), Resilienz-Gedeihen trotz widriger Umstände (S. 205-229). Heidelberg: Carl Auer Verlag. 
Hildenbrand, Bruno (2013). Genogrammarbeit. In Wolfgang Senf, Michael Broda, Bettina Wilms et.al. (Hg.), Techniken der Psychotherapie. Ein methodenübergreifendes Kompendium (S. 93-95). Stuttgart/New York: Georg Thieme.

Hildenbrand, Bruno (2015). Mikro-qualitative Transformationsforschung. In Ray Kollmorgen, Wolfgang Merkel \& Hans-Jürgen Wagener (Hg.), Handbuch Transformationsforschung (S. 231-242). Wiesbaden: Springer.

Hildenbrand, Bruno (2018). Genogrammarbeit für Fortgeschrittene: Vom Vorgegebenen zum Aufgegebenen. Heidelberg: Verlag Carl Auer-Systeme.

Hintz, Miriam u.a. (2017). Graz ernährt sich - mehr schlecht als recht. Endbericht eines Studierendenprojektes zur urbanen Selbstversorgung. Abgerufen am 13.11.2020 von https:/www.imzuwi.org/index.php/ site-map/articles/100-aktuelles/themen/198-endbericht-zum-studi erendenprojekt-graz-ernaehrt-sich.

Hiß, Christian u.a. (2018). Von der bäuerlichen Landwirtschaft zur regionalen Versorgungswirtschaft. Funktionale Eigenschaften bäuerlicher Ökonomien als Schlüsselfaktoren für die Gestaltung einer regionalen Versorgung mit Lebensmitteln. Abgerufen am 11.08.2020 von http://w ww.kasseler-institut.org/fileadmin/Arbeitsergebnisse/AE_12/Arbei tsergebnisse_12_KI_baeuerliche_Landwirtschaft_11-2017.pdf.

Hiß, Christian (2019). Regionalwert AG Bürgeraktiengesellschaft. Zivilgesellschaftliches Unternehmertum zur Entwicklung von regionaler Ernährungssouveränität. In Antoni-Komar u.a. (Hg.), Transformative Unternehmen und die Wende in der Ernährungswirtschaft. Marburg: Metropolis-Verlag.

Hofreither, Markus F. (1997). Agrarpolitik. In Herbert Dachs u.a. (Hg.), Handbuch des politischen Systems Österreichs. Die 2. Republik (S. 641651). Wien: Manzsche Verlagsbuchhandlung.

Holling, Crawford S. (1973). Resilience and Stability of Ecological Systems. Annual Review of Ecology and Systematics 4, 1-23.

Holling, Crawford S. (2001). Understanding the complexity of economic, ecological and social systems. Ecosystems 4 (5), 390-405.

Honneth, Axel (2005). Verdinglichung. In ders., Verdinglichung. Eine anerkennungstheoretische Studie (S. 9-106). Frankfurt a.M.: Suhrkamp. 
Hroch, Petra (2013). Resilience versus Resistance. MediaTropes IV (1), 1946.

IAASTD (International Assessment of Agricultural Knowledge, Science and Technology for Development) (2008). Agriculture at a Crossroads. Summary for Decision Makers of the Global Report. Abgerufen am 13.11.2020 von https://www.weltagrarbericht.de/fileadmin/files/we ltagrarbericht/IAASTDBerichte/GlobalSDM.pdf.

IFOAM Organics International, The Principle of Care. Abgerufen am 26.03.2020 von https://www.ifoam.bio/en/principles-organic-agric ulture/principle-care.

Iliadis, Andrew (2013). A new Individuation: Deleuze's Simondon Connection. MediaTropes 4 (1), 83-100. Abgerufen am 26.03.2020 von https://mediatropes.com/index.php/Mediatropes/article/view/ 20726/16970.

Inhetveen, Heide \& Schmitt, Mathilde (2010). Prekarisierung auf Dauer? Die Überlebenskultur bäuerlicher Familienbetriebe. In Andrea D. Bührmann \& Hans J. Pongratz (Hg.), Prekäres Unternehmertum. Unsicherheiten von selbstständiger Erwerbstätigkeit und Unternehmensgründung (S. 111-136). Wiesbaden: VS Verlag für Sozialwissenschaften.

Institut für Soziale Ökologie der Universität Klagenfurt (2015). Pressemitteilungen am 17. Juni 2015. Abgerufen am 12.07.2021 von https://w ww.aau.at/blog/uninews_44048.

Johnson, Allen W. (1972). Individuality and Experimentation in Traditional Agriculture. Human Ecology 1(2), 149-159.

Jurtschitsch, Aurelia (1998). Identität: Fortschritt. Beobachtungen zur Identitätsbildung/-wandlung durch das Auftreten einer neuen Idee/Produktionsmethode am Beispiel der Biobauern. In Jeff Bernard \& Gloria Withalm (Hg.), Identität/Identity/Identité: Sigharting 1990. Akten des 7. Symposiums der Österreichischen Gesellschaft für Semiotik (S. 411-426). Wien: Österreichische Gesellschaft für Semiotik.

Jurtschitsch, Aurelia (2009). Österreichische BioPioniere und ihr Erbe. In Karl. C. Berger, Margot Schindler \& Ingo Schneider (Hg.), Erb.gut? Kulturelles Erbe in Wissenschaft und Gesellschaft. Referat der 
25. Österreichischen Volkskundetagung vom 14.-17.11. 2007 in Innsbruck (S. 261-271). Wien: Selbstverlag des Vereins für Volkskunde.

Jurtschitsch, Aurelia (2010). Bio-Pioniere in Österreich. Vierundvierzig Leben im Dienste des biologischen Landbaus. Wien/Köln: Böhlau.

Karner, Stefan (2000). Die Steiermark im 20. Jahrhundert. Politik, Wirtschaft, Gesellschaft, Kultur. Graz: Styria.

Kaser, Karl \& Stocker, Karl (1986). Bäuerliches Leben in der Oststeiermark seit 1848. Band I. Landwirtschaft von der Selbstversorgung zum Produktivitätszwang. Wien: Böhlau.

Kaser, Karl \& Stocker, Karl (1987). Bäuerliches Leben in der Oststeiermark seit 1848. Band II. Die verspätete Revolution. Wien: Böhlau.

Kaser, Karl u.a. (2003). Vom Selbstversorger zum Nebenerwerbslandwirt. Das südoststeirische Flach- und Hügelland. In Ernst Bruckmüller \& Franz Ledermüller (Hg.), Geschichte der österreichischen Land- und Forstwirtschaft im 20. Jahrhundert. Bd. 2. Regionen, Betriebe, Menschen (S. 299-361). Wien: Ueberreuter.

Kohn, Eduardo O. (2005). Runa Realism: Upper Amazonian Attitudes to Nature Knowing. Ethnos 70 (2),171-196.

Kosnik, Elisabeth (2015). Strategien der Subsistenz. Neue prekäre, subversive und moralische Ökonomien. Berlin, 23. und 24. Jänner 2015. Österreichische Zeitschrift für Volkskunde 118 (1+2), 110-113.

Kosnik, Elisabeth (2017). »Von der Hand in den Mund«. Selbstversorgungslandwirtschaft in der postindustriellen Gesellschaft. Schweizerisches Archiv für Volkskunde 113 (1), 65-79.

Kosnik, Elisabeth (2018). Production for Consumption. Prosumer, citizen-consumer, and ethical consumption in a postgrowth context. Economic Anthropology 5 (1), 123-134.

Kosnik, Elisabeth (2019). Subsistence Farming in Styria, Austria. In Valeria Siniscalchi \& Krista Harper (Hg.), Food Values in Europe (S. 4862). London: Bloomsbury.

Krippner, Greta u.a. (2004). Polanyi Symposium: A conversation on embeddedness. Socio-Economic Review 2 (1), 109-135.

Kruse, Jan (2015). Qualitative Interviewforschung. Ein integrativer Ansatz. Weinheim und Basel: Verlag Beltz Juventa. 
Landwirtschaftskammer Österreich (2016). Agrarischer Ausblick Österreich 2025. Ergebnisse des Strategieprozesses. Abgerufen am 06.07.2021 von www.lko.at.

Landwirtschaftskammer Steiermark (2016). Die Steirische Landwirtschaft in Zahlen 2016. Abgerufen am 11.08.2020 von https://stmk.lko.at/.

Langthaler, Ernst (2010). Landwirtschaft vor und in der Globalisierung. In Reinhard Sieder \& Ernst Langthaler (Hg.), Globalgeschichte. 18002010 (S. 135-169). Wien, Köln, Weimar: Böhlau.

Leibert, Tim \& Wiest, Karin (2016). The interplay of gender and migration in Europe's remote and economically weak rural regions. Introduction to a special issue. Journal of Rural Studies 43, 261-266.

Lentzos, Filippa \& Rose, Nikolas (2009). Governing insecurity: Contingency planning, protection, resistance. Economy and Society 38 , 230-54.

Lévi-Strauss, Claude (1989). Das wilde Denken. Frankfurt a.M.: Suhrkamp.

Lock, Margaret \& Vinh-Kim Nguyen (2018). An Anthropology of Biomedicine. Hoboken, NJ: Wiley.

Lünzer, Immo (2002). Pioniere des Ökolandbaus. In Wolfgang Schaumann, Georg E. Siebeneicher \& Immo Lünzer (Hg.), Geschichte des ökologischen Landbaus (S. 115-191). Bad Dürkheim: Stiftung Ökologie und Landbau.

MacKinnon, Danny \& Driscoll Derickson, Kate D. (2012). From Resilience to Resourcefulness: A Critique of Resilience Policy and Activism. Progress in Human Geography 37 (2), 253-70.

Mäder, Paul u.a. (2002). Bodenfruchtbarkeit und biologische Vielfalt im Ökologischen Landbau. Ökologie und Landbau 124 (4), 12-16.

Mauss, Marcel (1990) [1925]. Die Gabe. Form und Funktion des Austauschs in archaischen Gesellschaften. Frankfurt a.M.: Suhrkamp.

Meadows, Dennis u.a. \& Club of Rome (1972). Die Grenzen des Wachstums: Bericht des Club of Rome Zur Lage Der Menschheit. Stuttgart: Deutsche Verlags-Anstalt.

Miller, Daniel (1995). Consumption as the Vanguard of History. In ders. (Hg.), Acknowledging Consumption. A Review of New Studies (1-57). London/New York: Routledge. 
Milone, Pierluigi \& Ventura, Flaminia (2014). The visible hand in building new markets for rural economies. In Paul Hebinck, Jan Douwe van der Ploeg \& Sergio Schneider (Hg.), Rural Development and the Construction of New Markets (S. 41-60). London: Routledge.

Milone, Pierluigi \& Ventura, Flaminia (2019). New Generation Farmers: Rediscovering the Peasantry. Journal of Rural Studies 65, 43-52.

Moschitz, Heidrun u.a. (2015). Anteil von Lebensmitteln regionalen Ursprungs am Gesamtverbrauch der Stadt Freiburg. Studie des Forschungsinstituts für biologischen Landbau (Fibl) im Auftrag der Stadt Freiburg i. Br.. Abgerufen am 13.11.2020 von http://www.agronauten.net/wp-cont ent/uploads/2016/04/Regionaler-Konsum-Freiburg_final-1.pdf.

Müller, Christa (1998). Von der lokalen Ökonomie zum globalen Dorf. Bäuerliche Überlebensstrategien zwischen Weltmarktintegration und Regionalisierung. Frankfurt a.M./New York: Campus.

Niewöhner, Jörg (2019) Situierte Modellierung. Ethnografische KoLaboration in der Mensch-Umwelt-Forschung. In Stefan Groth \& Christian Ritter (Hg.), Zusammen arbeiten. Praktiken der Koordination und Kooperation in kollaborativen Prozessen (S. 23-50). Bielefeld: transcript.

Nussbaum, Martha (1999). Gerechtigkeit oder Das gute Leben. Frankfurt a.M.: Suhrkamp.

O'Malley, Pat (2010). Resilient subjects: uncertainty, warfare and liberalism. Economy and Society 39 (4), 488-509.

Oedl-Wieser, Theresia (2017). Was ist dran am Exodus der Frauen vom Land? Gründe für geschlechterselektive Abwanderung und deren Konsequenzen für ländliche Regionen. Fact Sheet 14 der Bundesanstalt für Bergbauernfragen. Abgerufen am 11.08.2020 von http://www.lungauerfrauennetzwerk.at/wp-content/uploads/2 017/04/14_was_ist_dran_am_exodus_der_frauen.pdf.

Plakolm, Gerhard (2017). Als Pionier in der Codex-UK »Bio«. In BMGF (Hg.), Biologische Landwirtschaft. 35 Jahre Bio-Regelungen in Österreich (S. 12-15). Wien: BMGF.

Ploeg, Jan Douwe van der (2010). The peasantries of the twenty-first century. The commoditisation debate revisited. Journal of Peasant Studies 37 (1), 1-30. 
Ploeg, Jan Douwe van der (2014). Peasant-driven agricultural growth and food sovereignty. Journal of Peasant Studies 41 (6), 999-1030.

Ploeg, Jan Douwe van der (2018a). From de- to repeasantization. The modernization of agriculture revisited. Journal of Rural Studies 61, 236-243.

Ploeg, Jan Douwe van der (2018b). The New Peasantries. Rural Development in Times of Globalization. Oxon, NY: Routledge.

Polanyi, Karl (1977) [1944]. The Great Transformation. Politische und Ökonomische Ursprünge von Gesellschaften und Wirtschaftssystemen. Wien: Europaverlag.

Politische Ökologie 119 (2010). Peak Soil-Die unterschätzte Krise der Böden. oekom Verlag München.

Posch, Fritz (1978a). Geschichte des Verwaltungsbezirkes Hartberg. Erster, allgemeiner Teil. 1. Teilband: Von der Urzeit bis 1848. Graz: Leykam.

Posch, Fritz (1978b). Geschichte des Verwaltungsbezirkes Hartberg. Erster, allgemeiner Teil. 2. Teilband: Von 1848 bis zur Gegenwart. Graz: Leykam.

Puig de la Bellacasa, María (2014). Encountering Bioinfrastructure. Ecological Struggles and the Sciences of Soil. Social Epistemology 28 (1), 26-40.

Puig de la Bellacasa, Maria (2015). Making time for soil: Technoscientific futurity pace of care. Social Studies of Science 45 (5), Special issue: The Politics of Care in Technoscience, 691-716.

Puig de la Bellacasa, María (2017). Thinking with Care. In dies., Matters of care. Speculative Ethics in More Than Human Worlds (S. 69-94). Minneapolis \& London: University of Minnesota Press.

Puig de la Bellacasa, María (2019). Re-animating soils. Transforming human-soil affections through science, culture and community. The Sociological Review Monographs 67 (2), 391-407.

Sassatelli, Roberta \& Scott, Alan (2001). Novel Food, New Markets and Trust Regimes. Responses to the erosion of consumers' confidence in Austria, Italy and the UK. European Societies 3 (2), 213-244.

Schermer, Markus (2005). Die institutionelle Organisation des Biolandbaues in Österreich. In Michael Groier \& Markus Schermer (Hg.), Bio-Landbau in Österreich im internationalen Kontext. Band 2: Zwi- 
schen Professionalisierung und Konventionalisierung. Forschungsbericht 55 (S. 5-15). Wien: Bundesanstalt für Bergbauernfragen.

Schermer, Markus (2015). From >Food from Nowhere to >Food from Here«. Changing producer-consumer relations in Austria. Agriculture and Human Values 32, 121-132.

Schönborn, Gregor (2008). Corporate Citizenship und Wertemanagement im Unternehmen. In André Habisch, René Schmidpeter \& Martin Neureiter (Hg.), Handbuch Corporate Citizenship. Corporate Social Responsibility für Manager (S. 97-106). Berlin \& Heidelberg: Springer.

Schuda Susanne \& Heistinger, Andrea (2020). Late Night Group Therapy. WUK performing arts. Abgerufen am 13.06.2020 von https://vimeo.c om/428777427.

Shiva, Vandana (2008). Soil not oil. Environmental Justice in an Age of Climate Crisis. Cambridge, Massachusetts: South End Press.

Simondon, Gilbert (2007). Das Individuum und seine Genese. Einleitung. In Claudia Blümle (Hg.), Struktur, Figur, Kontur (S. 29-45). Zürich: diaphanes.

Soiland, Tove (2016). Die mütterliche Gabe hat keine symbolische Existenz (Interview). In Maya Dolderer \& Hannah Holme (Hg.), O Mother, Where Art Thou? (Queer)feministische Perspektiven auf Mutterschaft und Mütterlichkeit (S. 203-213). Münster: Westfälisches Dampfboot.

Soiland, Tove (2017). Landnahme der individuellen und sozialen Reproduktion: eine feministische Perspektive auf die Transformation des Sozialen. Abgerufen am 23.01.2019 von http://www.theoriekritik.ch/?p=3180.

Statista (2020). Anteil des ökologischen Landbaus in Österreich nach Bundesland im Jahr 2019. Abgerufen am 11.08.2020 von https://de.statista. com/statistik/daten/studie/997077/umfrage/bio-anteil-der-landwir tschaftlichen-nutzflaeche-in-oesterreich-nach-bundesland/.

Statistik Österreich (2016a). Agrarstrukturerhebung 2016. Land- und forstwirtschaftliche Betriebe in Österreich 1951-2016: Abgerufen am 25.11.2020 von https://www.statistik.gv.at/web_de/statistiken/wirt schaft/land_und_forstwirtschaft/agrarstruktur_flaechen_ertraege/ betriebsstruktur/index.html. 
Statistik Österreich (2016b). Agrarstrukturerhebung 2016. Land- und forstwirtschaftliche Arbeitskräfte in Österreich 1951-2016: Abgerufen am 25.11.2020 von https://www.statistik.at/web_de/statistiken/wirtsc haft/land_und_forstwirtschaft/agrarstruktur_flaechen_ertraege/ar beitskraefte/index.html.

Statistik Österreich (2016c). Agrarstrukturerhebung 2016. Betriebe und Gesamtfläche in Gegenüberstellung zu 2005, 2007, 2010, 2013 und 2016 nach Bundesländern: Abgerufen am 25.11.2020 von https://www.stat istik.gv.at/web_de/statistiken/wirtschaft/land_und_forstwirtschaf t/agrarstruktur_flaechen_ertraege/betriebsstruktur/index.html.

Staudenmaier, Peter (2013). Organic Farming in Nazi Germany. The Politics of Biodynamic Agriculture, 1933-1945. Environmental History 18 (2): 383-411.

Thompson, Edward P. (1971). The Moral Economy of the English Crowd in the Eighteenth Century. Past \& Present 50, 76-136.

Thünen Institut (2020). Projekt: Analyse der wirtschaftlichen Lage ökologisch wirtschaftender Betriebe. Abgerufen am 12.08.2020 von https://www. thuenen.de/de/bw/projekte/analyse-der-wirtschaftlichen-lage-oek ologisch-wirtschaftender-betriebe/.

Tronto, Joan C. (2015). Who cares? How to reshape a democratic politics. Cornell University Press Ithaca and London.

Valles-Colomer, Mireis u.a. (2019). The neuroactive potential of the human gut microbiota in quality of life and depression. Nature Microbiology 4, April 2019, 623-632.

Vankeerberghen, Audrey (2012). »Today, one can farm organic without living organic«. Belgian farmers and recent changes in organic farming. In James G. Carrier \& Peter G. Luetchford (Hg.), Ethical Consumption. Social value and economic practice (S. 99-117). New York, Oxford: Berghahn Books.

Vogt, Gunter (2000). Entstehung und Entwicklung des ökologischen Landbaus im deutschsprachigen Raum. Bad Dürkheim: SÖL.

Vogt, Gunter (2001a). Geschichte des ökologischen Landbaus im deutschsprachigen Raum. Teil 1. Ökologie und Landbau 118 (2): 47-49.

Vogt, Gunter (2001b). Geschichte des ökologischen Landbaus im deutschsprachigen Raum. Teil 2. Ökologie und Landbau 119 (3): 47-49. 
Wagner, Helga (2006). Die Anfänge einer großen Bewegung. Bio Austria. Fachzeitschrift für Landwirtschaft und Ökologie (4), 42-43.

Wahlhütter, Sebastian u.a. (2016). Soil as a key criteria in the construction of farmers' identities. The example of farming in the Austrian province of Burgenland. Geoderma 269, 39-53.

Weber, Gerlind \& Tatjana Fischer (2012). Gehen oder Bleiben? Die Motive des Wanderungs- und Bleibeverhaltens junger Frauen im ländlichen Raum der Steiermark und die daraus resultierenden Handlungsoptionen. Ländlicher Raum (4), 1-13.

Welter-Enderlin, Rosemarie \& Hildenbrand, Bruno (2004). Systemische Therapie als Begegnung. Stuttgart: Klett-Cotta.

Willer, Helga \& Schmid, Otto (2016). Geschichte. In Bernhard Freyer (Hg.), Ökologischer Landbau. Grundlagen, Wissensstand und Herausforderungen (S. 22-43). Bern: Haupt.

Winker, Gabriele (2015). Care revolution. Schritte in eine solidarische Gesellschaft. Bielefeld: transcript. 


\section{[transcript]}

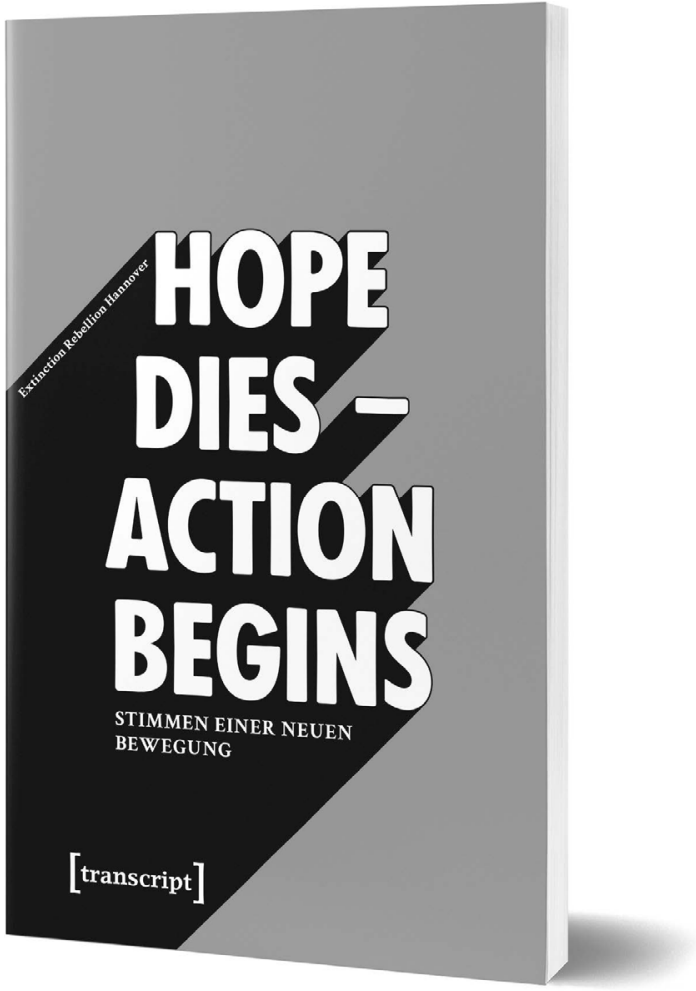

Extinction Rebellion Hannover

"Hope dies - Action begins": Stimmen einer neuen Bewegung

Oktober 2019, 96 Seiten, kart., 7,99€,

ISBN 978-3-8376-5070-9

"Hope dies - Action begins" - so lautet das Motto der neuen weltweiten Umweltbewegung "Extinction Rebellion" (XR). XR will uns alle dafür sensibilisieren, endlich radikale Maßnahmen gegen das gigantische Artensterben und die Klimakatastrophe zu ergreifen. In diesem Buch kommen XR-Aktivist*innen zu Wort, die XR-Forderungen, XR-Prinzipien und Werte und XR-Aktionen aus ihrer je eigenen Sichtweise erläutern. Dadurch sollen Leser*innen ermutigt werden, sich mit dieser Bewegung und ihren Zielen auseinanderzusetzen. XR bedeutet Rebellion für das Leben.

Extinction Rebellion Hannover (kurz XR-Hannover) ist Teil der neuen weltweiten Umweltbewegung "Extinction Rebellion", deren Ziel es ist, mit Mitteln des zivilen Ungehorsams den nötigen umfassenden und tief greifenden Wandel zu erreichen, um das Ausmaß der Auslöschung der Arten und des Kollapses unserer Ökosysteme zu begrenzen. 


\section{Soziologie}
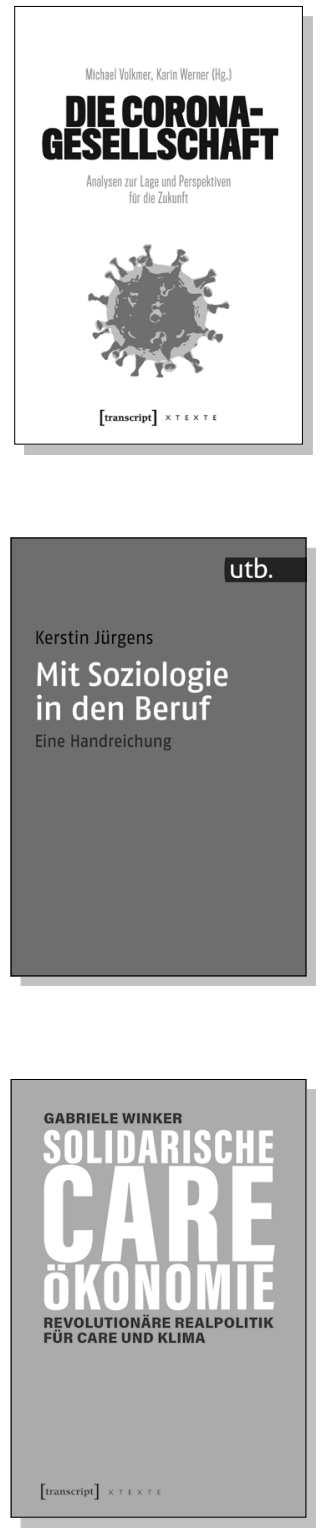

Michael Volkmer, Karin Werner (Hg.)

Die Corona-Gesellschaft

Analysen zur Lage und Perspektiven für die Zukunft

2020, 432 S., kart., Dispersionsbindung, 2 SW-Abbildungen

$24,50 €(D E), 978-3-8376-5432-5$

E-Book:

PDF: 21,99 € (DE), ISBN 978-3-8394-5432-9

EPUB: $21,99 €$ (DE), ISBN 978-3-7328-5432-5

Kerstin Jürgens

Mit Soziologie in den Beruf

Eine Handreichung

September 2021, 160 S., kart., Dispersionsbindung $18,00 €(D E), 978-3-8376-5934-4$

E-Book:

PDF: $15,99 €$ (DE), ISBN 978-3-8394-5934-8

Gabriele Winker

\section{Solidarische Care-Ökonomie}

Revolutionäre Realpolitik für Care und Klima

März 2021, 216 S., kart.

$15,00 €(D E), 978-3-8376-5463-9$

E-Book:

PDF: 12,99€ (DE), ISBN 978-3-8394-5463-3 


\section{Soziologie}

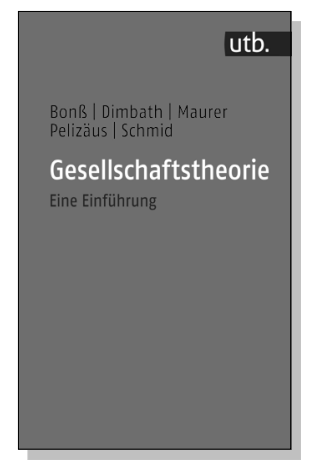

Wolfgang Bonß, Oliver Dimbath,

Andrea Maurer, Helga Pelizäus, Michael Schmid

\section{Gesellschaftstheorie}

Eine Einführung

Januar 2021, 344 S., kart.

25,00€ (DE), 978-3-8376-4028-1

E-Book:

PDF: $21,99 €$ (DE), ISBN 978-3-8394-4028-5

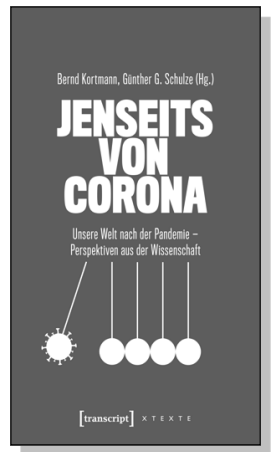

Bernd Kortmann, Günther G. Schulze (Hg.)

\section{Jenseits von Corona}

Unsere Welt nach der Pandemie -

Perspektiven aus der Wissenschaft

2020, 320 S.,

Klappbroschur, Dispersionsbindung, 1 SW-Abbildung

22,50€ (DE), 978-3-8376-5517-9

E-Book:

PDF: $19,99 €$ (DE), ISBN 978-3-8394-5517-3

EPUB: $19,99 €(D E)$, ISBN 978-3-7328-5517-9

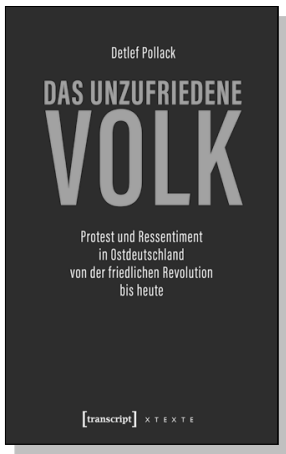

Detlef Pollack

\section{Das unzufriedene Volk}

Protest und Ressentiment in 0stdeutschland von der friedlichen Revolution bis heute

2020, 232 S.,

Klappbroschur, Dispersionsbindung, 6 SW-Abbildungen 20,00€ (DE), 978-3-8376-5238-3

E-Book:

PDF: $17,99 €$ (DE), ISBN 978-3-8394-5238-7

EPUB: $17,99 €(D E)$, ISBN 978-3-7328-5238-3 